CAHIER DE RECHERCHE \#2101E

WORKING PAPER \#2101E

DÉPARTEMENT DE SCIENCE ÉCONOMIQUE

DEPARTMENT OF ECONOMICS

FACULTÉ DES SCIENCES SOCIALES

UNIVERSITÉ D’OTTAWA

FACULTY OF SOCIAL SCIENCES

UNIVERSITY OF OTTAWA

\title{
Identity During a Pandemic: COVID-19 and Ethnic Divisions in the United States ${ }^{1}$
}

\author{
Jakina Debnam Guzman, Marie Christelle Mabeu and Roland Pongou
}

January 2021

\footnotetext{
${ }^{1}$ Address correspondence to: Jakina Debnam Guzman at jguzman@amherst.edu , Marie Christelle Mabeu at mmabe017@uottawa.ca, and Roland Pongou at rpongou@uottawa.ca or rpongou@hsph.harvard.edu.For helpful comments, we thank Peter Blair, Vicki Bogan, William Darity, Willa Friedman, Juan Carlos Suarez Serrato, Jean-Baptiste Tondji, and participants at the Diversity Initiative for Tenure in Economics Fellowship Program at Duke University and the Population Health Science Research Workshop at UPenn. We thank Laure-Anna Bomal for excellent research assistance. Mabeu and Pongou gratefully acknowledge generous financial support from the SSHRC's Partnership Engage Grants COVID-19 Special Initiative (PEG 231377-190299-2001).
} 


\begin{abstract}
Mobility restrictions have been imposed on over half of the world's population as part of efforts to slow the spread of the novel coronavirus. Given the economic and psychological expense of these policies, understanding how their benefits depend on structural factors is critical for optimal policy design. We find causal evidence that the effectiveness of mobility-restricting policies in the United States has been critically constrained by ethnic divisions-U.S. counties with high levels of ethnic divisions fared worse than their less-divided counterparts after lockdowns in both COVID-19 cases and related deaths. This is especially true in areas with higher racial segregation. Following President Trump's State of Emergency declaration, a one standard deviation increase in the ethnic fragmentation index (EFI) in the most racially segregated counties increased COVID-19 cases and associated deaths by 1; 014 and 63, respectively; in the least segregated counties these outcomes are 112 and 4, respectively. These results highlight that ethnic divisions, rather than ethnic diversity, spurred drastic differences in COVID-19's impact. Consistent with less effective mobility restrictions in more ethnically divided counties, we find smaller mobility reductions and less mask-wearing in these counties following policy implementation. These results are not driven by a lack of physical public goods or by socioeconomic differences. Instead, we interpret our findings as the result of mobility restriction policies' imperfect enforceability. Where ethnic divisions are present, communication is sparser, pro-social norms are weaker, and communities are less able to enforce adherence by enacting social sanctions. Our results suggest that policies promoting ethnic and racial integration can allay the negative social and economic impacts of contagious disease by decreasing the likelihood of disease spread.
\end{abstract}

Keywords: COVID-19; Ethnic Identity; Ethnic divisions; Racial segregation; Diversity with(out) divisions; Lockdown Policies; Mobility restrictions; Physical distancing; Mask Wearing; Pro-social Norms.

JEL classification: I14, I18, H12, H75, J15. 


\section{Introduction}

With over 25.1 million cases and 419,000 deaths due to COVID-19, the United States is among the countries most strained by the COVID-19 pandemic. ${ }^{1}$ A striking feature of the disease burden in the U.S. is its highly unequal distribution across communities. These disparities suggest that structural factors, about which we know little, may be contributing to the spread. This presents a major constraint to the design of optimal policies to curb the spread of the disease and avert its negative social and economic consequences.

In this paper, we document how ethnic divisions in the United States have stifled the efficacy of mobility-restricting policies such as State of Emergency declarations, business and school closures, and safer-at-home orders. There are several reasons to consider the role of ethnic divisions in defining COVID-19 outcomes, especially in the U.S. where the formal enforcement of preventative policy measures has been weak. Since members of tight-knit communities have on average more repeated interactions, the Folk theorem suggests that these communities can sustain more pro-social behavior. In addition, a lack of communication between fragmented groups means that information about infection cases occurring in one group may not easily be transmitted to members of another group, making it less likely that precautionary actions will be taken in fragmented neighborhoods. Moreover, contact tracing may not be as effective in ethnically fragmented neighborhoods as it should be; residents of these areas may not know each other well. Residents may be less altruistic towards out-group members, implying lower incentives to self-quarantine or to wear a face mask for infected individuals living in more ethnically fragmented areas. These possible mechanisms suggest that both the quality and the efficacy of government measures implemented to combat COVID-19 spread may have been negatively impacted by the presence of ethnic divisions.

To test this hypothesis, we combine daily county-level data on confirmed COVID-19 cases and deaths compiled from the Centers for Disease Control and Prevention (CDC) by the non-profit organization USAFacts with data on government responses to the pandemic. Using the timing of mobility restriction policies at the federal and county level, we implement a first difference and a double difference to estimate the causal impact of these policies and their interaction with ethnic divisions on COVID-19 outcomes. In addition to these two estimation approaches, we perform for robustness an event-study analysis and an in-time placebo check.

We find that ethnic divisions are an important driver of the growth of COVID-19 cases and fatalities in the United States. Figures 2 and 3 illustrate this fact. Figure 2 shows the number of new COVID-19 cases and deaths over time separately in counties

\footnotetext{
${ }^{1}$ Johns Hopkins University \& Medicine Coronavirus Resource Center accessed on January 25, 2021 at https://coronavirus.jhu.edu/map.html.
} 
with above-median ethnic fragmentation $(\mathrm{EFI})^{2}$ and below-median ethnic fragmentation. While the number of new COVID-19 cases and deaths has significantly increased across the U.S., the increase has been much more significant in more ethnically fragmented counties. This effect is driven by the role of residential segregation in highly fragmented counties. Figure 3 shows new COVID-19 cases and deaths over time in U.S. counties, this time disaggregated by above- and below-median levels of racial residential segregation. There are significantly more cases and deaths in highly segregated areas.

Our regression-based analyses confirm these observations. We find that while mobility restrictions have been effective in slowing the spread of COVID-19 and averting deaths, they have been much less effective in ethnically fragmented counties. First using a simple pre-post analysis, we show that following the federal State of Emergency declaration, a one standard deviation increase in EFI is associated with an increase of 373 COVID-19 cases and 22 additional COVID-19 deaths on average. These findings are confirmed using an index of stringency of government responses to COVID-19. The pre-post comparison, however, should be interpreted with caution because it lacks a proper counterfactual. We circumvent this issue with a second empirical strategy that exploits cross-county variation in the timing of county-level State of Emergency declarations in a difference-in-differences setting to document the causal effect of county-level preventative policies on COVID-19 outcomes. Consistent with the results of the federal policy, we find that after a countylevel emergency declaration, a one standard deviation increase in EFI is associated with an increase of 564 COVID-19 cases and 25 additional COVID-19 deaths on average. These findings are robust to considering other county-level mobility restriction policies such as safer-at-home and business closure orders.

Our analysis further advances the idea that ethnic divisions rather than ethnic diversity spurred disease spread during the COVID-19 pandemic. Ethnic (or ethnolinguistic) fragmentation has been used in economics to measure both ethnic diversity and ethnic divisions (c.f. (Alesina et al., 1999) and Alesina and Ferrara (2005)). However, we argue that the two are not necessarily equivalent. Ethnic diversity can exist without ethnic divisions, especially if different ethnic groups are integrated (Bazzi et al. (2019)). It follows that while the existence of ethnic divisions implies ethnic diversity, the converse may not be true. In communities where ethnic groups are sufficiently integrated, the above-mentioned channels through which ethnic fragmentation can affect the spread of COVID-19 may not operate. This implies that ethnic diversity will have little effect in ethnically integrated communities. In order to test this hypothesis, we analyze how the effect of EFI differs by level of racial residential segregation in a county. Figure 4 provides an illustration of the findings. We find that EFI increases COVID-19 cases and fatalities

\footnotetext{
${ }^{2}$ This is our metric for ethnic fragmentation. See Section 3 for a detailed description on how we construct this index. In this paper, we consider EFI together with racial residential segregation, which captures ethnic divisions in the United States.
} 
and constrains the effectiveness of mobility restriction policies mainly in counties that display a sufficiently high level of racial segregation. When the level of racial segregation is low, EFI has very little impact on these outcomes. Indeed, following President Trump's State of Emergency declaration, a one standard deviation increase in the ethnic fragmentation index (EFI) in the most racially segregated counties increased COVID-19 cases and associated deaths by 1,014 and 63, respectively; in the least segregated counties these outcomes are 112 and 4, respectively. These findings strongly support the idea that a lack of cooperation between different ethnic groups is driving the effects of ethnic fragmentation. By limiting interracial interactions, segregation makes undertaking collective actions to curb the pandemic and mitigate its consequences difficult.

We document several direct mechanisms through which the effect of mobility restriction measures differ by the level of ethnic divisions. Limiting physical contact with others and covering one's face are among the most powerful tools available to limit the spread of COVID-19. However, notice that for a healthy person without pre-existing conditions, the largest benefits of following these guidelines accrue to others with whom you happen to have contact. The nature of the externalities associated with these measures renders them public goods. Individuals may have a lower willingness to contribute to policies which are personally costly and which they view as benefiting an outside group. This idea has been explored in the literature primarily with focus to the area of preferences for redistribution (Alesina et al. (1999)). We therefore consider how mobility behaviors and mask-wearing, and the effects of different mobility restriction policies on these behaviors, differ by level of ethnic fragmentation and residential segregation.

Consistent with the finding of several others (c.f. Bonaccorsi et al. (2020)), we find that national and county emergency declarations were successful at increasing selfquarantining. Mobility levels, including visits to workplaces, transit stations, retailers and recreation outlets, dropped following emergency declarations. A distinctive feature of our analysis, however, is that we show that the efficacy of the emergency declarations was greater in counties with low levels of ethnic fragmentation. In addition, we find that the efficacy of national and county-level policies in curbing the spread of COVID-19 is much lower for more ethnically fragmented counties that are also more racially segregated. Moreover, we find that residents of more ethnically fragmented counties and of more racially segregated counties are less likely to report wearing face masks.

Our results therefore suggest that the ability of communities to take actions to limit the spread of the novel coronavirus - keeping distance between members of different households, maintaining distance from sick persons inside and outside the home, and wearing face-coverings in public - is negatively impacted by ethnic fragmentation, and even more so by racial residential segregation. Importantly, these differences persist even when controlling for socioeconomic differences and differences in aggregate health measures. There are several mechanisms consistent with these findings. Where ethnic 
divisions are present, communities communicate less effectively, behave less pro-socially, provide public goods less efficiently and sanction less effectively. The latter mechanism is supported by an additional finding that ethnic fragmentation negatively affects the likelihood of belonging to a social association only in racially segregated counties.

From a policy perspective, all of our proposed mechanisms suggest that federal policy making and enforcement, which can circumvent local coordination problems, could be a good approach to ensure that best practices are followed. Our analysis also suggests that designing, implementing, and sustaining policies of ethnic and racial integration can help contain the spread and consequences of infectious disease by decreasing the likelihood of disease spread.

The rest of this paper is organized as follows. Section 2 presents our conceptual framework. Section 3 describes the data used in the analysis. Section 4 presents our identification strategy, and Section 5 presents results. Section 6 investigates the different channels through which mobility restrictions and other preventative policies operate. Section 7 concludes.

\section{Conceptual Framework}

For most people, the choices to stay home in the event of fever, avoid socialization, and to wear awkward and uncomfortable face coverings are simply not rationalizable under purely self-interested preferences with reasonable levels of risk tolerance. Instead, these choices generate important externalities which benefit others. In the United States, government policies to address these externalities have been decentralized and patchworked across states and localities. County-level safer-at-home orders were unfurled across the country at a variety of different times and with varying levels of restrictiveness. For example, at their most restrictive levels, in some counties masks remained optional and gathering sizes remained unlimited. Other counties instituted strict mask requirement, business closing, and gathering size restrictions. ${ }^{3}$ Further, conditional on violating one of these policies, the likelihood of receiving a formal sanction for this violation is low.

Because group-level coordination underpins both policy formation and adherence, ethnic fragmentation may have impacted counties' COVID-19 measures through multiple channels. First, ethnic divisions have been linked to an inability to issue effective social sanctions in both developed and developing contexts. Miguel and Gugerty (2005) find that ethnic divisions in Kenya result in a decreased ability of community members to punish public good providers who renege. Using data from the United States, Algan et al. (2016) find that ethnic divisions in French public housing hamper members of a

\footnotetext{
${ }^{3}$ ProPublica has reported on the the extreme heterogeneity in county-level responses to the pandemic: https://www.propublica.org/article/states-with-few-coronavirus-restrictions-are -spreading-the-virus-beyond-their-borders
} 
community from sanctioning one another for vandalism. Since local face-covering, travel, and social-distancing guidelines are only imperfectly enforceable by formal authorities, norms and social sanctions make these policies more effective. In fact, Yan et al. (2020) find that a substantial amount of mobility restriction in the United States during the pandemic was induced by informal responses to local events rather than by the imposition of policy or legislation.

Second, if ethnic divisions in a county lead individuals to interact infrequently, it will be more difficult for county-level prosocial behavior to be sustained. Cooperation is easier to sustain when individuals carry reputation and when they expect to interact more often in the future. In work related to the Folk Theorem, Maskin et al. (1994) show that when individuals expect to interact in the future, cooperation can be sustained even if players imperfectly observe each other's actions. Players in a prisoner's dilemma can remain at a socially optimal outcome when games are repeated (Kreps and Wilson (1982)). Kandori's (1992) model extends this idea of cooperation within repeated games to the context of community. He finds that, in the presence of reputational concern, pro-social behavior can be maintained even between strangers.

Another potential mechanism arises from the potential for ethnic divisions to limit communication between groups. If some segment of a county's residents do not communicate with one another, the ability of that county to provide mutually beneficial public goods will be hampered. Contact tracing will be ineffective and knowledge about transmission will be sub-optimally shared. Balliet's (2010) meta-analysis of 45 studies across the political science, psychology, and sociology literatures finds a large positive effect of communication on cooperative behavior. In a study of the effect of communication on strategic games, Ellingsen and Östling (2010) show that in common interest games with positive spillovers, communication makes coordination between players more likely. Early work by Ostrom and Walker (1991) highlights the role of face-to-face communication in supporting the successful management of common-pool resources. In experiments among volunteers making anonymous contributions to an asset which increasingly compensates the entire group as the level of group contributions increases, Ostrom and Walker (1991) show that communication among participants increases overall payoffs and allows for the correction of non-conforming players. The authors replicate and extend this result in a later seminal paper (Ostrom et al. (1992)) which compares the efficacy of sanctioning power, communication, and the repeated nature of interactions on the management of common pool resources. The benefits of communication for supporting public good provision, however, may be hampered by intergroup conflict. Leibbrandt and Sääksvuori (2012) show that in a repeated intergroup contest when communication exists between groups, groups take turns winning a prize and spend less on wasteful punishment. However, when communication is limited to within-group, intergroup conflict results and spending on punishment erodes public good provision. 
Finally, we consider the potential impact of preference heterogeneity on the ability of counties to solve coordination problems. While the idea of preferences which are correlated with ethnicity is posited to impact ethnic divisions (Alesina et al. (1999)), the empirical evidence around this point is mixed. For example, Desmet et al. (2017) find that, while preferences around norms, attitudes, and values are correlated with ethnicity, within-ethnicity variation in cultural attitudes is greater than that between ethnicities. Nonetheless, if there is cultural transmission of preferences, ethnically diverse counties may face a more difficult time coordinating to form policy (as was found by Beach and Jones (2017)). Conversely, if the legislative production process benefits from a diversity of preferences and skills (Alesina and Ferrara (2005); Fafchamps (2000)), then the impact of ethnic divisions on the quality of policies designed during the pandemic may be positive.

Each of the mechanisms above - decreased sanctioning power, decreased pro-sociality, decreased communication - are affected by a community's ethnicity only inasmuch as ethnicity in that community defines and limits social relations. Where diversity and close personal contact between groups coexist, these mechanisms do not operate. For example, in a field experiment among Norwegian soldiers, Finseraas et al. (2019) find that soldiers randomly assigned to live with ethnic minorities display higher levels of trust toward members of immigrant communities. Following an Indonesian resettlement program, Bazzi et al. (2019) find that, while the level of local diversity is associated with increased willingness to contribute to village public goods and a decreased likelihood of ethnic conflict, this effect is dampened by residential segregation. Alesina and Zhuravskaya (2011) find that countries where ethnic groups are more residentially segregated have lower levels of trust and lower quality of governance. Several scholars in political science have highlighted similar results. Miguel (2004) notes that while ethnic diversity is associated with lower public goods provision in Kenya, this is not the case in Tanzania. Noting the arbitrary colonial-era boundary between the similarly diverse countries, he argues that the key differentiator is that the postcolonial Tanzanian government employed a large policy agenda to promote inter-ethnic dialogue and interaction while the Kenyan government employed no such policy. Ejdemyr et al. (2018) find that segregation enables politicians to preferentially target funds to co-ethnics' districts. Segregation in the electoral districts, rather than diversity, matters for the provision of new wells in Malawi. This effect of segregation persists despite controlling for the level of diversity in the district.

We therefore consider two measures of ethnicity in U.S. counties. The first, the Herfindahl diversity index, is increasing in the number of ethnicities present in a given county. This measure is the most common in the literature exploring the importance of ethnic divisions for public good provision (c.f. Alesina et al. (1999)). While this measure has been used in the literature to proxy for ethnic division or fractionalization, we emphasize that the construction of this measure captures the number of ethnic groups present and not the level of divisions between them. In and of themselves, the ethnicities 
of a county's residents are, of course, neither a hindrance nor a help to the spread of the novel coronavirus. We therefore also consider a second measure - black-white residential segregation as measured by a dissimilarity index. ${ }^{4}$ This measure of residential segregation captures the level of evenness with which the residences of black residents are dispersed among those of whites. Residential segregation as captured by a dissimilarity index increases as residential patterns deviate further from a random residential allocation. Contemporaneous residential segregation is a direct product of ethnic divisions both in its top-down causes (i.e. historical exclusion of blacks from certain areas through legal and racial restrictive covenants, lending restrictions), and in its bottom-up causes (i.e. preference-based sorting).

Racial residential segregation is correlated with a variety of social ills and has been hypothesized to be a key cause of systematically different outcomes between black Americans and white Americans. Chetty et al. (2014) find that racial segregation is a key factor inhibiting income mobility for both blacks and whites. In addition to decreased intergenerational income mobility, living in a highly racially segregated area has been associated with a larger black-white SAT score gap (Card and Rothstein (2007), decreased educational attainment (Guryan (2004)), and increased violence (Peterson and Krivo (2009)) among other negative outcomes. In the context of the COVID-19 pandemic, Pongou et al. (2020) combine economic theory and simulations to show that ethnic segregation disproportionately affects minority populations in terms of COVID-19 cases and deaths and related economic consequences.

Under racial residential segregation, members of different ethnicities interact less frequently and are therefore more divided. Sigelman et al. (1996) conduct a survey of the residents of Detroit, one of the most segregated cities in the United States. They find that contact between black and white residents is most frequently brief, casual, and nonintimate. Larger-scale empirical research underscores the relationship between residential segregation and ethnic divisions. School children living in more racially segregated areas are more likely to have ethnically segregated friendships (Mouw and Entwisle (2006)). Americans living in racially segregated areas are more likely to rely on racial stereotypes and media portrayals when forming their opinions of non-coethnics. Residents of highly segregated areas are also more likely to report higher instances of racial prejudice and feelings of racial competition (Eric Oliver and Wong (2003)).

Our paper adds to a growing literature which underscores the importance of race in shaping the economic and disease burden from COVID-19 (c.f. Andrasfay and Goldman (2021), Pongou et al. (2020)). We also contribute to a body of work which emphasizes the importance of social attitudes in mitigating the spread of COVID-19. Müller and Rau

\footnotetext{
${ }^{4}$ We focus on black-white segregation here as this measure of residential segregation has been the focus of economists studying the role of segregation in the United States. Our main results, however, replicate when we consider a dissimilarity index of residential segregation between whites and non-whites.
} 
(2020) find that pre-crisis indicators of social responsibility positively predict compliance with COVID-19 preventative policies. Barrios et al. (2021) use mobility and survey data to find that adherence to mask-wearing and social distancing in the United States and some regions of Europe is positively predicted by pre-crisis measures of civic capital. Durante et al. (2020) find similar results for the importance of civic capital in Italian provinces. Finally, Ding et al. (2020) find that demonstrated willingness to engage in costly social good provision predicts increased social distancing behavior in the United States.

\section{Data and Descriptive Statistics}

For this study, we combine different datasets covering the period between February 1, 2020 and June 07, 2020. Data include COVID-19 related cases and deaths, government policies, physical distancing, and socio-demographic characteristics. In this section, we describe the main data sources and highlight the general patterns in the data.

Data on COVID-19 cases and deaths. We obtain county-level daily data on new and cumulative confirmed COVID-19 cases and deaths from USAFacts. USAFacts is a private non-profit group that compiles data from the United States Centers for Disease Control and Prevention (CDC) and from state and local public health agencies. The USAFacts dataset on COVID-19 cases and deaths is a time series database spanning the period from January 22, 2020 to June 07, 2020 (the latest date available at the time the data was downloaded). The cumulative number of confirmed cases is updated each evening. Not every case is reported by county; some are not allocated due to lack of information. The number of missing observations is too small to bias our results $(0.73 \%$ of observations are missing across all county-days).

Data on national and sub-national government responses to COVID-19. With the spread of COVID-19, federal and local governments in the United States have implemented various non-pharmaceutical interventions. At the federal level, a national emergency was declared by the White House on March 13, 2020. ${ }^{5}$ This declaration increased the level of federal funding available for states and localities to respond to the crisis and to expand the scope of their emergency actions as the COVID-19 outbreak continued. We exploit this date to construct a proxy for national emergency declaration, a dummy which equals one on or following the day of the declaration and zero otherwise.

Another metric for national governments' response to COVID-19 crisis is the stringency index obtained from the Oxford COVID-19 Government Response Tracker (Ox-

\footnotetext{
${ }^{5}$ Availableathttps://www.whitehouse.gov/presidential-actions/proclamation-declaring -national-emergency-concerning-novel-coronavirus-disease-covid-19-outbreak/
} 
CGRT) (Hale et al. (2020)), which collects information on a range of physical distancing measures, assigns a score for the measure, and then aggregates this information into a composite stringency index. The stringency index is based on nine response indicators including school closings, workplace closings, the cancellation of public events, restrictions on gathering sizes, closing of public transportation, safer-at-home requirements, restrictions on internal movements and restrictions on international travel. Indicator values are aggregated and rescaled to values from 0 to 100, with a higher index indicating a stricter combination of measures. Importantly, strictness is distinct from effectiveness. This index simply records the number and stringency of government policies. The index's authors caution that index scores "should not be interpreted as 'scoring' the appropriateness or effectiveness of a country's response". ${ }^{6}$ Further details on the OxCGRT database are provided in Hale et al. (2020).

At the county level, data on policy response to COVID-19 are retrieved from the National Association of Counties (NACO). ${ }^{7}$ NACO collects a wide range of information on local governments' actions to mitigate the spread of COVID-19, including the onset of county-level emergency declarations and mobility restrictions in response to COVID19. We construct three measures of sub-national government response to COVID-19 using NACO's information on the dates of county-level implementation of: 1) State of Emergency declarations; 2) closure of all non-essential businesses; and 3) safer-at-home orders, which call for residents to remain at home. Each measure is defined by a dummy equal to one on or following the day of a given policy response and zero otherwise.

Data on social distancing. To capture social distancing behavior we rely on mobility variables compiled by Google Community Mobility reports. These data are collected from users who have opted-in to having their location history tracked by Google. Data have been temporarily made available by Google during the pandemic. These reports compile data on the percent change in visits to different categories of places such as retail and recreation, groceries and pharmacies, parks, transit stations, workplaces, and residences. The mobility data show how visits and duration of stay changed relative to a baseline for the same areas and same day of the week prior to the virus spread. We extract daily data on mobility from February 15, 2020 to May 29, 2020.

Measuring Ethnic Fragmentation. The American Community Survey (ACS) collects information about the ethnic and racial composition of the population. ${ }^{8}$ Respondents are asked if they belong to any of the following population groups: Hispanic, White, Black,

\footnotetext{
${ }^{6}$ Fromdatadescriptionavailableathttps://www.bsg.ox.ac.uk/research/research-projects/ coronavirus-government-response-tracker/

${ }^{7}$ Available at https://www.naco.org/covid19/topic/research-data

${ }^{8}$ For all analysis involving ACS data, we rely on the 2018 round of the American Community Survey, the most recent year for which data is available.
} 
Native American, Asian, Pacific Islander, and Other. We use this information along with the Herfindahl diversity formula to compute an index measuring the degree of county-level ethnic fragmentation. ${ }^{9}$ This index measures the probability that two randomly selected individuals from the same county belong to two different ethnic groups. Specifically, our index of ethnic fragmentation is calculated using the formula:

$$
E F I=1-\sum_{r=1}^{e} \frac{\left(N_{r}\right)^{2}}{N^{2}}
$$

Where EFI refers to Ethnic Fragmentation Index, $e$ corresponds to the number of ethnic groups listed, $\mathrm{N}_{\mathrm{r}}$ the size of ethnic group $r$ in the county, and $\mathrm{N}$ the county population total. As EFI increases, the likelihood that two randomly selected individuals belong to the same ethnic or racial group decreases. As EFI increases, so does the level of ethnic fragmentation in a given community. The spatial distribution of EFI for U.S. counties as of the 2018 ACS is shown in the top map of Figure 1. This map shows that EFI varies widely across U.S. counties.

Measuring residential segregation. A widely used measure of residential segregation is the dissimilarity index (Duncan and Duncan (1955); Massey and Denton (1988); Iceland et al. (2002); Graham (2018)). ${ }^{10}$ Our focus in this paper is on residential segregation by race, information drawn from the ACS. The dissimilarity index is a measure of the evenness with which two groups (either blacks and whites or whites and non-whites in our case) are distributed in a given area (a census tract in the case of the ACS). Conceptually, the black-white dissimilarity index, which ranges from 0 (complete integration) to 100 (complete segregation), measures the percentage of a group's population that would have to move to different geographical areas (census tracts) in order to produce a distribution that matches that of the metropolitan area overall (counties in the ACS). This index therefore shows to what extent two subgroups are isolated from one another. In the literature, the Dissimilarity Index (DI) is given by the formula:

$$
\mathrm{DI}=\frac{1}{2} \mathrm{E}\left[\left|\frac{\mathrm{s}(\mathrm{Z})}{\mathrm{Q}}-\frac{1-\mathrm{s}(\mathrm{Z})}{1-\mathrm{Q}}\right|\right]
$$

where $\mathbf{Z}$ is the proportion of census tract $z$ that is minority and $Q$ is the county-wide frequency of minority residents. Graham (2018) shows that DI equals the proportion of a county's minority residents who would need to move in order to achieve perfect residential integration, relative to the proportion of a perfectly segregated county's residents that

\footnotetext{
${ }^{9}$ This approach is widely used in the literature. See for example Mauro (1995), Easterly and Levine (1997), Alesina and La Ferrara (2000), and Pongou (2009).

${ }^{10}$ Massey and Denton (1988) identified five measures of residential segregation: dissimilarity index, isolation Index, delta Index, absolute centralization index, and spatial proximity index.
} 
would have to move to achieve perfect residential integration.

The spatial distribution of the racial residential segregation index for U.S. counties as of the 2018 ACS is shown in the bottom map of Figure 1, which highlights the differences in the spatial distributions of ethnic fragmentation and racial segregation. While the existence of within-county racial segregation implies residents of multiple races, the converse is not true. Some racially diverse counties are integrated, while others are not. Indeed, the correlation between EFI and the dissimilarity index measuring racial segregation between whites and non-whites is merely 0.0052. We show that in communities where ethnic groups are sufficiently integrated, the channels through which ethnic fragmentation affects COVID-19 outcomes do not operate. This implies that ethnic diversity has little effect in less segregated communities.

Other social and economic characteristics. Demographic and economic variables come from the ACS. Throughout, all socio-economic variables are an average across five years of ACS data collection ending in 2018. For the purpose of this paper, the following county-level statistics and indices are extracted from the ACS: population density, unemployment rates, foreign-born population, gender distribution of population, average age of the population, educational attainment, urban-rural distribution of the population, and poverty rates. We also use information about the health characteristics of counties including the percentage of adults reporting: fair or poor health, smoking, obesity, and diabetes.

To examine the relationship between ethnic fragmentation, government response to the pandemic, and COVID-19 cases and deaths, we merge the datasets described above and drop daily observations with missing EFI, confirmed cases of COVID-19, or government policy indexes. The refined sample consists of 433,872 daily observations from 3,143 counties spanning the period from January 22, 2020 to June 07, 2020. Tables 1 reports descriptive statistics of the variables of interest in our sample.

\section{Identification Strategy}

To assess the impact of ethnic divisions, government policy, and their interaction on COVID-19 cases and fatalities, we rely on two main methodologies. The first approach is a pre-post analysis that exploits the timing of the federal State of Emergency declaration to compare the main outcomes of interest before and after the policy announcement. This approach is useful because the policy does not vary at the county level for a fixed date. However, it lacks an appropriate comparison group in the post period. We therefore advance our analysis using a difference-in-differences (DiD) strategy which evaluates the efficacy of staggered county-level mobility restrictions.

Under the DiD strategy, counties that did not implement mobility restriction policies 
serve as counterfactuals for counties that did. This strategy exploits the differential timing of policy implementation and controls for various confounding factors, making it possible to identify the causal impact of mobility restrictions. In addition to these two approaches, we perform an event-study analysis and an in-time placebo robustness check.

\subsection{First Approach: Pre-post Analysis}

Using the federal State of Emergency declaration, we first implement a simple pre-post analysis at the national level. Specifically, we estimate the following OLS regression:

$$
\begin{gathered}
\text { Covid }_{\mathrm{cst}}=\lambda_{0}+\lambda_{1} \text { NationalPolicy }_{\mathrm{t}}+\lambda_{2} \mathrm{EFI}_{\mathrm{cs}}+\lambda_{3} \text { NationalPolicy }_{\mathrm{t}} \times \mathrm{EFI}_{\mathrm{cs}} \\
+\alpha_{z}+\delta_{\mathrm{t}}+\mathrm{X}_{\mathrm{cs}}^{\prime} \pi+\varepsilon_{\mathrm{cst}}
\end{gathered}
$$

Where Covid cst $_{\text {is }}$ the outcome of interest, which is alternatively the number of COVID-19 cases and deaths in county $c$ of state $s$ on date $t$. NationalPolicy $t_{t}$ refers to the United States federal government's response to the pandemic. This variable is measured in two ways. First, we exploit the timing of the national emergency declaration to define NationalPolicy as a dummy equal to one for dates $t$ greater than or equal to March 13, 2020 (the date on which the White House declared a federal State of Emergency), and zero otherwise. In a second specification, we use the Ox-CGRT stringency index which records how the strictness of the federal policy response has varied over the course of the pandemic (see description of this variable in the data section). In this case, NationalPolicy $y_{t}$ is a continuous variable taking a value between 0 and 100 . The next regressor, $\mathrm{EFI}_{\mathrm{cs}}$, is the ethnic fragmentation index in county $\mathrm{c}$ and state $s$ and is constructed as described in Section 3.

In alternative specifications, $\alpha_{z}$ is a set of county or state fixed effects to control for time-invariant unobserved heterogeneity at the county or state level. A set of time dummies to account for common trends is included in $\delta_{t}$. Finally, $\mathbf{X}_{\mathbf{c}}$ is a vector of county-level characteristics that correlate with the outcome of interest. This allows us to control for potential confounders including county-level demographic characteristics (i.e. population density, percentage of males, average age, poverty, percentage of adults with at least a high school degree, percentage of urban population, and percentage of population born outside of the United States) and county-level health characteristics (i.e. the percentage of adults with obesity, in "poor health", with diabetes, and who smoke). Since the residual $\varepsilon_{\mathrm{cst}}$ is likely to be correlated for observations in the same state, we adjust standard errors for clustering at the state level.

The parameters $\lambda_{1}$ and $\lambda_{2}$ show the effect of federal policy and ethnic fragmentation 
on COVID-19 cases and deaths. The main coefficient of interest is $\lambda_{3}$, the coefficient of the interaction term between federal policy and the ethnic fragmentation index. This term measures how the effect of federal policy interventions is modulated by counties' levels of ethnic fragmentation.

\subsection{Second Approach: Difference-in-differences Analysis}

Our second methodology exploits the staggered nature of county-level mobility restriction policies to conduct a double difference design that exploits within-county variation in the main outcome of interest before and after the policy implementation across treated and untreated counties. Specifically, we estimate the following difference-in-differences specification:

$$
\begin{gathered}
\text { Covid }_{\mathrm{cst}}=\lambda_{0}+\lambda_{1} \text { CountyPolicy }_{\mathrm{cst}}+\lambda_{2} \mathrm{EFI}_{\mathrm{cs}}+\lambda_{3} \text { CountyPolicy }_{\mathrm{cst}} \times \mathrm{EFI}_{\mathrm{cs}} \\
+\alpha_{z}+\delta_{\mathrm{t}}+\mathrm{X}_{\mathrm{cs}}^{\prime} \pi+\varepsilon_{\mathrm{cst}}
\end{gathered}
$$

Where all the regressors are defined as in the previous section save the explanatory variable CountyPolicy cst $_{\text {which }}$ refers to COVID-19 related policies implemented at the county level. For each of three mobility restriction policies, the dummy variable

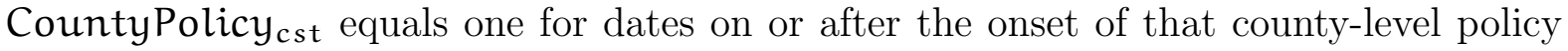
(in county $c$ of state $s$ ). In our preferred specification, the variable CountyPolicy $y_{c s t}$ is based on county-level declarations of a State of Emergency. In two other specifications

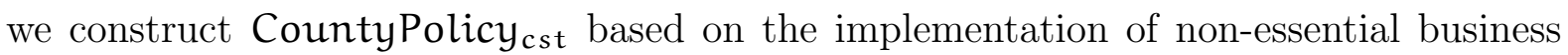
closure policies and on the implementation of safer-at-home orders.

Our key assumption is that, conditional on controls, the evolution of COVID-19 cases and fatalities for counties that implemented preventative policies would not have been different from those which did not. This is equivalent to an assumption of parallel trends in COVID-related health outcomes for treated and untreated counties.

\subsection{Additional Robustness Checks}

Finally, we conduct a number of additional robustness checks related to the above strategies. First, we analyze the dynamic effect of the interaction between ethnic fractionalization and State of Emergency declarations on COVID-19 outcomes. In another robustness check, we estimate our two main specifications using a fictitious "policy date" 45 days after the true date. Finally, we estimate an event study model to test the parallel trends assumption in our DiD model. We use an event study regression model to examine how county-level COVID-19 related health outcomes evolve during the period leading up to and following county-level mobility restrictions: 


$$
\begin{gathered}
\text { Covid }_{c s t}=\lambda_{0}+\sum_{t=-40}^{80} \lambda_{1(t+10)} P_{c s(t+10)}+\lambda_{2} E_{c F}+\sum_{t=-40}^{80} \lambda_{3} P_{c s(t+10)} \times E F I_{c s} \\
+\alpha_{z}+\delta_{t}+X_{c s}^{\prime} \pi+\varepsilon_{c s t}
\end{gathered}
$$

Where $P_{c s(t+10)}$ are dummy variables for the $t+10$ days before the policy for positive values and the $t+10$ days after the policy for negative values. The period from the beginning of data collection until thirty one days before the mobility-restricting policy is the reference period. For example, the estimated coefficients on the $P_{c s(20)}$ dummies should therefore be interpreted as the effect of being twenty days after the policy as compared to the period ending thirty one days before it.

\section{Results}

In this section, we summarize our estimation results. We find that while government responses have been effective in slowing the spread of COVID-19 and averting deaths, they have been much less effective in ethnically fragmented counties; this is particularly true in highly segregated areas.

\subsection{Emergency Declarations, Ethnic Fragmentation, and COVID- 19}

We begin our analysis with a graphical illustration of the interplay between county-level emergency declarations, ethnic fragmentation, and the number of new COVID-19 cases and deaths. Figures 2- $a$ and $-b$ show the trends in the number of new COVID-19 cases and deaths by level of ethnic fragmentation. On the x-axis of each figure, we report the distance (in days) from the county-level State of Emergency announcement (CSOE). These graphs compare the average number of daily new COVID-19 cases (2- $a$ ) and deaths $(2-b)$ in counties with above-median levels of the ethnic fragmentation index (highly fragmented counties) and below-median levels of the ethnic fragmentation index (relatively unfragmented counties). These graphs clearly illustrate that following the county-level Sate of Emergency declaration, the number of new COVID-19 cases and deaths increased substantially more in highly fragmented counties. These observed differences suggest an important differential effect of mobility restriction policies in counties with differing levels of ethnic fragmentation.

These results are confirmed in the regression-based analysis in Table 2. In this table we present estimates of the impact of mobility restriction policies, EFI, and their interaction 
on COVID-19 outcomes. The first two panels of this table display results of the prepost analysis using the federal State of Emergency as a measure of mobility restriction policy (see equation (1)). The two panels at the bottom of the table show estimates of the difference-in-differences analysis that use the county-level State of Emergency as a measure of mobility restriction policy (see equation (2)). The outcome of interest is the cumulative number of COVID-19 cases in Panels $A$ and $C$, and the cumulative number of COVID-19 deaths in Panels $B$ and $D$. Estimates in column (1) show the average effects of mobility restriction policies and EFI on COVID-19 outcomes. In both the prepost analysis and the double difference analysis, we find that ethnic fragmentation has a positive effect on COVID-19 cases and related deaths. These effects are both economically and statistically significant. In fact, moving from a county with just one ethnic group to a county that is completely fragmented along ethnic lines increases COVID-19 cases by 1,280 and COVID-19 deaths by 75 in the pre-post estimation. These numbers are 1,932 and 87 in the double difference analysis. Importantly, the positive association between the mobility restriction policy and COVID-19 outcomes also indicate that the number of infected individuals and deaths continued to rise following both the federal and county-level emergency declarations, suggesting that these policies might not have been uniformly effective.

In column (2), we add an interaction between our index of ethnic fragmentation and the mobility restriction policy. In Panels $A$ and $B$, we find that while the effect of the policy on COVID-19 outcomes is negative, the coefficient of the interaction between mobility restriction policy and EFI is highly positive and statistically significant. Estimates in column (2) of Table 2 show that a marginal increase in EFI caused the number of COVID-19 cases (resp. deaths) to increase by 2,030 (resp. 119) following the federal State of Emergency declaration, and by 3,224 (resp. 146) following the county-level State of Emergency declaration. These results mean that government responses to COVID-19 were less effective in preventing COVID-19 infections and deaths in ethnically fragmented counties. Ethnic fragmentation can therefore be seen as an important constraint on the effectiveness of quarantine measures and regulations. In column (3), we add state fixed effects to control for time-invariant state-level observed and unobserved characteristics, and day fixed effects to control for any day-specific shock common to all counties. The results remain the same. We can easily see that ethnic fragmentation continues to increase COVID-19 severity, and that federal and county-level State of Emergency policies continue to be ineffective in more ethnically fragmented counties.

In related literature, several demographic and economic factors have been linked to the spread of the pandemic. We account for these confounding factors in two ways. First, in column (4), we control for a set of county-level demographic characteristics, including population density, percentage of males, average age, poverty, education, percentage of population living in urban areas, and the percentage of immigrants. We also control for 
county-level health characteristics, including the percentage of adults in poor health, the percentage of adults smokers, the percentage of adults with obesity and the percentage of adults with diabetes. Adding these controls does not change the main result: both federal and county-level State of Emergency declarations remain less effective in preventing COVID-19 cases and deaths. Interestingly, the coefficient of EFI is negatively associated with COVID-19 outcomes when controlling for county-level demographic characteristics in both the pre-post and the double difference analyses (see estimates in column (4) of Table 2 ). This is in contrast with the positive effect in column (3) of the same table. An interpretation for these results is that the positive effect of ethnic fragmentation on COVID-19 outcomes pre-policy is likely mediated by some of the county-level socioeconomic characteristics we control for. However, these same characteristics do not seem to play any significant mediating role post-policy. Our second approach to addressing confounding factors is by controlling for county and day fixed effects in column (5) (which therefore subsumes all the controls of column (4)). We find that the interaction between mobility restrictions and EFI continues to have a positive and statistically significant effect on COVID-19 outcomes, confirming that ethnic fragmentation has significantly constrained the effectiveness of both federal and county-level State of Emergency policies.

For robustness, we consider an alternative measure of the federal policy response to COVID-19. Using the pre-post analysis specification in equation (1), we replace the timing of the federal State of Emergency announcement with an index measuring the degree of stringency of the federal policy response to COVID-19 (see description in Section 3). Results are reported in Panels $A$ and $B$ of Table 3. In these panels we replicate the same analysis as in the top two panels of Table 2, but this time measuring mobility restriction using the stringency index. Consistent with the results in Table 2 we find that government responses to COVID-19 were more effective at reducing COVID-19 infections and deaths in less ethnically fragmented counties.

County governments implemented several other mobility restriction measures to reduce COVID-19 infections. For instance, governments declared safer-at-home orders and business closures. In a second sensitivity analysis, we assess the interplay between the announcement of these alternative mobility restriction measures and the ethnic fragmentation index. Results are summarized in Panels $C-F$ of Table 3. Our main conclusion that mobility restriction policies were less effective at reducing COVID-19 cases and deaths in more ethnically fragmented counties remain the same. When we consider alternative mobility restriction policies including safer-at-home orders and business closures, the findings are qualitatively similar and the magnitude of the effect is stronger (see Panels $C-F$ of Table 5$)$.

We next study the dynamics of the effect of mobility-restricting policies' interactions with ethnic fragmentation. To do so, we consider different bandwidths around the date of the federal and county-level State of Emergency declarations. The estimated coefficients 
of the interaction terms between the federal State of Emergency and EFI, and the countylevel State of Emergency and EFI are represented under increasingly large bandwidths in Figure 5. We find that the ineffectiveness of federal and county-level mobility restrictions in averting new COVID-19 cases and deaths in more ethnically fragmented counties increases over time. These results indicate that mobility restriction policies generated sharp and increasing inequalities in COVID-19 outcomes between ethnically fragmented counties and those that are more homogeneous.

As discussed in Section 4), our difference-in-differences methodology assumes parallel trends in the outcome of interest between treated and control groups in the pre-policy period. To consider potential violation of common trends, we conduct an event-study analysis of COVID-19 cases and deaths. The results are reported in Figure 6. We find no statistically significant evidence of a differential effect of mobility restriction policies in highly fragmented counties during the days prior to the county-level State of Emergency declaration. Each point estimate is also near zero. Following the policy date, the estimated effect of the interaction between county State of Emergency and EFI on COVID-19 cases and deaths increases, becoming largest after 80 days following the emergency declaration. These findings are consistent with a causal interpretation of our findings in Table 2 and 3.

We further validate our results by conducting an in-time placebo test. We create a fictitious policy 45 days after the true emergency declaration date, whether at the federal or county level. The estimates of the effect of the interaction between the fictitious date of the State of Emergency declaration and EFI are reported in Figure 7 for different bandwidths around this date. We do not find any significant differential effect of mobility restrictions on COVID-19 cases or deaths in more ethnically fragmented areas. The estimates are small and statistically indistinguishable from zero for both the federal and county emergency declarations, for all bandwidths. This clearly contrasts with the results displayed in Figure 5 showing the dynamics of these effects under the true policy date.

\subsection{Emergency Declarations, Racial Segregation, and COVID- 19}

We now document the effect of racial residential segregation, mobility restriction policies, and their joint impact on COVID-19 outcomes. Similar to Figures 2- $a$ and 2- $b$, Figures $3-a$ and 3- $b$ plot the trends in the average number of new daily COVID-19 cases and deaths in counties with above-median levels of racial segregation and counties with belowmedian levels of racial segregation for the days before and after the county-level State of Emergency declaration. What clearly emerges is that following the federal and countylevel State of Emergency declarations, there is a substantial increase in the number of new COVID-19 cases and deaths in more segregated counties, suggesting that federal State 
of Emergency and county-level State of Emergency policies are significantly less effective in reducing the spread of COVID-19 in counties with a high level of racial segregation. Regression analyses in Table 4 underscore the magnitude of these effects.

In Table 4, Panels $A$ and $B$ replicate the pre-post analysis in Table 2, while Panels $C$ and $D$ replicate the difference-in-differences analysis from the same table, this time replacing ethnic fragmentation with black-white residential segregation as defined in Section 3. ${ }^{11}$ The first column presents the average effects of the mobility restriction policy and racial segregation. We find that racial segregation positively affects both COVID-19 cases and deaths. Moving from a county with no racial segregation to a county that is completely segregated increases COVID-19 cases by 12.17 and COVID-19 deaths by 0.81 when we control for the federal State of Emergency declaration (see Panels $A$ and $B$ ). These outcomes are 18.82 and 0.97 , respectively, when we control for the county-level State of Emergency declaration (see Panels $C$ and $D$ ).

In column (2), we add an interaction between the index of racial residential segregation and the mobility restriction policy. We find that the effect of the policy on COVID-19 outcomes is negative while the coefficient of the interaction term is significantly positive. This is the case regardless of whether we consider the federal policy (Panels $A$ and $B$ ) or the county-level policy (Panels $C$ and $D$ ). These findings imply that mobility restriction measures were effective in counties displaying low levels of racial segregation, but were ineffective in highly segregated counties. Following President Trump's State of Emergency declaration, moving from a county with no racial segregation to a county with the highest level of racial segregation increased COVID-19 cases and associated deaths by 1,931 and 128, respectively. Similarly, following the county-level State of Emergency declaration, moving from a county with no racial segregation to a county with the highest level of racial segregation increased COVID-19 cases and associated deaths by 3, 174 and 164, respectively. ${ }^{12}$ As shown in columns (3), (4), and (5), these results are not driven by time-invariant state and/or county level determinants of COVID-19 outcomes. These results are also robust to alternative specifications. In particular, we replicate the analysis in Table 4 using other mobility restriction policies and find similar results that mobility restrictions to reduce COVID-19 cases and deaths are less effective in highly segregated counties (see Table 5). In Appendix Table A1, we conduct a similar robustness check by considering an index of residential segregation between white and non-white county residents and reach the same conclusion.

\footnotetext{
${ }^{11}$ In the Appendix, we find similar results when using an index of residential segregation between white and non-white county residents (Appendix Table A1).

${ }^{12} \mathrm{By}$ construction, the value of the segregation index is 0 in a county with no racial segregation and 100. These estimates are therefore obtained by multiplying the regression coefficients by 100 .
} 


\subsection{Diversity with(out) Divisions: When Does Ethnic Fragmen- tation Matter?}

We argue that ethnic division, rather than ethnic diversity, is driving the ineffectiveness of mobility-restricting policies in the United States. This is because the mechanisms by which ethnicity could matter for communicable disease transition matter only if ethnicity represents a barrier to interaction between groups. While ethnic heterogeneity and ethic division have been considered, at least empirically, to be commensurate in economics, we emphasize the role of measured residential segregation in capturing ethnic divisions. Ethnic diversity and racial segregation are only weakly correlated in United States cities (Uslaner (2010)). By examining the interaction between diversity (EFI) and racial divisions (racial residential segregation), we find that the negative impact of EFI on the efficacy of mobility-restricting policies only exists where both diversity and divisions are present. Our paper contributes to a small literature which explores the role of both segregation and diversity for economic outcomes. For example, Beach and Jones's (2017) finding that public good provision is lower in U.S. cities with more diverse city councils is driven by cities with high segregation. In a study of neighborhood diversity in England, Fumagalli and Fumagalli (2019) find that while neighborhood diversity increases purposeful activity among adolescents, neighborhood ethnic segregation decreases it. Uslaner (2012) presents correlational evidence from several countries; he finds that integrated diverse neighborhoods display high levels of trust while diverse neighborhoods with high levels of residential segregation display low levels of trust.

Figure 8 and Appendix Table A7 summarize the effects of EFI on the effectiveness of mobility restriction policies, disaggregating by decile of racial residential segregation. For each decile of residential segregation, Panel $A$ of Figure 8 reports the coefficient of a regression of cases of COVID-19 on an interaction of EFI and the federal State of Emergency declaration (in blue), and the coefficient of a regression of cases of COVID-19 on interaction between EFI and CSOE (in red). Both regression specifications include controls for: county-level characteristics (i.e. population density, percentage of males, average age, poverty, education, urban area, the percentage of immigrants), and countylevel health characteristics (i.e. the percentage of adults with obesity, "poor health", diabetes, and who smoke), the interacted measures separately, as well as for state and day fixed effects. Panel $B$ of Figure 8 reports the same information for deaths associated with COVID-19. Coefficient estimates suggest that EFI has a non-positive effect on the efficacy of both the federal State of Emergency declaration and on county-level State of Emergency declarations. However, when black-white residential segregation is in the lowest decile, the marginal effect of EFI on the effectiveness of mobility restriction policies is quite small (an increase of 14 cases and of less than 1 death). As the decile of residential segregation increases, the negative impact of EFI on mobility restriction policies increases 
as well. At the highest decile of residential segregation, a one standard deviation increase in the level of EFI in a county is associated with 2, 735 additional cases and 202 additional deaths following the federal declaration. Following the institution of county-level State of Emergencies, a one standard deviation increase in the level of EFI in a county is associated with 2,809 additional cases and 151 additional deaths in the most segregated counties. $^{13}$

The regression analysis in Table 6 further illustrates the importance of residential segregation in explaining the role of EFI on the efficacy of mobility restriction policies. Panels $A$ and $B$ of this table summarize the effects of EFI, the federal State of Emergency declaration, and their interaction on the number of COVID-19 cases and deaths separately for counties with below-median and above-median levels of residential segregation. Following the emergency declaration, the effect of an increase in EFI in counties with high levels of residential segregation is roughly eight times the effect of an increase in EFI in counties with low residential segregation across all specifications. In our preferred specification (shown in columns 3 and 4), a one standard deviation increase in EFI is associated with a statistically significant increase of 684.4 daily cases following the federal State of Emergency declaration in areas of high residential segregation, and by an increase of only 101.6 cases in low-segregation areas. A one standard deviation increase in EFI is associated with a statistically significant increase in 34.9 deaths following the federal declaration in areas of high residential segregation, and by an increase of 3.6 deaths in low-segregation areas.

This pattern - that preventative policies are drastically less effective in areas of high-segregation relative to areas of low-segregation - holds for COVID-19 cases and deaths following the institution of county-level State of Emergency policies as well. A one standard deviation increase in EFI in a high-segregation county following countylevel State of Emergency is associated with an increase of 968.7 additional cases and 41.1 additional deaths relative to living in a low-segregation county. These results remain the same when using alternative measures of mobility restrictions as we can see from estimates in Table 7. Also, the findings presented in this section do not change qualitatively when we consider an index of residential segregation between white and non-white county residents (see Appendix Tables A3 and A4).

\section{Mechanisms}

In this section, we document possible mechanisms through which ethnic divisions may have reduced the effectiveness of containment policies. First, we analyze how ethnic divisions matter for self-quarantining. We next describe the relationship between eth-

\footnotetext{
${ }^{13}$ These numbers are computed using estimates in Appendix Table A7
} 
nic divisions and the use of masks following the implementation of mobility-restricting policies. Finally, we provide evidence that ethnic divisions reduce the prevalence of membership associations potentially rendering communication more sparse, pro-social norms weaker, and the ability of communities to enact social sanctions reduced.

\subsection{Mobility Evidence of Restriction Policies' Efficacy}

We have shown that ethnic fragmentation has negatively impacted the number of COVID19 cases and deaths, and has reduced the efficacy of public policies aimed at mitigating these negative outcomes. The negative role played by ethnic fragmentation is heightened in areas that are more racially segregated. In this section we provide direct evidence of lockdown policies' decreased effectiveness in ethnically divided counties — the mobility impacts of State of Emergency declarations. We explore multiple mobility variables which measure change in visits to: (1) retailers and recreational outlets; (2) groceries and pharmacies; (3) parks; (4) transit stations; (5) work places; and (6) residences. Time spent at some locations was directly impacted by lockdown policies which closed physical businesses (i.e. retail and recreation, workplaces), while others remained open under emergency declarations (i.e. groceries, pharmacies, parks, transit). While mobility changes in the former set of locations may reflect the stringency of local legislation, mobility changes in the latter set of locations represent voluntary changes in response to COVID-19 risk. Examining mobility in these locations provides a measure of voluntary personal and pro-social risk reduction.

Our mobility variables are adjusted for COVID-19 cases and deaths. Indeed, while an individual might change their mobility behavior in response to mobility restriction policies, behavioral change is also likely to be endogenous to COVID-19 prevalence in their neighborhood. We account for this endogeneity by computing the ratio of a given mobility variable at time $t$ to the accumulated number of COVID-19 cases at time $t$. We then estimate the effects of policies on the variables thus generated and analyze how these effects vary by level of ethnic divisions.

A graphical description of the findings is presented in Figure 9. This figure shows that county-level emergency declarations were successful at increasing self-quarantining. Mobility levels dropped following emergency declarations, but mobility in certain categories including visits to workplaces, transit stations, and retail and recreational outlets increased soon thereafter (though not reaching pre-emergency declaration levels in general). In addition, the efficacy of the emergency declaration was higher in counties where ethnic fragmentation is low. Prior to the declaration, counties with low and high levels of ethnic fragmentation had similar mobility levels. Following the emergency declaration, mobility dropped more in counties with low levels of ethnic fragmentation.

We confirm these descriptive findings in a regression-based framework. We estimate 
equations (1) and (2), where the dependent variable is any of the aforementioned mobility variables. As in Section 5, we consider both national and county-level State of Emergency policies. Our results are presented in Tables 8-11. In Table 8, we analyze the effect of the national emergency declaration on different categories of mobility. We find that the national emergency declaration increases visits to residences (column (1) of Panel F) and decreases all of the other categories of mobility (column (1) of Panels A-E). However, the efficacy of this policy at reducing mobility is much lower in counties with higher levels of ethnic fragmentation. Indeed, the effect of the interaction term between the national emergency declaration and ethnic fragmentation is positive for all categories of mobility (columns (2)-(5) of Panels A-E) except visits to residential places for which the effect is negative (columns (2)-(5) of Panel F). When we consider county-level emergency declarations (Table 9), the findings are qualitatively similar and the effects are stronger in magnitude and statistical significance.

In Table 10, we analyze the interacting effect of the national emergency declaration and ethnic fragmentation by level of residential segregation. We find that this effect is much higher in highly segregated counties, except when the outcome variables are visits to groceries and pharmacies and visits to parks. In general, these findings imply that the efficacy of policies aimed at curbing the spread of COVID-19 is even much lower for more ethnically fragmented counties that are also more racially segregated. The findings are qualitatively similar, for most outcomes, when we consider county-level emergency declarations (Table 11). In addition, in Appendix Tables A5 and A6, we find stronger results when using an index of residential segregation between white and non-white county residents.

\subsection{Mask-Wearing and Ethnic Divisions}

In addition to reduced mobility and physical distancing, the use of masks to cover the mouth and nose has been prescribed by health organizations and governments around the world as a way to limit the spread of COVID-19. Due to its health externalities, the use of masks can be considered a contribution to a public good. In this section, we analyze how ethnic divisions have impacted the adoption of this behavior in U.S. counties.

Our data on mask-wearing come from county-level estimates released by the New York Times, and are available only for the month of July 2020. This variable is measured at the county level and represents the proportion of individuals who use a mask to cover their face when they are outside of their home. Because these data were only collected after most mobility-restricting measures were in place, we cannot analyze how these policies affected face covering. However, we believe that observing the correlation between face covering and ethnic divisions is likely to shed additional light on how the latter have reduced the efficacy of preventative policies. 
We regress mask-wearing on EFI and on residential segregation (Table 12). All specifications include state fixed effects. The estimate reported in column (1) implies that a one standard deviation increase in EFI decreases the share of people wearing a mask "frequently" by 0.013 percentage points. In column (2), mask-wearing is regressed only on black-white residential segregation. The estimate implies that a one standard deviation increase in this variable decreases the frequent use of masks by 0.0015 percentage points. column (3) includes controls for both variables. We note that the effect of EFI decreases while that of black-white segregation increases. The reduction in the effect of EFI can be explained by the drop of observations for which the value of black-white segregation is not available. In column (4), we regress mask-wearing on the index of segregation between whites and others, uncovering an effect that is larger than that of black-white segregation. When both EFI and the index of segregation between whites and others are controlled in column (5), we see that each has a negative and significant effect on mask-wearing. Overall, these findings show that ethnic divisions discouraged mask-wearing during the COVID-19 pandemic, which provides another channel through which they might have weakened the effectiveness of preventative policies in more ethnically divided counties of the United States.

\subsection{Membership Associations and Ethnic Divisions}

In this section, we provide some evidence that ethnic divisions reduce social association rates, which potentially renders communication more sparse and pro-social norms weaker, reducing the ability of communities to enact social sanctions. Indeed, the ability of communities to enforce policies critically depends on how internally cohesive and well-integrated they are. Social cohesion facilitates communication and makes it easier to define common rules and expectations during a pandemic like COVID-19. Better communication can also facilitate the implementation of preventative policies like contact tracing.

We analyze how the effect of EFI on social association rates-measured as the number of membership associations per 10,000 individuals in a county- varies by level of racial segregation. Data on social association rates are obtained from 2017 County Health Rankings, the most recent year for which data are available. We regress social association rate on EFI for each decile of black-white residential segregation, and report the estimates in Figure 10 and Appendix Table A8. We find that ethnic fragmentation decreases social association, but that this negative effect is driven by racial segregation. When the level of racial segregation is low, EFI has no statistically significant effect on social association, but its effect is larger and statistically significant in areas with sufficiently high levels of racial segregation. A one standard deviation increase in EFI increases the number of membership associations by 0.10 per 10,000 individuals in the first decile of racial 
segregation, and decreases the number of membership associations by 1.25 in the tenth decile.

These results are consistent with the earlier reported findings that the reduced effectiveness of mobility-restricting policies associated with ethnic fragmentation is almost entirely driven by racial segregation. Altogether, our analysis suggests that ethnic fragmentation weakened mobility restriction measures only in areas where interracial interactions and social associations are absent. Ethnic fragmentation in the absence of racial divisions does not appear to be harmful.

\section{Conclusion}

Understanding how structural factors matter for the effectiveness of government policies is critical for optimal policy design. In this paper, we present causal evidence that ethnic divisions in the United States have constrained the effectiveness of mobility-restricting policies during the COVID-19 pandemic. While areas with high levels of ethnic diversity fared worse in both COVID-19 cases and deaths after federal and county-level State of Emergency declarations, these effects are driven by the response of counties with high levels of racial residential segregation - a one standard deviation increase in the level of ethnic fragmentation is associated with nearly seven times more cases of COVID-19 and ten times more deaths in highly segregated counties than in more integrated counties. In areas with high levels of ethnic divisions, there were smaller mobility reductions in response to federal and county-level policies. Despite higher disease prevalence, residents of these areas were less likely to report frequently wearing a mask.

Our analysis therefore suggests that ethnicity matters for disease spread only inasmuch as it presents a barrier to interactions between groups. Ethnic division, rather than ethnic diversity, forms such a barrier. Where group divisions exist, communication is sparser, pro-social norms are weaker, and communities are less able to enforce mobility restrictions by enacting social sanctions. These group divisions are particularly problematic in the United States which has, to date, been unable to enact rigorous formal enforcement against violations of COVID-19 related policies. Further, the delegation of pandemic management to states and localities has meant that local group divisions which might hinder policy production, pro sociality, and public goods provision have had an outsized impact on the effect of preventative policies. From a policy perspective, all of our proposed mechanisms suggest that federal policy making and enforcement, which can circumvent local coordination problems, could be a good approach to ensure that best practices are followed. Our analysis also suggests that policies which promote ethnic and racial integration can allay the negative social and economic impacts of contagious disease by decreasing the likelihood of disease spread. 


\section{References}

Alesina, A., Baqir, R., \& Easterly, W. (1999). Public goods and ethnic divisions. The Quarterly Journal of Economics, 114(4), 1243-1284.

Alesina, A., \& Ferrara, E. L. (2005). Ethnic diversity and economic performance. Journal of Economic Literature, 43(3), 762-800.

Alesina, A., Gennaioli, C., \& Lovo, S. (2019). Public goods and ethnic diversity: Evidence from deforestation in indonesia. Economica, 86(341), 32-66.

Alesina, A., \& La Ferrara, E. (2000). Participation in heterogeneous communities. The Quarterly Journal of Economics, 115(3), 847-904.

Alesina, A., \& Zhuravskaya, E. (2011). Segregation and the quality of government in a cross section of countries. American Economic Review, 101(5), 1872-1911.

Algan, Y., Hémet, C., \& Laitin, D. D. (2016). The social effects of ethnic diversity at the local level: A natural experiment with exogenous residential allocation. Journal of Political Economy, 124(3), 696-733.

Andrasfay, T., \& Goldman, N. (2021, February). Reductions in 2020 US life expectancy due to COVID-19 and the disproportionate impact on the Black and Latino populations. Proceedings of the National Academy of Sciences, 118(5). (Publisher: National Academy of Sciences Section: Social Sciences)

Balliet, D. (2010). Communication and cooperation in social dilemmas: A meta-analytic review. Journal of Conflict Resolution, 54 (1), 39-57.

Barrios, J. M., Benmelech, E., Hochberg, Y. V., Sapienza, P., \& Zingales, L. (2021, January). Civic capital and social distancing during the Covid-19 pandemic. Journal of Public Economics, 193, 104310.

Bazzi, S., Gaduh, A., Rothenberg, A. D., \& Wong, M. (2019). Unity in diversity? how intergroup contact can foster nation building. American Economic Review, 109 (11), 3978-4025.

Beach, B., \& Jones, D. B. (2017). Gridlock: Ethnic diversity in government and the provision of public goods. American Economic Journal: Economic Policy, 9(1), 112-36.

Blau, P. M. (1964). Exchange and Power in Social Life. Transaction Publishers.

Bonaccorsi, G., Pierri, F., Cinelli, M., Flori, A., Galeazzi, A., Porcelli, F., ... others (2020). Economic and social consequences of human mobility restrictions under covid-19. Proceedings of the National Academy of Sciences, 117(27), 15530-15535.

Card, D., \& Rothstein, J. (2007). Racial segregation and the black-white test score gap. Journal of Public Economics, 91(11-12), 2158-2184.

Chetty, R., Hendren, N., Kline, P., \& Saez, E. (2014). Where is the land of opportunity? the geography of intergenerational mobility in the united states. The Quarterly Journal of Economics, 129(4), 1553-1623. 
Desmet, K., Ortuño-Ortín, I., \& Wacziarg, R. (2017). Culture, ethnicity, and diversity. American Economic Review, 107(9), 2479-2513.

Dincer, O. C. (2011). Ethnic diversity and trust. Contemporary Economic Policy, 29(2), 284-293.

Ding, W., Levine, R., Lin, C., \& Xie, W. (2020, June). Social Distancing and Social Capital: Why U.S. Counties Respond Differently to COVID-19 (Tech. Rep. No. w27393). National Bureau of Economic Research.

Duncan, O. D., \& Duncan, B. (1955). A methodological analysis of segregation indexes. American Sociological Review, 20(2), 210-217.

Durante, R., Guiso, L., \& Gulino, G. (2020). Asocial capital: Civic culture and social distancing during covid-19. Journal of Public Economics, 194, 104342.

Easterly, W., \& Levine, R. (1997). Africa's growth tragedy: policies and ethnic divisions. The Quarterly Journal of Economics, 112(4), 1203-1250.

Ejdemyr, S., Kramon, E., \& Robinson, A. L. (2018). Segregation, ethnic favoritism, and the strategic targeting of local public goods. Comparative Political Studies, 51(9), $1111-1143$.

Ellingsen, T., \& Östling, R. (2010). When does communication improve coordination? American Economic Review, 100(4), 1695-1724.

Eric Oliver, J., \& Wong, J. (2003). Intergroup prejudice in multiethnic settings. American Journal of Political Science, 47(4), 567-582.

Fafchamps, M. (2000). Ethnicity and credit in african manufacturing. Journal of Development Economics, 61(1), 205-235.

Finseraas, H., Hanson, T., Johnsen, Å. A., Kotsadam, A., \& Torsvik, G. (2019). Trust, ethnic diversity, and personal contact: A field experiment. Journal of Public Economics, 173, 72-84.

Fumagalli, E., \& Fumagalli, L. (2019). Neighbourhood ethnic composition and social participation of young people in england. The Economic Journal, 129(622), 24592521.

Graham, B. S. (2018). Identifying and estimating neighborhood effects. Journal of Economic Literature, 56(2), 450-500.

Guryan, J. (2004). Desegregation and black dropout rates. American Economic Review, 94(4), 919-943.

Hale, T., Petherick, A., Phillips, T., \& Webster, S. (2020). Variation in government responses to covid-19. Blavatnik School of Government Working Paper, 31.

Iceland, J., Weinberg, D. H., \& Steinmetz, E. (2002). Racial and ethnic residential segregation in the united states: 1980-2000. In Census 2000 Special Reports (p. 151). Washington, DC: U.S. Government Printing Office.

Kandori, M. (1992). Social norms and community enforcement. The Review of Economic Studies, 59(1), 63-80. 
Kolata, G. (2020, December). Social Inequities Explain Racial Gaps in Pandemic, Studies Find. The New York Times. Retrieved 2020-12-11, from https://www.nytimes .com/2020/12/09/health/coronavirus-black-hispanic.html

Kreps, D. M., \& Wilson, R. (1982). Reputation and imperfect information. Journal of Economic Theory, 27(2), 253-279.

Leibbrandt, A., \& Sääksvuori, L. (2012). Communication in intergroup conflicts. European Economic Review, 56(6), 1136-1147.

Lindqvist, E., \& Östling, R. (2013). Identity and redistribution. Public Choice, 155(3-4), 469-491.

Maskin, E., Fudenberg, D., \& Levine, D. (1994). The folk theorem with imperfect public information. Econometrica, 62(5).

Massey, D. S., \& Denton, N. A. (1988). The dimensions of residential segregation. Social Forces, 67(2), 281-315.

Mauro, P. (1995). Corruption and growth. The Quarterly Journal of Economics, 110(3), $681-712$.

Miguel, E. (2004, April). Tribe or Nation? Nation Building and Public Goods in Kenya versus Tanzania. World Politics, 56 (3), 327-362. (Publisher: Cambridge University Press)

Miguel, E., \& Gugerty, M. K. (2005). Ethnic diversity, social sanctions, and public goods in kenya. Journal of Public Economics, 89(11-12), 2325-2368.

Mouw, T., \& Entwisle, B. (2006). Residential segregation and interracial friendship in schools. American Journal of Sociology, 112(2), 394-441.

Müller, S., \& Rau, H. A. (2020). Economic preferences and compliance in the social stress test of the covid-19 crisis. Journal of Public Economics, 104322.

Ostrom, E., \& Walker, J. (1991). Communication in a commons: cooperation without external enforcement. Laboratory Research in Political Economy, 287-322.

Ostrom, E., Walker, J., \& Gardner, R. (1992). Covenants with and without a sword: Self-governance is possible. American Political Science Review, 86 (2), 404-417.

Peterson, R. D., \& Krivo, L. J. (2009). Segregated spatial locations, race-ethnic composition, and neighborhood violent crime. The Annals of the American Academy of Political and Social Science, 623(1), 93-107.

Pongou, R. (2009). Anonymity and infidelity: Ethnic identity, strategic cross-ethnic sexual network formation, and hiv/aids in africa. Unpublished Paper, Department of Economics, Brown University.

Pongou, R., Tchuente, G., \& Tondji, J.-B. (2020). An economic model of health-vswealth prioritization during covid-19: Optimal lockdown, network centrality, and segregation (Tech. Rep.). National Institute of Economic and Social Research.

Rose, A. M. (1966). Review of negroes in cities: Residential segregation and neighborhood change. Political Science Quarterly, 81(2), 346-348. (Publisher: [Academy of 


\section{Political Science, Wiley])}

Rothwell, J. T. (2012). The effects of racial segregation on trust and volunteering in us cities. Urban Studies, 49(10), 2109-2136.

Sigelman, L., Bledsoe, T., Welch, S., \& Combs, M. W. (1996). Making contact? blackwhite social interaction in an urban setting. American Journal of Sociology, 101 (5), $1306-1332$.

Sparber, C. (2008). A theory of racial diversity, segregation, and productivity. Journal of Development Economics, 87(2), 210-226.

Uslaner, E. M. (2010). Segregation, mistrust and minorities. Ethnicities, 10(4), 415-434.

Uslaner, E. M. (2012). Segregation and mistrust: Diversity, isolation, and social cohesion. Cambridge University Press.

Yan, Y., Malik, A. A., Bayham, J., Fenichel, E. P., Couzens, C., \& Omer, S. B. (2020). Measuring voluntary social distancing behavior during the covid-19 pandemic. MedRxiv.

Zingher, J. N., \& Steen Thomas, M. (2014). The spatial and demographic determinants of racial threat. Social Science Quarterly, 95(4), 1137-1154. 
Figure 1

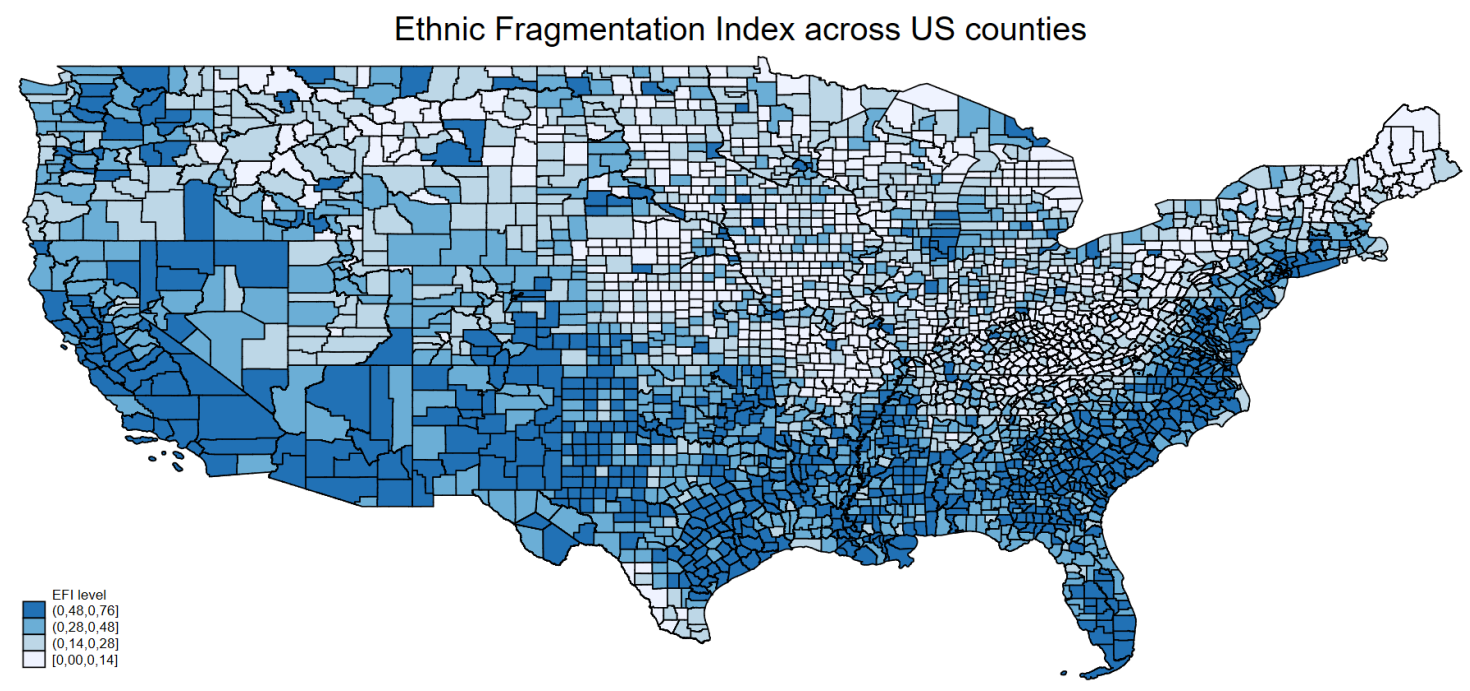

Residential segregation (White - non-Whites) across US counties

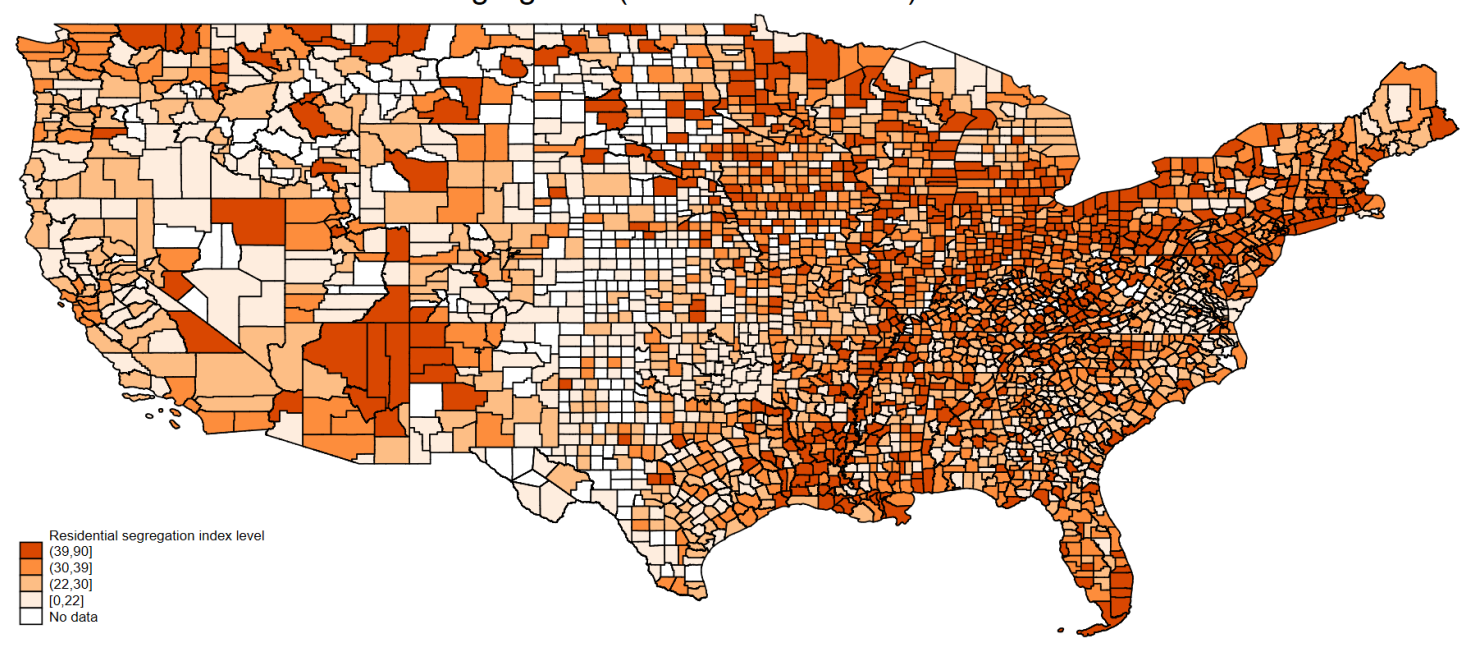

Note: The top graphic depicts county-level ethnic fragmentation across the continental United States. As colors progress from white to blue, the level of ethnic fragmentation increases. The bottom graphic shows countylevel residential segregation between White and Non-White residents in the United States as measured by a dissimilarity index. As colors progress from pale orange to red, the level of racial residential segregation in the county increases. Both graphs are generated by the authors using data from the 2018 American Community Survey. 
Figure 2: COVID-19 and county-level emergency declaration by level of ethnic fragmentation

(a) COVID-19 new cases

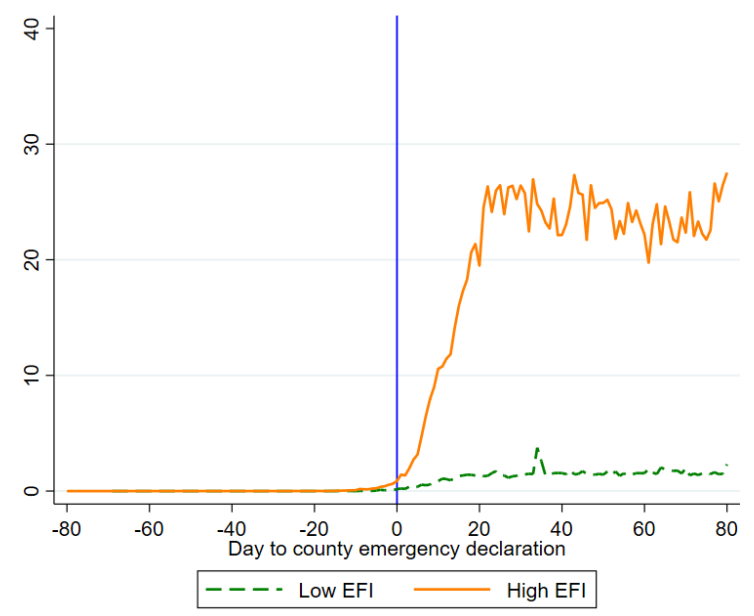

(b) COVID-19 new deaths

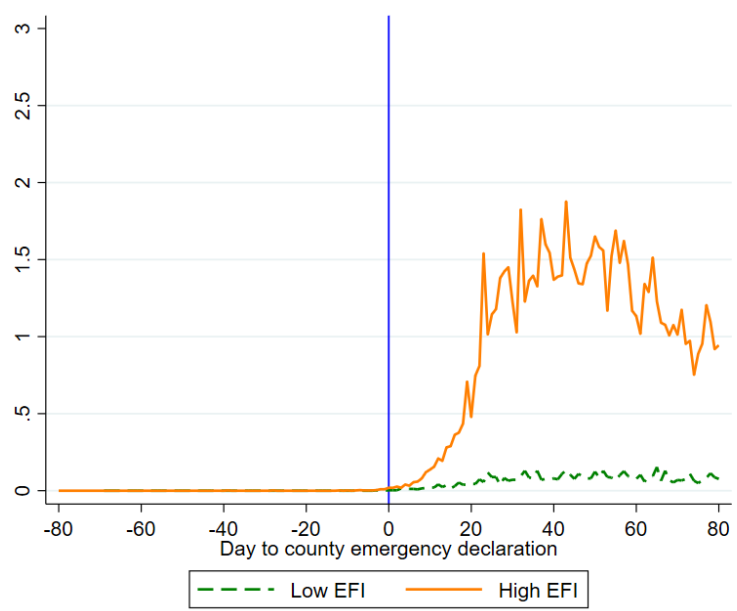

Note: Panel (a) of Figure 2 plots the average number of daily COVID-19 cases in counties in the U.S. relative to the date of their county-level State of Emergency declarations (denoted by the blue line at zero). The average number of new daily cases in the days preceding and following the county-level State of Emergency declarations is shown separately for counties with above-median values of ethnic fragmentation (shown in orange) and below-median values of ethnic fragmentation (shown in green), where ethnic fragmentation is defined for each county as the value of the Herfindahl-Hirschman Index. Panel (b) of Figure 2 plots the equivalent statistics for average daily deaths attributed to COVID-19 relative to the date of county-level State of Emergency declaration. 
Figure 3: COVID-19 and county-level emergency declaration by level of racial segregation

(a) COVID-19 new cases

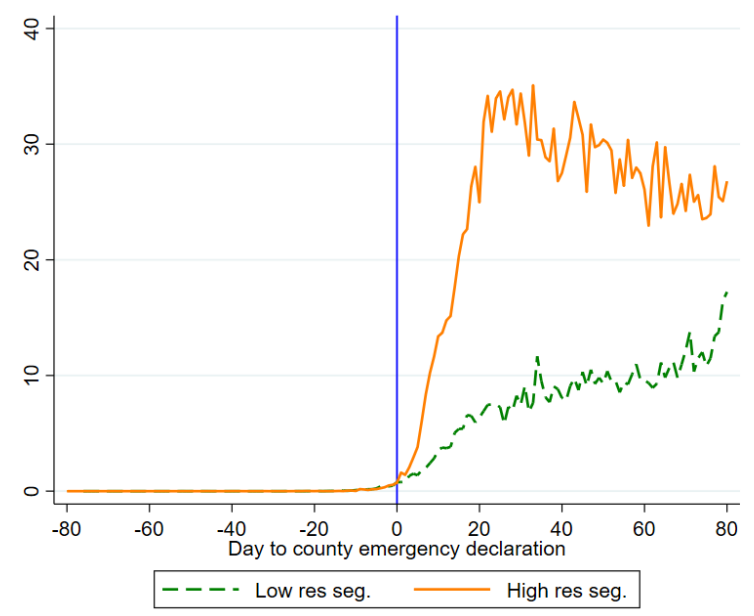

(b) COVID-19 new deaths

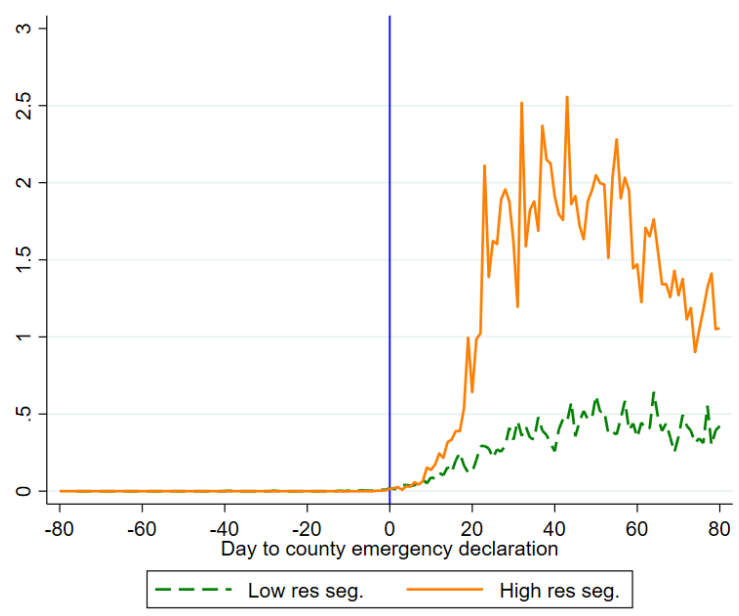

Note: Panel (a) of Figure 3 plots the average number of new daily COVID-19 cases in counties in the U.S. relative to the date of their county-level State of Emergency declarations (denoted by the blue line at zero). The average number of daily cases in the days preceding and following the county-level State of Emergency declarations is shown separately for counties with above-median values of Black-White racial residential segregation (shown in orange) and below-median values of Black-White racial residential segregation (shown in green), where the Black-White racial residential segregation is defined for each county in the 2018 American Community Survey. Panel (b) of Figure 3 plots the equivalent statistics for average daily deaths attributed to COVID-19 relative to the date of county-level State of Emergency declaration. 
Figure 4: COVID-19 and county-level emergency declaration by level of ethnic fragmentation and racial segregation
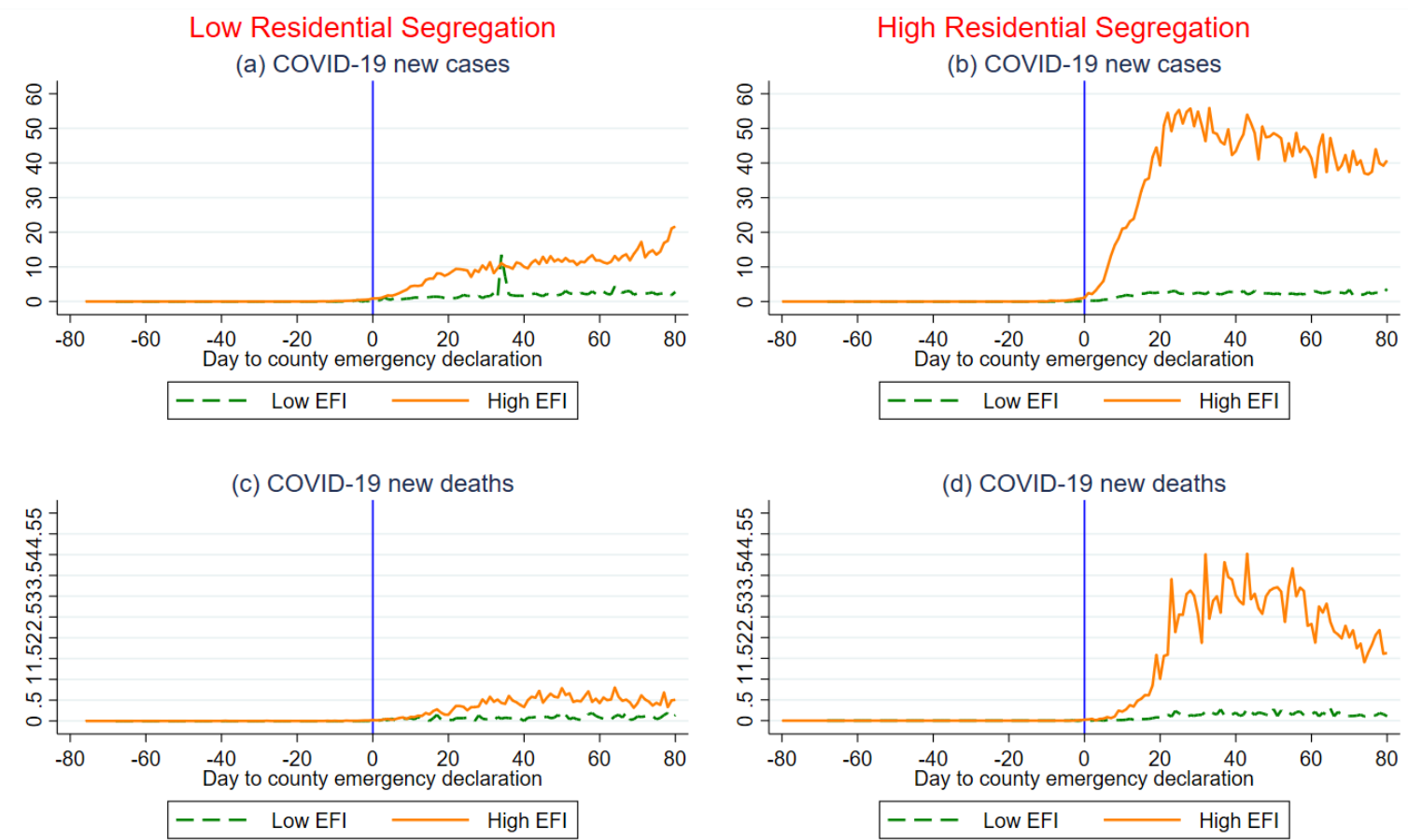

Note: Figure 4 plots the average number of new daily COVID-19 cases and deaths in U.S. counties relative to the date of their county-level State of Emergency declarations (denoted by the blue line), shown in separate graphs for counties with below-median (Panels a and c) and above-median (Panels b and d) levels of BlackWhite racial residential segregation. The average number of daily cases (Panels a and b) is shown for counties with above-median values of ethnic fragmentation (shown in orange) and below-median values of ethnic fragmentation (shown in green), where ethnic fragmentation is defined for each county as the value of the Herfindahl-Hirschman Index. Panels $\mathrm{c}$ and $\mathrm{d}$ of Figure 4 plot the equivalent statistics for average daily deaths attributed to COVID-19. 
Figure 5: Dynamic of the effect of the interaction between emergency declarations and EFI on COVID-19 outcomes
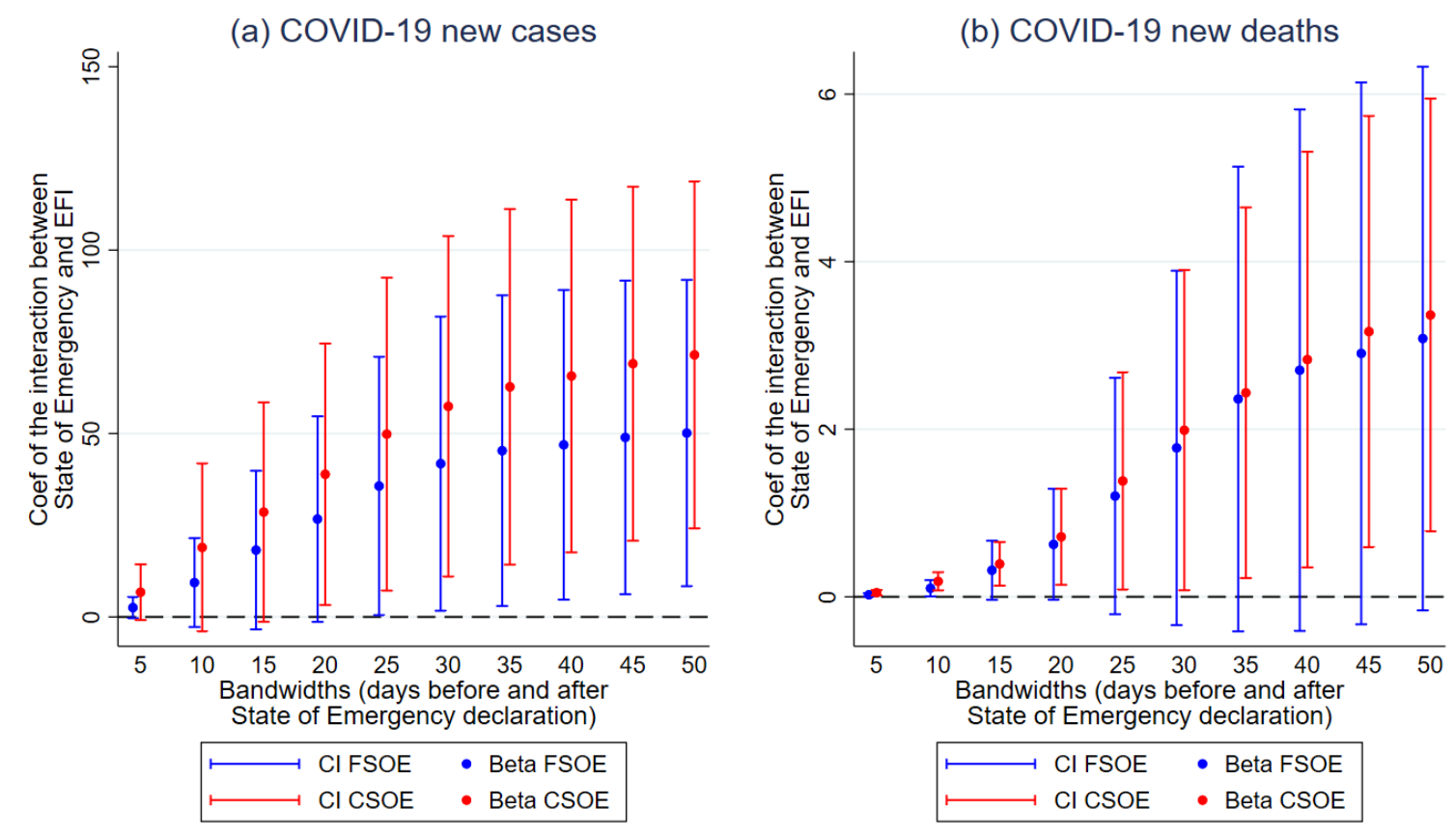

Note: Figure 5 summarizes, for different bin sizes around the policy dates, the regression coefficients and $95 \%$ confidence intervals of the interaction term between the Federal State of Emergency Declaration and EFI when equation 1 is estimated (denoted by FSOE, shown in blue), and the regression coefficient of the interaction term between the county-level State of Emergency Declaration and EFI when equation 2 is estimated (denoted by CSOE, shown in red). For example, 5 on the $\mathrm{x}$-axis indicates a bin size of five days before and after the lockdown. Panel (a) shows coefficients of equations 1 and 2 when estimated for the outcome of new daily COVID-19 cases. Panel (b) shows coefficients of equations 1 and 2 when estimated for the outcome of new daily COVID-19 deaths. All specifications include county-level characteristic controls (i.e. population density, percentage of males, average age, poverty, education, urban area, the percentage of immigrants, the percentage of adults with obesity, poor health, diabetes, and who smoke). Standard errors are clustered at the state level. 
Figure 6: Event-study estimates of the effect of the interaction between county-level emergency declaration and EFI on COVID-19 outcomes

(a) COVID-19 cases

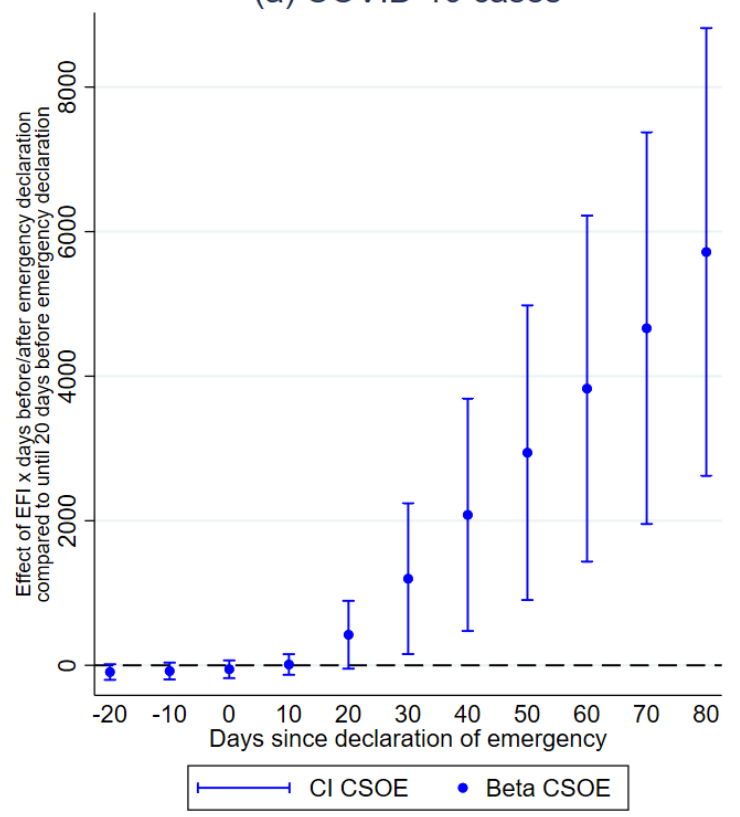

(b) COVID-19 deaths

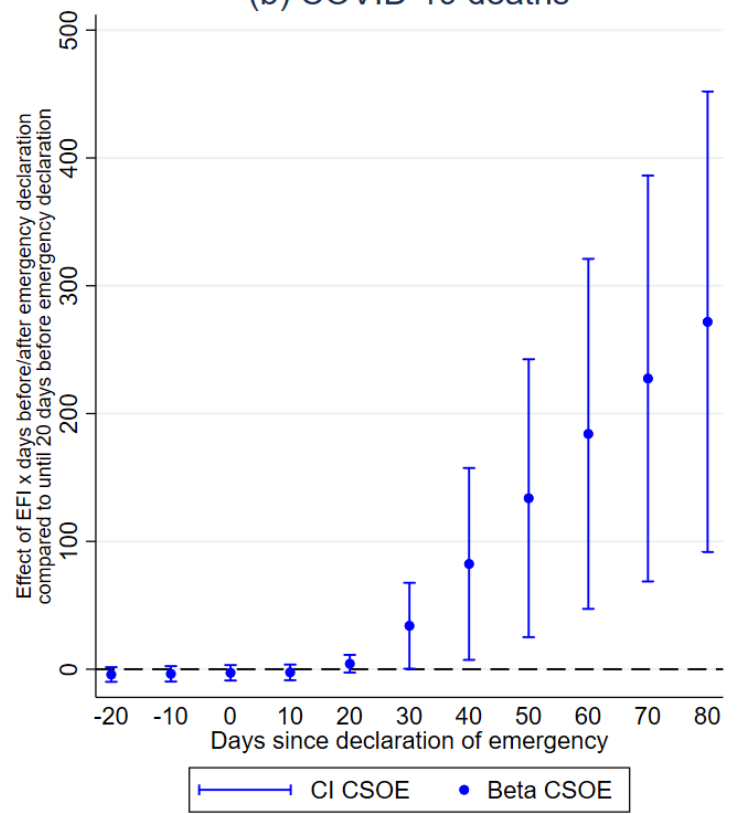

Note: Figure 6 summarizes, for different bin sizes, the event-study coefficients and 95\% confidence intervals of the effect of interaction between the county-level State of Emergency declaration and EFI on COVID-19 outcomes when equation 3 is estimated. The vertical axis shows event-study estimates. The period from January 22, 2020 to until 31 days before the State of Emergency declaration is the reference period. The model includes dummies for each period of 10 days before and after the State of Emergency declaration. 95\% confidence intervals around the estimated regression coefficients are plotted. Standard errors are clustered at the state level. 
Figure 7: Placebo test: Dynamic of the effect of the interaction between fictitious emergency declarations and EFI on COVID-19 outcomes

(a) Placebo test: COVID-19 new cases

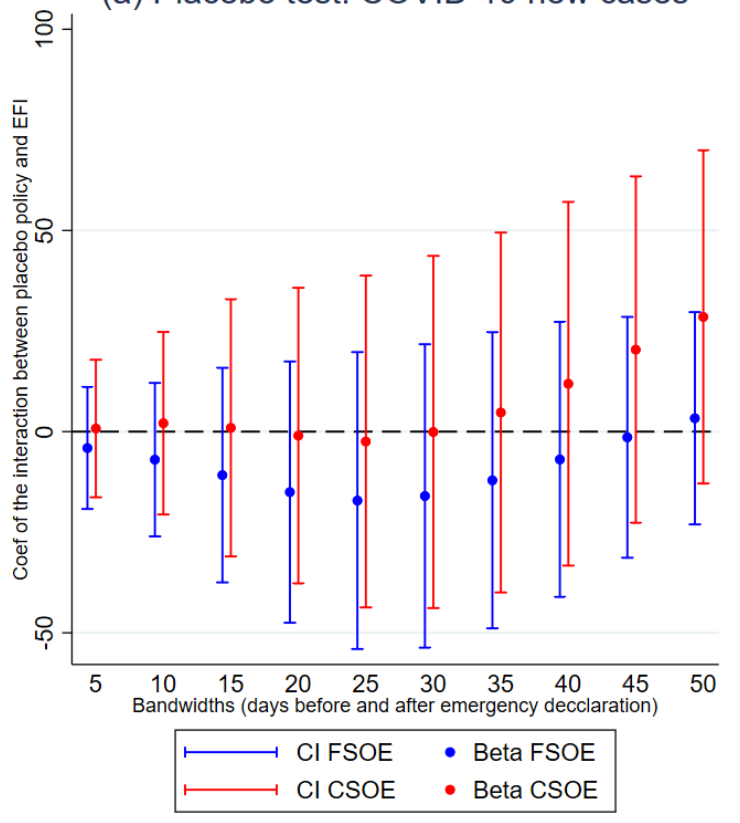

(b) Placebo test: COVID-19 new deaths

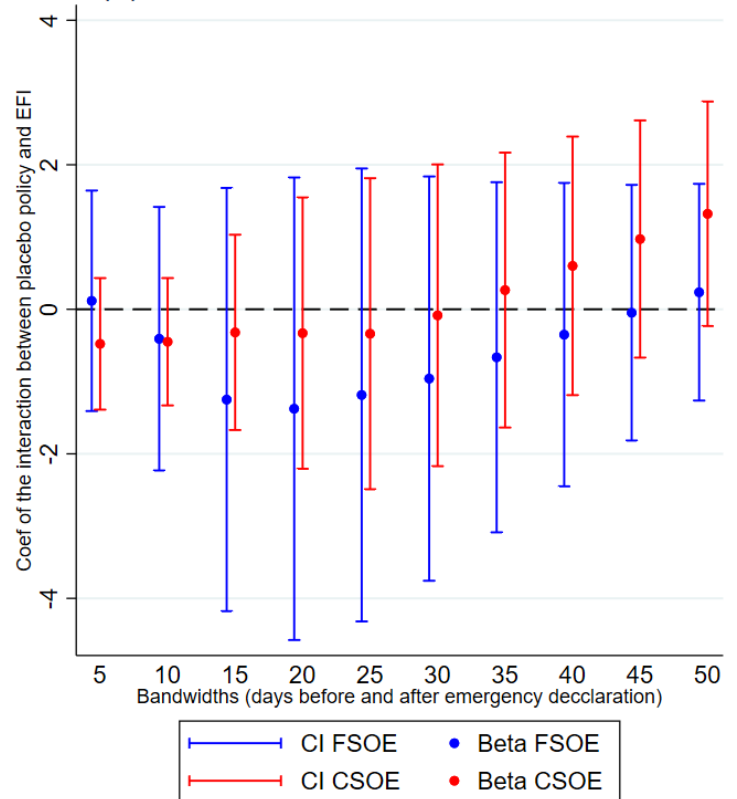

Note: Figure 7 summarizes, for different bin sizes around the fictitious policy dates, the regression coefficients and 95\% confidence intervals of the interaction term between a placebo policy 45 days after the Federal State of Emergency Declaration and EFI when equation 1 is estimated (denoted by FSOE, shown in blue), and the regression coefficients of the interaction term between the a placebo policy 45 days after the county-level State of Emergency Declaration and EFI when equation 2 is estimated (denoted by CSOE, shown in red). For example, 5 on the x-axis indicates a bin size of five days before and after the placebo policy. Panel (a) shows coefficients of equations 1 and 2 when estimated for the outcome of new daily COVID-19 cases. Panel (b) shows coefficients of equations 1 and 2 when estimated for the outcome of new daily COVID-19 deaths. All specifications include county-level characteristic controls (i.e. population density, percentage of males, average age, poverty, education, urban area, the percentage of immigrants, the percentage of adults with obesity, poor health, diabetes, and who smoke). Standard errors are clustered at the state level. 
Figure 8: Effect of the interaction between emergency declarations and EFI on COVID-19 outcomes by level of racial segregation
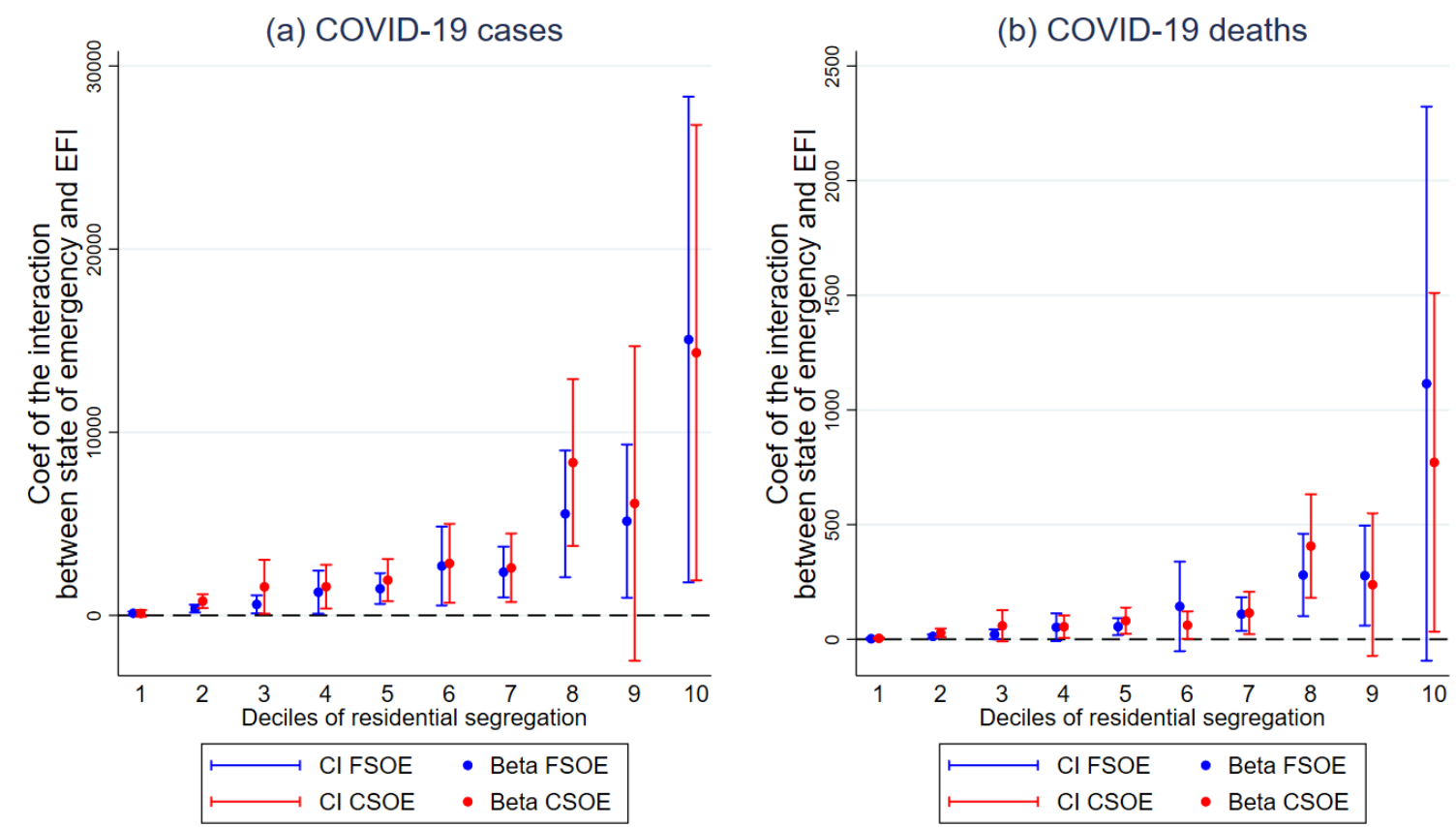

Note: Figure 8 summarizes the regression coefficients and $95 \%$ confidence intervals of the interaction term between the Federal State of Emergency Declaration and EFI when equation 1 is estimated (denoted by FSOE, shown in blue), and the regression coefficient of the interaction term between the county-level State of Emergency Declaration and EFI when equation 2 is estimated (denoted by CSOE, shown in red). Each regression is estimated separately for each decile of residential segregation. Panel (a) shows coefficients of equations 1 and 2 when estimated for the outcome of new daily COVID-19 cases. Panel (b) shows coefficients of equations 1 and 2 when estimated for the outcome of new daily COVID-19 deaths. All specifications include county-level characteristic controls (i.e. population density, percentage of males, average age, poverty, education, urban area, the percentage of immigrants, the percentage of adults with obesity, poor health, diabetes, and who smoke). Standard errors are clustered at the state level. 
Figure 9: Mobility and county-level emergency declaration by level of ethnic fragmentation
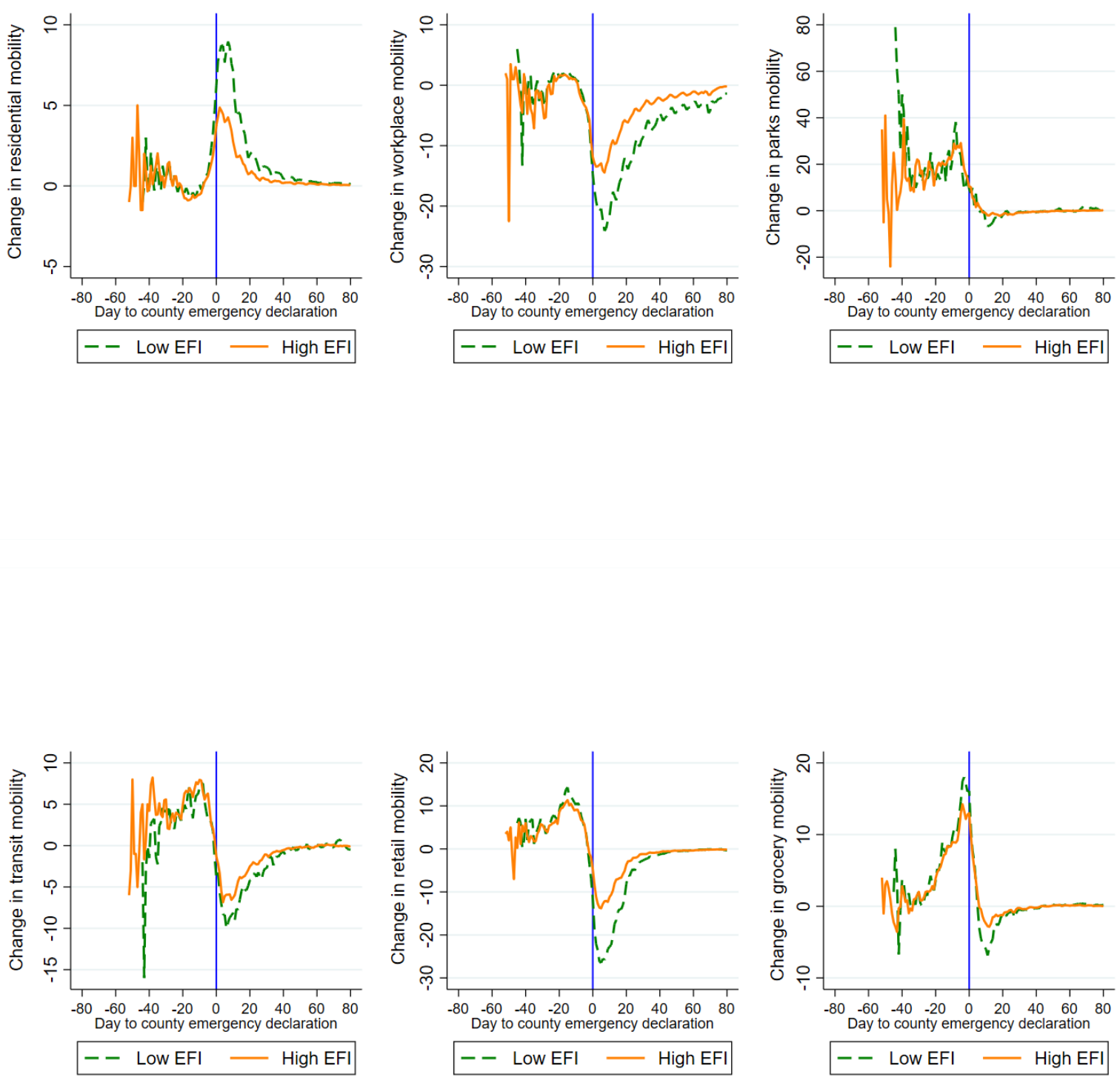

Note: Figure 9 plots the average change in each of six measures of mobility relative to the date of implementation of county-level State of Emergency declarations using data from Google Community Mobility Reports. Changes in mobility are changes relative to the median value of frequency of visit and duration of stay for the same day of the week in a pre-pandemic reference week (January 3, 2020 through February 6, 2020). From left to right, top to bottom, mobility data are presented for change in visits to residences, workplaces, parks and outdoor spaces, transit stations, retailers and recreational outlets, and groceries and pharmacies. In each panel of the figure, changes in mobility are shown separately for counties with above-median values of ethnic fragmentation (shown in orange) and below-median values of ethnic fragmentation (shown in green), where ethnic fragmentation is defined for each county as the value of the Herfindahl-Hirschman Index. In this figure, mobility measures are adjusted for the cumulative number of COVID-19 cases. 
Figure 10: Effect of EFI on social association rate by level of racial segregation

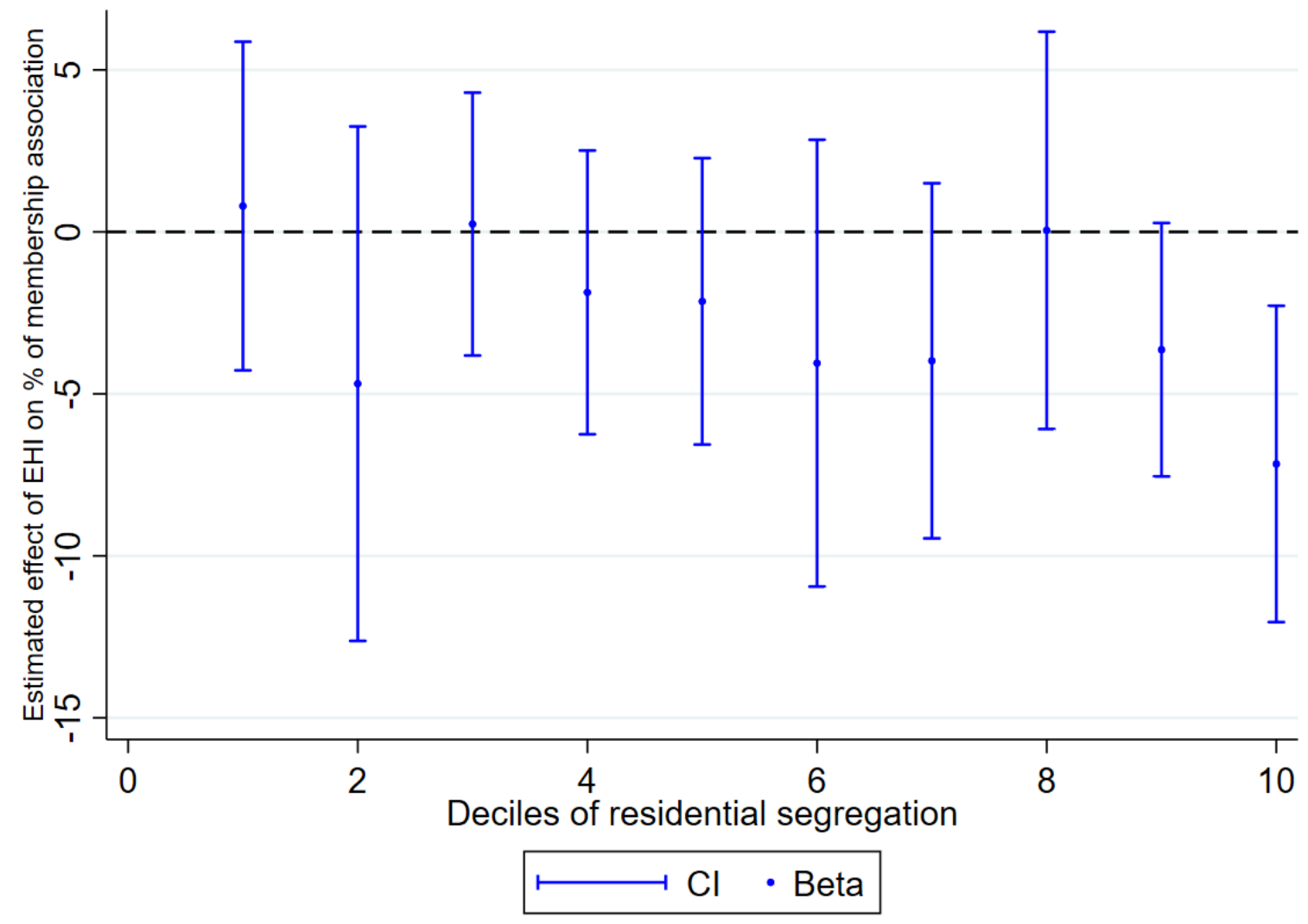

Note: Figure 10 reports of the coefficients of a regression of social association rate (measured as the number of membership associations per 10,000 individuals in a county) on EFI, estimated separately for each decile of Black-White residential segregation. Data on social association rates are obtained from 2017 County Health Rankings. 
Table 1: Descriptive Statistics of the Main Variables of Interest

\begin{tabular}{lccccc}
\hline & $\mathrm{N}$ & Mean & Std. de. & Min. & Max. \\
\hline Total cases* & 3,143 & 610.29 & 3307.51 & 0 & 82,427 \\
Total death* & 3,143 & 34.71 & 247.11 & 0 & 6,841 \\
Duration of the pandemic & 3,143 & 67.80 & 22.34 & 0 & 231 \\
Ethnic Fragmentation Index & 3,142 & 0.31 & 0.18 & 0 & 0.83 \\
Residential segregation index & 2,069 & 45.18 & 16.42 & 0 & 89 \\
County with SOE (in \%) & 3,143 & 0.28 & 0.45 & 0 & 1 \\
County with safer-at-home order (in \%) & 3,143 & 0.05 & 0.21 & 0 & 1 \\
County with business closure (in \%) & 3,143 & 0.01 & 0.09 & 0 & 1 \\
Residential** & 1,541 & 1.15 & 1.20 & -4 & 8.70 \\
Workplace** & 2,740 & -6.70 & 6.91 & -67 & 1.11 \\
Retail** & 2,528 & -4.15 & 10.77 & -66 & 47.64 \\
Grocery** & 2,438 & 2.95 & 6.63 & -50 & 70.05 \\
Transit** & 1,133 & -1.17 & 6.41 & -51 & 33.87 \\
Parks** & 984 & 0.96 & 14.12 & -63 & 193.00 \\
Population density & 3,117 & 431.96 & 2193.84 & 0 & 79761.45 \\
Percentage of male & 3,142 & 50.09 & 2.38 & 41 & 79.00 \\
Median age & 3,142 & 41.29 & 5.41 & 22 & 67.00 \\
Poverty rate & 3,141 & 15.60 & 6.48 & 2 & 55.10 \\
Educational attainment & 3,142 & 0.86 & 0.06 & 0 & 0.99 \\
Urban population (in \%) & 3,140 & 0.41 & 0.32 & 0 & 1.00 \\
Foreign-born (in \%) & 3,142 & 4.72 & 5.71 & 0 & 53.25 \\
Adults with fair or poor health (in \%) & 3,142 & 17.94 & 4.74 & 8 & 40.99 \\
Smokers (in \%) & 3,142 & 17.47 & 3.61 & 6 & 41.49 \\
Adults with obesity (in \%) & 3,142 & 32.86 & 5.45 & 12 & 57.70 \\
Adults with diabetes (in \%) & 3,142 & 12.12 & 4.06 & 2 & 34.10 \\
\hline
\end{tabular}

Note: Table 1 presents descriptive statistics on county-level characteristics and COVID-19 outcomes. Mobility data are not available from Google Community Reports for all counties as Google does not release data for which insufficient observations of mobility exist. Sociodemographic variables are calculated from the 2018 American Community Survey. COVID-19 outcomes are compiled from USAFacts. County-level policy variables are retrieved from the National Association of Counties. *Average of the cumulative number of COVID-19 cases and deaths as of June 07, 2020. **Mobility measures are adjusted for the cumulative number of COVID-19 cases. 
Table 2: Emergency declarations, ethnic fragmentation, and COVID-19 outcomes

$\begin{array}{lllll}(1) & (2) & (3) & (4) & (5)\end{array}$

\section{Government policy: National Emergency Declaration}

\begin{tabular}{|c|c|c|c|c|c|}
\hline \multicolumn{6}{|c|}{ Panel A: Covid-19 cases } \\
\hline Post national emergency & $\begin{array}{l}284.95^{* *} \\
(82.98)\end{array}$ & $\begin{array}{c}*-345.70 * * \\
(149.28)\end{array}$ & & & \\
\hline EFI & $\begin{array}{l}1280.17^{* *} \\
(483.40)\end{array}$ & $\begin{array}{c}0.34^{* *} \\
(0.15)\end{array}$ & $\begin{array}{c}930.48^{*} \\
(487.46)\end{array}$ & $\begin{array}{l}-599.67^{*} \\
(355.59)\end{array}$ & \\
\hline Post national emergency $\times$ EFI & & $\begin{array}{l}2030.08^{* *} \\
(766.65)\end{array}$ & $\begin{array}{l}2030.08^{* *} \\
(766.77)\end{array}$ & $\begin{array}{l}2056.31^{* *} \\
(775.65)\end{array}$ & $\begin{array}{l}2030.08^{* *} \\
(766.77)\end{array}$ \\
\hline Observations & 433,596 & 433,596 & 433,596 & 430,008 & 433,596 \\
\hline \multicolumn{6}{|c|}{ Panel B: Covid-19 deaths } \\
\hline Post national emergency & $\begin{array}{l}15.77^{\text {*** }} \\
(5.74)\end{array}$ & $\begin{array}{c}-21.15^{*} \\
(11.66)\end{array}$ & & & \\
\hline EFI & $\begin{array}{l}74.93^{* *} \\
(35.97)\end{array}$ & $\begin{array}{c}0.02 \\
(0.01)\end{array}$ & $\begin{array}{c}59.80 \\
(37.37)\end{array}$ & $\begin{array}{l}-50.44 \\
(32.43)\end{array}$ & \\
\hline Post national emergency $\times$ EFI & & $\begin{array}{l}118.84^{* *} \\
(57.05)\end{array}$ & $\begin{array}{l}118.84^{* *} \\
(57.06)\end{array}$ & $\begin{array}{l}120.38^{* *} \\
(57.73)\end{array}$ & $\begin{array}{l}118.84^{* *} \\
(57.06)\end{array}$ \\
\hline Observations & 433,596 & 433,596 & 433,596 & 430,008 & 433,596 \\
\hline
\end{tabular}

Government policy: County Emergency Declaration

Panel C: Covid-19 cases

Post county emergency

$532.70^{* * *}-617.52^{* * *}-1578.46 * * * 1656.03 * * * 1721.41^{* * *}$

EFI

$\begin{array}{lllll}(137.89) & (204.98) & (484.65) & (483.56) & (471.89)\end{array}$

$1931.77^{* * *} 1.32^{* * *} 1251.62^{* *}-160.24$

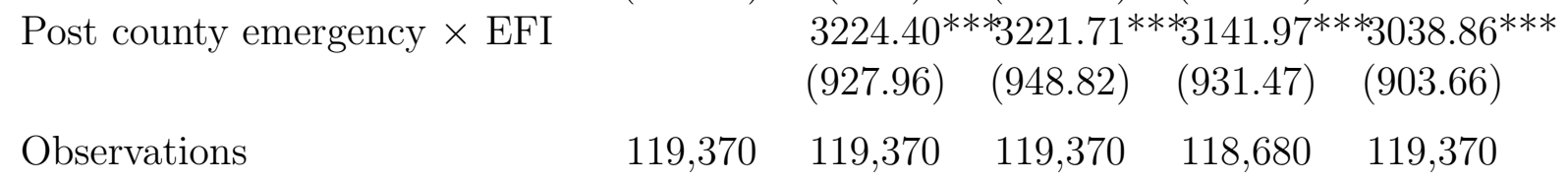

$(561.13) \quad(0.43) \quad(506.34) \quad(455.24)$

Panel D: Covid-19 deaths

Post county emergency

EFI

$\begin{array}{llll}87.31 * * * & 0.03^{*} & 64.61^{* *} & -10.43\end{array}$

Post county emergency $\times$ EFI

$(29.46) \quad(0.02) \quad(27.52) \quad(17.13)$

$145.78^{* * *} 145.82^{* * *} 140.60^{* * *} 137.41^{* * *}$

$\begin{array}{llll}(48.92) & (49.78) \quad(48.55) \quad(47.40)\end{array}$

\begin{tabular}{llllll} 
Observations & 119,370 & 119,370 & 119,370 & 118,680 & 119,370 \\
\hline
\end{tabular}

State FE

County FE

Day FE

Controls

Note: Each column of each panel reports coefficients from a separate regression. The dependent variable in each regression is denoted by the corresponding panel title. Controls include county-level demographic characteristics (i.e. population density, percentage of males, average age, poverty, education, urban area, the percentage of immigrants) and county-level health characteristics (i.e. the percentage of adults with obesity, in "poor health", with diabetes, and who smoke). Standard errors are clustered at the state level. ${ }^{* * *} \mathrm{p}<.001,{ }^{* *} \mathrm{p}<.01,{ }^{*} \mathrm{p}<.05$. 
Table 3: Other mobility restriction policies, ethnic fragmentation, and COVID-19 outcomes

\begin{tabular}{|c|c|c|c|c|c|}
\hline & $(1)$ & $(2)$ & $(3)$ & $(4)$ & $(5)$ \\
\hline \multicolumn{6}{|c|}{$\begin{array}{c}\text { Government policy: National Stringency Index } \\
\text { Panel A: Covid-19 cases }\end{array}$} \\
\hline Stringency index & $\begin{array}{l}4.45^{* * *} \\
(1.31)\end{array}$ & $\begin{array}{l}-5.42^{* *} \\
(2.37)\end{array}$ & & & \\
\hline EFI & $\begin{array}{l}1215.94^{* *} \\
(465.17)\end{array}$ & $\begin{array}{l}-265.48^{* *} \\
(101.62)\end{array}$ & $\begin{array}{c}621.13 \\
(391.52)\end{array}$ & $\begin{array}{l}-843.71^{*} \\
(422.95)\end{array}$ & \\
\hline Stringency index $\times$ EFI & & $\begin{array}{l}31.75^{* *} \\
(12.15)\end{array}$ & $\begin{array}{l}31.75^{* *} \\
(12.15)\end{array}$ & $\begin{array}{l}32.16^{* *} \\
(12.29)\end{array}$ & $\begin{array}{l}31.75^{* *} \\
(12.15)\end{array}$ \\
\hline Observations & 424,170 & 424,170 & 424,170 & 420,660 & 424,170 \\
\hline \multicolumn{6}{|c|}{ Panel B: Covid-19 deaths } \\
\hline Stringency index & $\begin{array}{l}0.25^{* * *} \\
(0.09)\end{array}$ & $\begin{array}{l}-0.33^{*} \\
(0.18)\end{array}$ & & & \\
\hline EFI & $\begin{array}{l}71.04^{* *} \\
(34.40)\end{array}$ & $\begin{array}{l}-15.54^{* *} \\
(7.54)\end{array}$ & $\begin{array}{c}41.24 \\
(29.45)\end{array}$ & $\begin{array}{l}-64.16^{*} \\
(38.27)\end{array}$ & \\
\hline Stringency index $\times$ EFI & & $\begin{array}{l}1.86^{* *} \\
(0.90)\end{array}$ & $\begin{array}{l}1.86^{* *} \\
(0.90)\end{array}$ & $\begin{array}{l}1.88^{* *} \\
(0.91)\end{array}$ & $\begin{array}{l}1.86^{* *} \\
(0.90)\end{array}$ \\
\hline Observations & 424,170 & 424,170 & 424,170 & 420,660 & 424,170 \\
\hline \multicolumn{6}{|c|}{$\begin{array}{c}\text { Government policy: County Safer-at-Home } \\
\text { Panel C:Covid-19 cases }\end{array}$} \\
\hline Post county safer-at-home order & $\begin{array}{l}884.94^{* * *} \\
(175.10)\end{array}$ & $\begin{array}{l}-802.24^{* *} \\
(288.03)\end{array}$ & $\begin{array}{l}-1945.57^{* * *} \\
(516.71)\end{array}$ & $\begin{array}{c}\text { *-2030.43*** } \\
(525.24)\end{array}$ & $\begin{array}{c}\text { *2090.13*** } \\
(523.77)\end{array}$ \\
\hline EFI & $\begin{array}{l}1954.60^{* * *} \\
(384.10)\end{array}$ & $\begin{array}{l}8.50^{* * *} \\
(2.44)\end{array}$ & $\begin{array}{c}57.18 \\
(324.01)\end{array}$ & $\begin{array}{l}-1173.57 \\
(925.62)\end{array}$ & \\
\hline Post county safer-at-home order $\times$ EFI & & $\begin{array}{l}3584.40^{* * *} \\
(669.13)\end{array}$ & $\begin{aligned} * & 3648.38^{* * *} \\
& (744.42)\end{aligned}$ & $\begin{array}{l}3537.06^{\text {*** }} \\
(673.34)\end{array}$ & $\begin{array}{l}3559.64^{* * * *} \\
(689.96)\end{array}$ \\
\hline Observations & 20,424 & 20,424 & 20,424 & 20,424 & 20,424 \\
\hline \multicolumn{6}{|c|}{ Panel D: Covid-19 deaths } \\
\hline Post county safer-at-home order & $\begin{array}{l}31.66^{* * *} \\
(7.87)\end{array}$ & $\begin{array}{l}-27.77^{* *} \\
(12.94)\end{array}$ & $\begin{array}{l}-73.47^{* * *} \\
(23.82)\end{array}$ & $\begin{array}{l}-76.30^{* * *} \\
(24.22)\end{array}$ & $\begin{array}{l}-78.25^{* * *} \\
(24.42)\end{array}$ \\
\hline EFI & $\begin{array}{l}68.73^{* * *} \\
(19.66)\end{array}$ & $\begin{array}{l}0.18^{* * *} \\
(0.06)\end{array}$ & $\begin{array}{c}3.18 \\
(15.10)\end{array}$ & $\begin{array}{l}-32.03 \\
(35.68)\end{array}$ & \\
\hline Post county safer-at-home order $\times$ EFI & & $\begin{array}{l}126.26^{* * *} \\
(34.74)\end{array}$ & $\begin{array}{l}128.35^{* * *} \\
(37.94)\end{array}$ & $\begin{array}{l}124.18^{\text {*** }} \\
(35.05)\end{array}$ & $\begin{array}{l}124.64^{* * *} \\
(35.48)\end{array}$ \\
\hline Observations & 20,424 & 20,424 & 20,424 & 20,424 & 20,424 \\
\hline \multicolumn{6}{|c|}{$\begin{array}{c}\text { Government policy: County Business Closure } \\
\text { Panel E: Covid-19 cases }\end{array}$} \\
\hline Post county business closure & $\begin{array}{l}1737.71 \\
(951.12)\end{array}$ & $\begin{array}{l}-1816.66^{* *} \\
(633.00)\end{array}$ & $\begin{array}{l}-4228.16^{* *} \\
(1344.15)\end{array}$ & $\begin{array}{l}-4412.56^{* *} \\
(1496.10)\end{array}$ & $\begin{array}{l}-4391.32^{* *} \\
(1495.40)\end{array}$ \\
\hline EFI & $\begin{array}{l}4808.93^{* * *} \\
(1406.67)\end{array}$ & $\begin{array}{l}14.25^{* *} \\
(5.75)\end{array}$ & $\begin{array}{l}-3941.06 \\
(2579.40)\end{array}$ & $\begin{array}{l}-5188.04^{* *} \\
(1644.88)\end{array}$ & \\
\hline Post county business closure $\times$ EFI & & $\begin{array}{l}8735.92^{\text {*** }} \\
(2513.79)\end{array}$ & $\begin{array}{c}* 8878.28^{* * * *} \\
(2615.63)\end{array}$ & $\begin{array}{l}\text { * } 8758.48^{* * *} \\
(2609.22)\end{array}$ & $\begin{array}{l}\text { * } 8747.93^{* * * *} \\
(2605.72)\end{array}$ \\
\hline Observations & 3,726 & 3,726 & 3,726 & 3,726 & 3,726 \\
\hline \multicolumn{6}{|c|}{ Panel F: Covid-19 deaths } \\
\hline Post county business closure & $\begin{array}{r}76.88^{*} \\
(41.38)\end{array}$ & $\begin{array}{l}-87.83^{* *} \\
(35.16)\end{array}$ & $\begin{array}{l}-196.40^{* *} \\
(66.82)\end{array}$ & $\begin{array}{l}-197.85^{* *} \\
(69.32)\end{array}$ & $\begin{array}{l}-197.27^{* *} \\
(69.30)\end{array}$ \\
\hline EFI & $\begin{array}{l}222.37^{* *} \\
(74.96)\end{array}$ & $\begin{array}{c}0.19^{*} \\
(0.09)\end{array}$ & $\begin{array}{l}-146.74 \\
(109.66)\end{array}$ & $\begin{array}{l}-159.45^{*} \\
(78.70)\end{array}$ & \\
\hline Post county business closure $\times$ EFI & & $\begin{array}{l}404.82^{* *} \\
(134.34)\end{array}$ & $\begin{array}{l}413.10^{* *} \\
(138.92)\end{array}$ & $\begin{array}{c}408.08^{* *} \\
(138.80)\end{array}$ & $\begin{array}{l}407.76^{* *} \\
(138.62)\end{array}$ \\
\hline Observations & 3,726 & 3,726 & 3,726 & 3,726 & 3,726 \\
\hline State FE & & & $\checkmark$ & $\checkmark$ & \\
\hline County FE & & & & & $\checkmark$ \\
\hline Day FE & & & $\checkmark$ & $\checkmark$ & $\checkmark$ \\
\hline Controls & & & & $\checkmark$ & \\
\hline
\end{tabular}


Table 4: Emergency declarations, racial segregation, and COVID-19 outcomes

(1) (2) (3) $\quad(4)$

\section{Government policy: National Emergency Declaration}

\section{Panel A: Covid-19 cases}

Post national emergency

$428.31^{* * *}-444.00$

(123.98) (269.17)

Black/White Segr. index

$12.17^{* *} \quad 0.00^{* *}$

$(5.24)$

$(0.00)$

$19.31^{* *}$

$-2.87^{*} \quad-8.60^{* *}$

Post national emergency $\times$ Black/White Segr. index

$(8.31) \quad(8.31) \quad(8.35)$

(1.68)

$(3.79)$

$19.31^{* *}$

(8.31) (8.35) (8.31)

Observations

$285,522 \quad 285,522 \quad 285,522 \quad 283,590 \quad 285,522$

\section{Panel B: Covid-19 deaths}

Post national emergency

$23.76^{* * *}-34.08$

$(8.61) \quad(21.21)$

Black/White Segr. index

$0.81^{* *} \quad 0.00$

$(0.40) \quad(0.00)$

$-0.21^{* *}-0.64^{* *}$

$(0.10) \quad(0.29)$

Post national emergency $\times$ Black/White Segr. index

$1.28^{* *} \quad 1.28^{* *} \quad 1.29^{*}$

$\begin{array}{llll}(0.64) \quad(0.64) \quad(0.64) & (0.64)\end{array}$

Observations

$285,522 \quad 285,522 \quad 285,522 \quad 283,590 \quad 285,522$

\section{Government policy: County Emergency Declaration}

\section{Panel C: Covid-19 cases}

Post county emergency

\begin{tabular}{ccccc}
$684.82^{* * *}-799.55$ & \multicolumn{4}{l}{$-1751.72^{* *}-1987.84^{* *}-2061.25^{* *}$} \\
$(172.93)$ & $(516.33)$ & $(748.16)$ & $(789.18)$ & $(768.43)$ \\
$18.82^{* *}$ & 0.00 & -2.18 & -9.61 & \\
$(8.38)$ & $(0.00)$ & $(4.22)$ & $(5.77)$ & \\
& $31.74^{* *}$ & $31.52^{* *}$ & $31.41^{* *}$ & $29.72^{* *}$ \\
& $(14.08)$ & $(13.91)$ & $(13.94)$ & $(13.36)$ \\
92,184 & 92,184 & 92,184 & 91.908 & 92,184
\end{tabular}

Observations

$$
92,184 \quad 92,184 \quad 92,184 \quad 91,908 \quad 92,184
$$

\section{Panel D: Covid-19 deaths}

Post county emergency

$31.87^{* * *}-44.67$

$(8.88) \quad(27.07)$

$-89.73^{* *}-101.73^{* *}-104.00^{* *}$

Black/White Segr. index

$\begin{array}{llll}0.97^{* *} & -0.00 & -0.23 & -0.69^{* *}\end{array}$

$(0.44)$

$(0.00)$

$(0.20)$

$(0.32)$

Post county emergency $\times$ Black/White Segr. index

$\begin{array}{llll}1.64^{* *} & 1.62^{* *} & 1.60^{* *} & 1.53^{* *} \\ (0.73) & (0.72) & (0.72) & (0.70)\end{array}$

\begin{tabular}{|c|c|c|c|c|}
\hline Observations & 92,184 & 92,184 & 91,908 & 92,184 \\
\hline State FE & & $\checkmark$ & $\checkmark$ & \\
\hline County FE & & & & $\checkmark$ \\
\hline Day FE & & $\checkmark$ & $\checkmark$ & $\checkmark$ \\
\hline Controls & & & $\checkmark$ & \\
\hline
\end{tabular}

Note: Each column of each panel reports coefficients from a separate regression. The dependent variable in each regression is denoted by the corresponding panel title. Controls include county-level demographic characteristics (i.e. population density, percentage of males, average age, poverty, education, urban area, the percentage of immigrants) and county-level health characteristics (i.e. the percentage of adults with obesity, in "poor health", with diabetes, and who smoke). Standard errors are clustered at the state level. ${ }^{* * *} \mathrm{p}<.001,{ }^{* *} \mathrm{p}<.01,{ }^{*} \mathrm{p}<.05$. 
Table 5: Other mobility restriction policies, racial segregation, and COVID-19 outcomes

\begin{tabular}{|c|c|c|c|c|c|}
\hline & (1) & $(2)$ & $(3)$ & (4) & $(5)$ \\
\hline \multicolumn{6}{|c|}{$\begin{array}{c}\text { Government policy: National Stringency Index } \\
\text { Panel A: Covid-19 cases }\end{array}$} \\
\hline Stringency index & $\begin{array}{l}6.68^{* * *} \\
(1.96)\end{array}$ & $\begin{array}{l}-7.04 \\
(4.27)\end{array}$ & & & \\
\hline Black/White Segr. index & $\begin{array}{l}11.63^{* *} \\
(5.05)\end{array}$ & $\begin{array}{l}-2.54^{* *} \\
(1.10)\end{array}$ & $\begin{array}{l}-5.30^{* *} \\
(2.56)\end{array}$ & $\begin{array}{l}-10.79^{* *} \\
(4.70)\end{array}$ & \\
\hline Stringency index $\times$ Black/White Segr. index & & $\begin{array}{l}0.30^{* *} \\
(0.13)\end{array}$ & $\begin{array}{l}0.30^{* *} \\
(0.13)\end{array}$ & $\begin{array}{l}0.30^{* *} \\
(0.13)\end{array}$ & $\begin{array}{l}0.30^{* *} \\
(0.13)\end{array}$ \\
\hline Observations & 279,315 & 279,315 & 279,315 & 277,425 & 279,315 \\
\hline \multicolumn{6}{|c|}{ Panel B: Covid-19 deaths } \\
\hline Stringency index & $\begin{array}{l}0.37^{* * *} \\
(0.14)\end{array}$ & $\begin{array}{l}-0.53 \\
(0.33)\end{array}$ & & & \\
\hline Black/White Segr. index & $\begin{array}{c}0.77^{*} \\
(0.38)\end{array}$ & $\begin{array}{l}-0.17^{*} \\
(0.08)\end{array}$ & $\begin{array}{l}-0.37^{* *} \\
(0.17)\end{array}$ & $\begin{array}{l}-0.78^{* *} \\
(0.36)\end{array}$ & \\
\hline Stringency index $\times$ Black/White Segr. index & & $\begin{array}{c}0.02^{*} \\
(0.01)\end{array}$ & $\begin{array}{c}0.02^{*} \\
(0.01)\end{array}$ & $\begin{array}{c}0.02^{*} \\
(0.01)\end{array}$ & $\begin{array}{c}0.02^{*} \\
(0.01)\end{array}$ \\
\hline Observations & 279,315 & 279,315 & 279,315 & 277,425 & 279,315 \\
\hline \multicolumn{6}{|c|}{$\begin{array}{c}\text { Government policy: County Safer-at-Home } \\
\text { Panel C: Covid-19 cases }\end{array}$} \\
\hline Post county safer-at-home order & $\begin{array}{l}968.12^{* * *} \\
(186.76)\end{array}$ & $\begin{array}{l}-1327.60^{*} \\
(627.89)\end{array}$ & $\begin{array}{l}-2504.13^{* *} \\
(844.14)\end{array}$ & $\begin{array}{l}-2665.81^{* * *} \\
(859.22)\end{array}$ & $\begin{array}{l}*-2661.59^{* * *} \\
(808.44)\end{array}$ \\
\hline Black/White Segr. index & $\begin{array}{l}27.75^{* * *} \\
(9.28)\end{array}$ & $\begin{array}{c}0.12 \\
(0.07)\end{array}$ & $\begin{array}{l}-0.66 \\
(2.48)\end{array}$ & $\begin{array}{l}-19.57^{* *} \\
(7.38)\end{array}$ & \\
\hline Post county safer-at-home order $\times$ Black/White Segr. index & & $\begin{array}{l}51.13^{* * *} \\
(16.80)\end{array}$ & $\begin{array}{l}51.44^{* * *} \\
(17.13)\end{array}$ & $\begin{array}{l}51.33^{* *} \\
(17.50)\end{array}$ & $\begin{array}{l}50.51^{* *} \\
(17.20)\end{array}$ \\
\hline Observations & 18,630 & 18,630 & 18,630 & 18,630 & 18,630 \\
\hline \multicolumn{6}{|c|}{ Panel D: Covid-19 deaths } \\
\hline Post county safer-at-home order & $\begin{array}{l}34.74^{* * *} \\
(8.67)\end{array}$ & $\begin{array}{l}-52.20^{* *} \\
(22.42)\end{array}$ & $\begin{array}{l}-99.63^{* * *} \\
(32.55)\end{array}$ & $\begin{array}{l}-105.39^{* * *} \\
(34.34)\end{array}$ & $\begin{array}{l}-104.23^{* * *} \\
(32.21)\end{array}$ \\
\hline Black/White Segr. index & $\begin{array}{l}1.05^{* * *} \\
(0.34)\end{array}$ & $\begin{array}{l}-0.00 \\
(0.00)\end{array}$ & $\begin{array}{l}-0.10 \\
(0.12)\end{array}$ & $\begin{array}{l}-0.82^{* *} \\
(0.28)\end{array}$ & \\
\hline Post county safer-at-home order $\times$ Black/White Segr. index & & $\begin{array}{l}1.94^{* * *} \\
(0.62)\end{array}$ & $\begin{array}{l}1.95^{* * *} \\
(0.64)\end{array}$ & $\begin{array}{l}1.94^{* *} \\
(0.65)\end{array}$ & $\begin{array}{l}1.89^{* * *} \\
(0.63)\end{array}$ \\
\hline Observations & 18,630 & 18,630 & 18,630 & 18,630 & 18,630 \\
\hline \multicolumn{6}{|c|}{$\begin{array}{c}\text { Government policy: County Business Closure } \\
\text { Panel E: Covid-19 cases }\end{array}$} \\
\hline Post county business closure & $\begin{array}{r}2449.57^{*} \\
(1096.51)\end{array}$ & $\begin{array}{l}-2666.46 \\
(2370.83)\end{array}$ & $\begin{array}{l}-5974.72 \\
(3379.89)\end{array}$ & $\begin{array}{l}-5984.31 \\
(3441.74)\end{array}$ & $\begin{array}{l}-5984.31 \\
(3434.79)\end{array}$ \\
\hline Black/White Segr. index & $\begin{array}{c}54.76 \\
(33.04)\end{array}$ & $\begin{array}{l}0.08 \\
(0.07)\end{array}$ & $\begin{array}{l}-18.58 \\
(59.86)\end{array}$ & $\begin{array}{l}-15.73 \\
(35.40)\end{array}$ & \\
\hline Post county business closure $\times$ Black/White Segr. index & & $\begin{array}{c}99.83 \\
(59.71)\end{array}$ & $\begin{array}{c}98.63 \\
(62.66)\end{array}$ & $\begin{array}{c}98.32 \\
(61.75)\end{array}$ & $\begin{array}{c}98.32 \\
(61.62)\end{array}$ \\
\hline Observations & 2,622 & 2,622 & 2,622 & 2,622 & 2,622 \\
\hline \multicolumn{6}{|c|}{ Panel F: Covid-19 deaths } \\
\hline Post county business closure & $\begin{array}{l}108.76^{*} \\
(47.58)\end{array}$ & $\begin{array}{c}-112.61 \\
(106.37)\end{array}$ & $\begin{array}{l}-253.58 \\
(144.96)\end{array}$ & $\begin{array}{l}-249.97 \\
(145.38)\end{array}$ & $\begin{array}{l}-249.97 \\
(145.08)\end{array}$ \\
\hline Black/White Segr. index & $\begin{array}{c}2.37 \\
(1.46)\end{array}$ & $\begin{array}{c}0.00 \\
(0.00)\end{array}$ & $\begin{array}{l}-2.02 \\
(2.43)\end{array}$ & $\begin{array}{l}-1.85 \\
(1.57)\end{array}$ & \\
\hline Post county business closure $\times$ Black/White Segr. index & & $\begin{array}{c}4.32 \\
(2.64)\end{array}$ & $\begin{array}{c}4.25 \\
(2.78)\end{array}$ & $\begin{array}{c}4.28 \\
(2.76)\end{array}$ & $\begin{array}{c}4.28 \\
(2.75)\end{array}$ \\
\hline Observations & 2,622 & 2,622 & 2,622 & 2,622 & 2,622 \\
\hline State FE & & & $\checkmark$ & $\checkmark$ & \\
\hline County FE & & & & & $\checkmark$ \\
\hline Day FE & & & $\checkmark$ & $\checkmark$ & $\checkmark$ \\
\hline Controls & & & & $\checkmark$ & \\
\hline
\end{tabular}


Table 6: Emergency declarations, ethnic fragmentation, and COVID-19 by level of racial segregation

Low res. seg. High res. seg. Low res. seg. High res. seg. (1)

\section{Government policy: National Emergency Declaration}

\section{Panel A: Covid-19 cases}

Post national emergency

$\begin{array}{ll}167.65^{* * *} & 702.13^{* * *} \\ (30.36) & (217.46) \\ 459.11^{* * *} & 3649.95^{* *} \\ (116.56) & (1370.23)\end{array}$

Post national emergency $\times$ EFI

$(116.56)$

$(1370.23)$

\section{EFI}

Observations

146,280

139,242

$$
\begin{aligned}
& 727.80^{* * *} \\
& (184.74)
\end{aligned}
$$

146,280
(2174.24)

139,242

\section{Panel B: Covid-19 deaths}

Post national emergency

$\begin{array}{ll}6.95^{* * *} & 41.42^{* *} \\ (1.62) & (15.67) \\ 17.05^{* * *} & 228.38^{* *} \\ (4.87) & (108.00)\end{array}$

Post national emergency $\times$ EFI

$27.01^{* * *}$

(7.71)

$362.21^{* *}$

Observations

146,280

139,242

146,280

(171.40)

139,242

Government policy: County Emergency Declaration

Panel C: Covid-19 cases

Post county emergency

$\begin{array}{ll}294.79^{* * *} & 1030.25^{* * *} \\ (55.55) & (287.40) \\ 873.46^{* * *} & 4112.05^{* * *} \\ (227.45) & (1261.37)\end{array}$

$-871.28 * * *$

$-3359.14^{* * *}$

(273.38)

(936.63)

EFI

Post county emergency $\times$ EFI

$\begin{array}{ll}1373.90^{* * *} & 6515.25^{* * *} \\ (350.79) & (2054.52)\end{array}$

Observations

44,298

47,886

44,298

47,886

\section{Panel D: Covid-19 deaths}

Post county emergency

$11.57^{* * *}$

$50.00^{* * *}$

(2.30)

(14.73)

$-33.16^{* * *}$

(10.13)

$-161.34^{* * *}$

$33.51^{* * *}$

$192.63^{* * *}$

(49.72)

EFI

(9.06)

(67.71)

Post county emergency $\times$ EFI

$53.33^{* * *}$

(14.27)

$304.91^{* * *}$

(109.98)

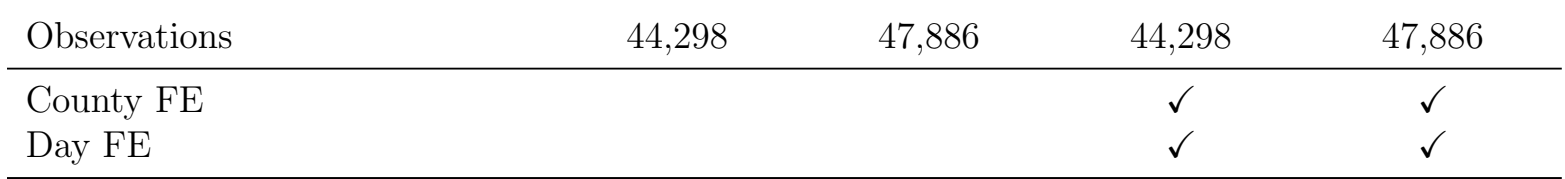

Note: Each column of each panel reports coefficients from a separate regression. "High res. seg." and "Low res. seg." refer to regressions limited to counties with above- and below-median values of racial residential segregation, respectively. The dependent variable in each regression is denoted by the corresponding panel title. Controls include county-level demographic characteristics (i.e. population density, percentage of males, average age, poverty, education, urban area, the percentage of immigrants) and county-level health characteristics (i.e. the percentage of adults with obesity, in "poor health", with diabetes, and who smoke). Standard errors are clustered at the state level. ${ }^{* * *} \mathrm{p}<.001,{ }^{* *} \mathrm{p}<.01,{ }^{*} \mathrm{p}<.05$. 
Table 7: Other mobility restriction policies, ethnic fragmentation, and COVID-19 by level of racial segregation

Low res. seg. High res. seg. Low res. seg. High res. seg. (1)

(2)

(3)

(4)

\section{Government policy: National Stringency Index}

Panel A: Covid-19 cases

Stringency index

$\begin{array}{lc}2.59^{* * *} & 10.98^{* * *} \\ (0.47) & (3.45) \\ 429.12^{* * *} & 3477.16^{* *} \\ (109.34) & (1322.56)\end{array}$

EFI

Stringency index $\times$ EFI

Observations

143,100

136,215

$11.20^{* * *}$

$(2.85)$

143,100

$(34.55)$

Panel B: Covid-19 deaths

Stringency index

EFI

Stringency index $\times$ EFI

$\begin{array}{ll}0.11^{* * *} & 0.65^{* *} \\ (0.03) & (0.25) \\ 15.97^{* * *} & 216.85^{* *} \\ (4.57) & (103.50)\end{array}$

Observations

143,100

136,215

$0.42^{* * *}$

$(0.12)$

$5.66^{* *}$

143,100

(2.71)

136,215

\section{Government policy: County Safer-at-Home}

Panel C: Covid-19 cases

Post county safer-at-home order

$\begin{array}{ll}421.28^{* * *} & 1679.26^{* * *} \\ (49.51) & (294.95) \\ 746.47^{* * *} & 3681.56^{* * *} \\ (180.65) & (585.24)\end{array}$

$-806.02 * * *$

$-3826.41^{* * *}$

EFI

$746.47^{*}$

$(585.24)$

Post county safer-at-home order $\times$ EFI

$10,764 \quad 7,866$

(215.05)

(695.74)

$1343.75^{* * *}$

$6892.65^{* * *}$

(325.25)

(1105.17)

Observations

D: Covid-19 deaths

Post county safer-at-home order

Panel D: Covid

$\begin{array}{ll}15.12^{* * *} & 60.31^{* * *} \\ (2.94) & (12.76) \\ 23.56^{* * *} & 130.86^{* * *} \\ (7.55) & (29.46)\end{array}$

10,764

7,866

EFI

Post county safer-at-home order $\times$ EFI

10,764

7,866

$-26.75^{* * *}$

$-145.82^{* * *}$

(33.25)

$42.40^{* * *}$

$243.84^{* * *}$

(13.81)

(54.59)

Observations

10,764

7,866

Government policy: County Business Closure

Panel E: Covid-19 cases

Post county business closure

747.15

(827.18)

$3470.71^{* *}$

(1164.69)

3908.78

$6507.50^{* *}$

(4590.53)

(1810.98)

Post county business closure $\times$ EFI

$966 \quad 1,656$

$-4494.71$

(6085.53)

$-5683.93^{* *}$

(2048.81)

Observations

6629.39

(9094.36)

$11640.66^{* *}$

966

(3559.88)

Panel F: Covid-19 deaths

Post county business closure

29.84

(27.64)

EFI

123.74

$156.24^{* *}$

(53.05)

(157.48)

$313.59^{* *}$

$-149.35$

(208.75)

$-259.26^{* *}$

(102.90)

Post county business closure $\times$ EFI

(104.82)

$211.30 \quad 565.05^{* *}$

(313.99) (201.32)

Observations

966

1,656

966

1,656

\begin{tabular}{lcc} 
County FE & $\checkmark$ & $\checkmark$ \\
Day FE & $\checkmark$ & $\checkmark$ \\
\hline
\end{tabular}

Note: Each column of each panel reports coefficients from a separate regression. "High res. seg." and "Low res. seg." refer to regressions limited to counties with above- and below-median values of racial residential segregation, respectively. The dependent variable in each regression is denoted by the corresponding panel title. Controls include county-level demographic characteristics (i.e. population density, percentage of males, average age, poverty, education, urban area, the percentage of immigrants) and county-level health characteristics (i.e. the percentage of adults with obesity, in "poor health", with diabetes, and who smoke). Standard errors are clustered at the state level. ${ }^{* * *} \mathrm{p}<.001,{ }^{* *} \mathrm{p}<.01,{ }^{*} \mathrm{p}<.05$. 
Table 8: Federal state of emergency, ethnic fragmentation, and Google mobility measures

\begin{tabular}{|c|c|c|c|c|c|}
\hline & (1) & $(2)$ & $(3)$ & (4) & $(5)$ \\
\hline \multicolumn{6}{|c|}{ Panel A: Retail } \\
\hline Post national emergency & $\begin{array}{l}-15.80^{* * *} \\
(0.57)\end{array}$ & $\begin{array}{l}*-22.03^{* * *} \\
(0.90)\end{array}$ & & & \\
\hline EFI & $\begin{array}{l}9.53^{* * *} \\
(1.50)\end{array}$ & $\begin{array}{l}-3.15^{* *} \\
(1.40)\end{array}$ & $\begin{array}{l}-3.74^{* * *} \\
(1.34)\end{array}$ & $\begin{array}{l}-7.13^{* * *} \\
(1.92)\end{array}$ & \\
\hline Post national emergency $\times$ EFI & & $\begin{array}{l}18.85^{* * *} \\
(2.45)\end{array}$ & $\begin{array}{l}16.17^{* * *} \\
(1.99)\end{array}$ & $\begin{array}{l}16.35^{* * *} \\
(2.06)\end{array}$ & $\begin{array}{l}17.72^{* * *} \\
(2.10)\end{array}$ \\
\hline Observations & 194,738 & 194,738 & 194,738 & 194,522 & 194,722 \\
\hline \multicolumn{6}{|c|}{ Panel B: Grocery } \\
\hline Post national emergency & $\begin{array}{l}-3.65^{* * *} \\
(0.31)\end{array}$ & $\begin{array}{l}-4.04^{* * *} \\
(0.37)\end{array}$ & & & \\
\hline EFI & $\begin{array}{l}-1.83^{*} \\
(1.02)\end{array}$ & $\begin{array}{l}-2.57^{* *} \\
(1.24)\end{array}$ & $\begin{array}{l}-2.36^{*} \\
(1.22)\end{array}$ & $\begin{array}{c}0.23 \\
(1.18)\end{array}$ & \\
\hline Post national emergency $\times$ EFI & & $\begin{array}{c}1.13 \\
(1.31)\end{array}$ & $\begin{array}{l}1.90 \\
(1.34)\end{array}$ & $\begin{array}{c}1.95 \\
(1.36)\end{array}$ & $\begin{array}{c}1.95 \\
(1.52)\end{array}$ \\
\hline Observations & 184,737 & 184,737 & 184,737 & 184,560 & 184,718 \\
\hline \multicolumn{6}{|c|}{ Panel C: Parks } \\
\hline Post national emergency & $\begin{array}{l}-19.63^{* * *} \\
(1.37)\end{array}$ & $\begin{array}{l}{ }^{*}-20.26^{* * *} \\
(2.05)\end{array}$ & & & \\
\hline EFI & $\begin{array}{l}-1.26 \\
(2.07)\end{array}$ & $\begin{array}{l}-2.35 \\
(4.74)\end{array}$ & $\begin{array}{c}4.01 \\
(4.35)\end{array}$ & $\begin{array}{l}-1.48 \\
(4.24)\end{array}$ & \\
\hline Post national emergency $\times$ EFI & & $\begin{array}{c}1.49 \\
(4.06)\end{array}$ & $\begin{array}{c}1.73 \\
(4.00)\end{array}$ & $\begin{array}{c}1.65 \\
(4.04)\end{array}$ & $\begin{array}{c}0.40 \\
(4.11)\end{array}$ \\
\hline Observations & 65,129 & 65,129 & 65,129 & 65,129 & 65,066 \\
\hline \multicolumn{6}{|c|}{ Panel D: Transit } \\
\hline Post national emergency & $\begin{array}{l}-7.82^{* * *} \\
(0.58)\end{array}$ & $\begin{array}{l}-9.35^{* * *} \\
(0.74)\end{array}$ & & & \\
\hline EFI & $\begin{array}{c}1.64 \\
(1.17)\end{array}$ & $\begin{array}{l}-1.30 \\
(2.17)\end{array}$ & $\begin{array}{l}-0.20 \\
(2.81)\end{array}$ & $\begin{array}{l}-1.81 \\
(2.32)\end{array}$ & \\
\hline Post national emergency $\times$ EFI & & $\begin{array}{l}3.91^{* *} \\
(1.80)\end{array}$ & $\begin{array}{l}4.05^{* *} \\
(1.79)\end{array}$ & $\begin{array}{l}4.07^{* *} \\
(1.78)\end{array}$ & $\begin{array}{l}4.07^{* *} \\
(1.75)\end{array}$ \\
\hline Observations & 102,118 & 102,118 & 102,118 & 102,118 & 102,102 \\
\hline \multicolumn{6}{|c|}{ Panel E: Workplace } \\
\hline Post national emergency & $\begin{array}{l}-8.54^{* * *} \\
(0.58)\end{array}$ & $\begin{array}{l}-13.95^{* * *} \\
(0.81)\end{array}$ & & & \\
\hline EFI & $\begin{array}{l}9.56^{* * *} \\
(1.31)\end{array}$ & $\begin{array}{l}-3.09^{* * *} \\
(0.69)\end{array}$ & $\begin{array}{l}-1.27 \\
(1.57)\end{array}$ & $\begin{array}{l}-7.92^{* * *} \\
(1.73)\end{array}$ & \\
\hline Post national emergency $\times$ EFI & & $\begin{array}{l}16.88^{* * *} \\
(1.98)\end{array}$ & $\begin{array}{l}16.70^{* * *} \\
(1.96)\end{array}$ & $\begin{array}{l}16.68^{* * *} \\
(1.95)\end{array}$ & $\begin{array}{l}16.29^{* * * *} \\
(1.94)\end{array}$ \\
\hline Observations & 261,011 & 261,011 & 261,011 & 260,671 & 261,000 \\
\hline \multicolumn{6}{|c|}{ Panel F: Residential } \\
\hline Post national emergency & $\begin{array}{l}1.87^{* * *} \\
(0.13)\end{array}$ & $\begin{array}{l}3.06^{* * *} \\
(0.19)\end{array}$ & & & \\
\hline EFI & $\begin{array}{l}-2.75^{* * *} \\
(0.30)\end{array}$ & $\begin{array}{l}-0.40^{*} \\
(0.21)\end{array}$ & $\begin{array}{l}-0.49 \\
(0.33)\end{array}$ & $\begin{array}{c}0.75^{* *} \\
(0.31)\end{array}$ & \\
\hline Post national emergency $\times$ EFI & & $\begin{array}{l}-3.32^{\text {*** }} \\
(0.48)\end{array}$ & $\begin{array}{l}-3.36^{* * *} \\
(0.51)\end{array}$ & $\begin{array}{l}-3.41^{* * *} \\
(0.50)\end{array}$ & $\begin{array}{l}-3.38^{* * * *} \\
(0.50)\end{array}$ \\
\hline Observations & 120,706 & 120,706 & 120,706 & 120,668 & 120,699 \\
\hline State FE & & & $\checkmark$ & $\checkmark$ & \\
\hline $\begin{array}{l}\text { County FE } \\
\text { Day FE }\end{array}$ & & & $\checkmark$ & $\checkmark$ & $\checkmark$ \\
\hline Controls & & & & $\checkmark$ & \\
\hline
\end{tabular}

Note: In this table, mobility measures are adjusted for the cumulative number of COVID-19 cases. Each column of each panel reports coefficients from a separate regression. The dependent variable in each regression is denoted of each panel reports coefficients from a separate regression. The dependent variable in each regression is denoted
by the corresponding panel title. Controls include county-level demographic characteristics (i.e. population density, by the corresponding panel title. Controls include county-level demographic characteristics (i.e. population density, percentage of males, average age, poverty, education, urban area, the percentage of immigrants) and county-level
health characteristics (i.e. the percentage of adults with obesity, in "poor health", with diabetes, and who smoke). Standard errors are clustered at the state level. ${ }^{* * *} \mathrm{p}<.001,{ }^{* *} \mathrm{p}<.01,{ }^{*} \mathrm{p}<.05$. 
Table 9: County state of emergency, ethnic fragmentation, and Google mobility measures

\begin{tabular}{|c|c|c|c|c|c|}
\hline & (1) & (2) & (3) & (4) & (5) \\
\hline \multicolumn{6}{|c|}{ Panel A: Retail } \\
\hline Post county emergency & $\begin{array}{l}-11.57^{* *} \\
(0.70)\end{array}$ & $\begin{array}{l}* * 18.11^{* *} \\
(1.36)\end{array}$ & $\begin{array}{l}* *-8.52^{* * *} \\
(1.31)\end{array}$ & $\begin{array}{l}*-8.95^{* * *} \\
(1.36)\end{array}$ & $\begin{array}{l}* *-10.24^{* * *} \\
(1.34)\end{array}$ \\
\hline EFI & $\begin{array}{l}8.50^{* * *} \\
(1.10)\end{array}$ & $\begin{array}{c}*-2.73^{*} \\
(1.57)\end{array}$ & $\begin{array}{l}-2.25 \\
(1.78)\end{array}$ & $\begin{array}{l}-6.41^{* *} \\
(2.63)\end{array}$ & \\
\hline Post county emergency $\times$ EFI & & $\begin{array}{l}17.42^{* *} \\
(2.81)\end{array}$ & $\begin{array}{l}* * 15.59^{* *} \\
(2.27)\end{array}$ & $\begin{array}{l}* * 15.95^{* *} \\
(2.35)\end{array}$ & $\begin{array}{l}* * 17.52^{* * *} \\
(2.40)\end{array}$ \\
\hline Observations & 67,239 & 67,239 & 67,239 & 67,025 & 67,235 \\
\hline \multicolumn{6}{|c|}{ Panel B: Grocery } \\
\hline Post county emergency & $\begin{array}{l}-7.09^{* * *} \\
(0.38)\end{array}$ & $\begin{array}{l}*-8.87 * * \\
(0.50)\end{array}$ & $\begin{array}{l}*-6.49^{* * *} \\
(0.94)\end{array}$ & $\begin{array}{l}*-6.44^{* * *} \\
(0.90)\end{array}$ & $\begin{array}{l}\text { ** }-6.81^{* * * *} \\
(0.85)\end{array}$ \\
\hline EFI & $\begin{array}{l}-0.07 \\
(0.93)\end{array}$ & $\begin{array}{l}-3.05^{*} \\
(1.81)\end{array}$ & $\begin{array}{l}-3.26^{* *} \\
(1.45)\end{array}$ & $\begin{array}{l}-0.84 \\
(1.50)\end{array}$ & \\
\hline Post county emergency $\times$ EFI & & $\begin{array}{l}4.68^{* * *} \\
(1.70)\end{array}$ & $\begin{array}{c}3.28^{* *} \\
(1.57)\end{array}$ & $\begin{array}{l}3.47^{* *} \\
(1.57)\end{array}$ & $\begin{array}{l}4.03^{* *} \\
(1.76)\end{array}$ \\
\hline Observations & 65,056 & 65,056 & 65,056 & 64,880 & 65,053 \\
\hline \multicolumn{6}{|c|}{ Panel C: Parks } \\
\hline Post county emergency & $\begin{array}{l}-19.60^{* *} \\
(1.59)\end{array}$ & $\begin{array}{l}* * 23.09^{* *} \\
(3.36)\end{array}$ & $\begin{array}{l}\text { ** } 11.08^{* *} \\
(3.87)\end{array}$ & $\begin{array}{l}* * 11.17^{* *} \\
(3.88)\end{array}$ & $\begin{array}{l}* * 11.18^{* * * *} \\
(3.93)\end{array}$ \\
\hline EFI & $\begin{array}{l}-1.34 \\
(3.05)\end{array}$ & $\begin{array}{l}-6.83 \\
(6.47)\end{array}$ & $\begin{array}{l}-0.66 \\
(6.20)\end{array}$ & $\begin{array}{l}-5.60 \\
(5.76)\end{array}$ & \\
\hline Post county emergency $\times$ EFI & & $\begin{array}{c}7.76 \\
(5.43)\end{array}$ & $\begin{array}{c}6.96 \\
(5.62)\end{array}$ & $\begin{array}{l}7.17 \\
(5.66)\end{array}$ & $\begin{array}{l}7.32 \\
(5.64)\end{array}$ \\
\hline Observations & 34,310 & 34,310 & 34,310 & 34,310 & 34,295 \\
\hline \multicolumn{6}{|c|}{ Panel D: Transit } \\
\hline Post county emergency & $\begin{array}{l}-6.55^{* *}= \\
(0.49)\end{array}$ & $\begin{array}{l}*-8.49^{* * *} \\
(1.75)\end{array}$ & $\begin{array}{l}*-8.19^{* * *} \\
(2.10)\end{array}$ & $\begin{array}{l}*-8.13^{* * *}+ \\
(2.04)\end{array}$ & $\begin{array}{l}k *-8.30^{* * *} \\
(1.95)\end{array}$ \\
\hline EFI & $\begin{array}{l}2.34 \\
(1.74)\end{array}$ & $\begin{array}{l}-0.91 \\
(3.99)\end{array}$ & $\begin{array}{l}-1.24 \\
(4.20)\end{array}$ & $\begin{array}{l}-3.89 \\
(3.85)\end{array}$ & \\
\hline Post county emergency $\times$ EFI & & $\begin{array}{c}4.53 \\
(3.38)\end{array}$ & $\begin{array}{c}4.90 \\
(3.49)\end{array}$ & $\begin{array}{c}4.83 \\
(3.47)\end{array}$ & $\begin{array}{c}5.01 \\
(3.39)\end{array}$ \\
\hline Observations & 42,907 & 42,907 & 42,907 & 42,907 & 42,899 \\
\hline \multicolumn{6}{|c|}{ Panel E: Workplace } \\
\hline Post county emergency & $\begin{array}{l}-5.08^{* *} \\
(0.77)\end{array}$ & $\begin{array}{c}*-11.17^{* *} \\
(1.27)\end{array}$ & $\begin{array}{l}* *-6.05^{* * *} \\
(1.01)\end{array}$ & $\begin{array}{l}*-6.53^{* * *} \\
(1.03)\end{array}$ & $\begin{array}{c}\text { * }-6.63^{* * *} \\
(1.06)\end{array}$ \\
\hline EFI & $\begin{array}{l}9.87^{* * *} \\
(1.54)\end{array}$ & $\begin{array}{l}{ }^{*}-1.94^{* *} \\
(0.96)\end{array}$ & $\begin{array}{l}-0.87 \\
(1.84)\end{array}$ & $\begin{array}{l}-10.31^{* *} \\
(2.40)\end{array}$ & \\
\hline Post county emergency $\times$ EFI & & $\begin{array}{l}16.66^{* *} \\
(2.46)\end{array}$ & $\begin{array}{l}* 16.76^{* *} \\
(2.18)\end{array}$ & $\begin{array}{l}\text { * } 16.55^{* *} \\
(2.13)\end{array}$ & $\begin{array}{c}* * 16.04^{* * *} \\
(2.07)\end{array}$ \\
\hline Observations & 80,004 & 80,004 & 80,004 & 79,739 & 80,002 \\
\hline \multicolumn{6}{|c|}{ Panel F: Residential } \\
\hline Post county emergency & $\begin{array}{l}0.89^{* * *} \\
(0.13)\end{array}$ & $\begin{array}{l}* 1.92^{* * *} \\
(0.28)\end{array}$ & $\begin{array}{l}* 0.85^{* *} \\
(0.32)\end{array}$ & $\begin{array}{l}0.96^{\text {*** }} \\
(0.32)\end{array}$ & $\begin{array}{c}* 1.01^{* * * *} \\
(0.33)\end{array}$ \\
\hline EFI & $\begin{array}{l}-2.65^{* *} \\
(0.31)\end{array}$ & $\begin{array}{l}{ }^{*}-0.89^{* * *} \\
(0.28)\end{array}$ & $\begin{array}{l}{ }^{*}-1.14^{* * *} \\
(0.28)\end{array}$ & $* 0.44$ & \\
\hline Post county emergency $\times$ EFI & & $\begin{array}{l}-2.56^{* * *} \\
(0.57)\end{array}$ & $\begin{array}{l}*-2.94^{* * *} \\
(0.36)\end{array}$ & $\begin{array}{l}*-2.97^{* * *} \\
(0.37)\end{array}$ & $\begin{array}{c}k *-2.92 * * * \\
(0.38)\end{array}$ \\
\hline Observations & 49,424 & 49,424 & 49,424 & 49,386 & 49,423 \\
\hline State FE & & & $\checkmark$ & $\checkmark$ & \\
\hline & & & & & $\checkmark$ \\
\hline Day FE & & & $\checkmark$ & $\checkmark$ & $\checkmark$ \\
\hline Controls & & & & $\checkmark$ & \\
\hline
\end{tabular}


Table 10: Federal state of emergency, ethnic fragmentation, and Google mobility measures by level of racial segregation

\begin{tabular}{|c|c|c|c|c|}
\hline & $\begin{array}{l}\text { Low res. seg. } \\
\text { (1) }\end{array}$ & $\begin{array}{l}\text { High res. seg. } \\
\text { (2) }\end{array}$ & $\begin{array}{l}\text { Low res. seg. } \\
\text { (3) }\end{array}$ & $\begin{array}{l}\text { High res. seg. } \\
\text { (4) }\end{array}$ \\
\hline \multicolumn{5}{|c|}{ Panel A: Retail } \\
\hline Post national emergency & $\begin{array}{l}-13.99^{* * *} \\
(0.46)\end{array}$ & $\begin{array}{l}-13.88^{* * *} \\
(0.55)\end{array}$ & & \\
\hline EFI & $\begin{array}{l}4.68^{* * *} \\
(0.91)\end{array}$ & $\begin{array}{l}6.52^{* * *} \\
(1.13)\end{array}$ & & \\
\hline Post national emergency $\times$ EFI & & & $\begin{array}{l}9.97^{* * *} \\
(2.06)\end{array}$ & $\begin{array}{l}15.84^{* * *} \\
(2.11)\end{array}$ \\
\hline Observations & 74,860 & 89,403 & 74,858 & 89,399 \\
\hline \multicolumn{5}{|c|}{ Panel B: Grocery } \\
\hline Post national emergency & $\begin{array}{l}-2.77^{* * *} \\
(0.49)\end{array}$ & $\begin{array}{l}-4.22 \text { *** } \\
(0.26)\end{array}$ & & \\
\hline EFI & $\begin{array}{l}-3.50^{* * *} \\
(1.21)\end{array}$ & $\begin{array}{l}-1.22 \\
(1.10)\end{array}$ & & \\
\hline Post national emergency $\times$ EFI & & & $\begin{array}{c}2.81 \\
(2.26)\end{array}$ & $\begin{array}{l}-0.51 \\
(1.10)\end{array}$ \\
\hline Observations & 73,769 & 85,946 & 73,766 & 85,946 \\
\hline \multicolumn{5}{|c|}{ Panel C: Parks } \\
\hline Post national emergency & $\begin{array}{l}-18.09^{* * *} \\
(1.72)\end{array}$ & $\begin{array}{l}-20.35^{* * *} \\
(1.37)\end{array}$ & & \\
\hline EFI & $\begin{array}{l}-7.66^{* *} \\
(3.00)\end{array}$ & $\begin{array}{l}-1.35 \\
(2.32)\end{array}$ & & \\
\hline Post national emergency $\times$ EFI & & & $\begin{array}{l}10.67 \\
(7.29)\end{array}$ & $\begin{array}{l}-3.02 \\
(5.04)\end{array}$ \\
\hline Observations & 23,655 & 38,904 & 23,636 & 38,869 \\
\hline \multicolumn{5}{|c|}{ Panel D: Transit } \\
\hline Post national emergency & $\begin{array}{l}-8.46^{* * *} \\
(0.55)\end{array}$ & $\begin{array}{l}-6.73^{* * *} \\
(0.44)\end{array}$ & & \\
\hline EFI & $\begin{array}{c}0.13 \\
(1.59)\end{array}$ & $\begin{array}{c}1.35 \\
(1.12)\end{array}$ & & \\
\hline Post national emergency $\times$ EFI & & & $\begin{array}{l}1.84 \\
(2.29)\end{array}$ & $\begin{array}{l}7.90^{* * * *} \\
(2.15)\end{array}$ \\
\hline Observations & 40,647 & 52,345 & 40,641 & 52,339 \\
\hline \multicolumn{5}{|c|}{ Panel E: Workplace } \\
\hline Post national emergency & $\begin{array}{l}-6.39^{* * *} \\
(0.49)\end{array}$ & $\begin{array}{l}-6.50^{* * *} \\
(0.50)\end{array}$ & & \\
\hline EFI & $\begin{array}{l}4.70^{* * *} \\
(1.31)\end{array}$ & $\begin{array}{l}6.65^{* * *} \\
(1.38)\end{array}$ & & \\
\hline Post national emergency $\times$ EFI & & & $\begin{array}{l}11.31^{* * *} \\
(1.97)\end{array}$ & $\begin{array}{l}12.82^{* * *} \\
(2.12)\end{array}$ \\
\hline Observations & 97,974 & 102,171 & 97,970 & 102,171 \\
\hline \multicolumn{5}{|c|}{ Panel F: Residential } \\
\hline Post national emergency & $\begin{array}{l}1.74^{* * *} \\
(0.14)\end{array}$ & $\begin{array}{l}1.80^{* * *} \\
(0.14)\end{array}$ & & \\
\hline EFI & $\begin{array}{l}-1.83^{* * *} \\
(0.33)\end{array}$ & $\begin{array}{l}-3.04^{* * * *} \\
(0.29)\end{array}$ & & \\
\hline Post national emergency $\times$ EFI & & & $\begin{array}{l}-2.37^{* * *} \\
(0.62)\end{array}$ & $\begin{array}{l}-3.79^{* * *} \\
(0.44)\end{array}$ \\
\hline Observations & 46,486 & 67,882 & 46,484 & 67,880 \\
\hline $\begin{array}{l}\text { County FE } \\
\text { Day FE }\end{array}$ & & & $\begin{array}{l}\checkmark \\
\checkmark\end{array}$ & $\begin{array}{l}\checkmark \\
\checkmark\end{array}$ \\
\hline
\end{tabular}

Note: In this table, mobility measures are adjusted for the cumulative number of COVID-19 cases. Each column of each panel reports coefficients from a separate regression. "High res. seg." and "Low res. seg." refer to regressions limited to counties with aboveand below-median values of racial residential segregation, respectively. The dependent variable in each regression is denoted by the corresponding panel title. Controls include county-level demographic characteristics (i.e. population density, percentage of males, average age, poverty, education, urban area, the percentage of immigrants) and county-level health characteristics (i.e. the percentage of adults with obesity, in "poor health", with diabetes, and who smoke). Standard errors are clustered at the state level. *** $<.001$, ** $\mathrm{p}<.01, * \mathrm{p}<.05$. 
Table 11: County state of emergency, ethnic fragmentation, and Google mobility measures by level of racial segregation

Low res. seg. High res. seg. Low res. seg. High res. seg.

(1)

\section{Panel A: Retail}

Post county emergency

EFI

Post county emergency $\times$ EFI

Observations

Post county emergency

EFI

Post county emergency $\times$ EFI

Observations

Post county emergency

EFI

Post county emergency $\times$ EFI

Observations

Post county emergency

EFI

Post county emergency $\times$ EFI

Observations

Post county emergency

EFI

Post county emergency $\times$ EFI

Observations

Post county emergency

EFI

Post county emergency $\times$ EFI

Observations

$-10.45^{* * *}$

$(0.76)$

$-10.20^{* * *}$

$5.54^{* * *}$

$(0.67)$

$(1.43)$

$5.47^{* * *}$

(1.00)

27,693

33,057

(3)

(4)

Panel B: Grocery

$\begin{array}{ll}-6.41^{* * *} & -7.12^{* * *} \\ (0.51) & (0.53) \\ -2.19^{*} & -0.17 \\ (1.27) & (1.00)\end{array}$

(1.27)

(1.00)

27,096

32,240

$-8.44^{* * *}$

$-8.05^{* * *}$

(1.74)

(1.49)

$10.98^{* * *} \quad 16.13^{* * *}$

(2.69)

(3.08)

27,693

33,054

\section{Panel C: Parks}

$\begin{array}{ll}-18.44^{* * *} & -20.19^{* *} \\ (1.62) & (1.73) \\ -5.63 & -1.20 \\ (4.10) & (3.07)\end{array}$

(4.10)

(3.07)

$\begin{array}{ll}-6.07^{* * *} & -7.20^{* * *} \\ (1.18) & (0.97)\end{array}$

4.49** $\quad 2.65$

(2.18) (2.34)

$27,096 \quad 32,240$

$-15.31^{* * *} \quad-10.40^{* *}$

(5.29) (4.20)

14.93* $\quad 4.30$

(7.73) (6.74)

$\begin{array}{llll}12,794 & 20,671 & 12,787 & 20,663\end{array}$

Panel D: Transit

$-7.29 * * *$

$-5.60 * * *$

$(0.44)$

$(0.55)$

$-9.66^{* * *}$

$-8.21 * * *$

$-1.80$

$2.56^{*}$

$(1.95)$

(1.45)

$(2.40)$

(2.48)

$8.54^{* *} \quad 7.74^{*}$

(4.05) (3.98)

16,704

23,682

16,701

23,678

Panel E: Workplace

$\begin{array}{llll}-3.08^{* * *} & -3.68^{* * *} & -5.90^{* * *} & -3.75^{* * *} \\ (0.77) & (0.55) & (1.22) & (1.29) \\ 6.43^{* * *} & 6.95^{* * *} & & \\ (1.62) & (1.59) & (.) & (.) \\ & & 12.27^{* * *} & 12.06^{* * *} \\ & & (1.94) & (2.37) \\ 31,852 & 35,709 & 31,852 & 35,709\end{array}$

Panel F: Residential

\begin{tabular}{llll}
$0.73^{* * *}$ & $0.86^{* * *}$ & $0.95^{*}$ & $0.77^{* *}$ \\
$(0.17)$ & $(0.12)$ & $(0.47)$ & $(0.34)$ \\
$-1.93^{* * *}$ & $-2.85^{* * *}$ & & \\
$(0.46)$ & $(0.27)$ & & \\
& & $-1.98^{* * *}$ & $-3.14^{* * *}$ \\
& & $(0.60)$ & $(0.38)$ \\
20,397 & 27,636 & 20,396 & 27,636 \\
\hline & $\checkmark$ & $\checkmark$ \\
& & $\checkmark$ & $\checkmark$ \\
\hline
\end{tabular}

Day FE

Note: Each column of each panel reports coefficients from a separate regression. "High res. seg." and "Low res. seg." refer to regressions limited to counties with above- and below-median values of racial residential segregation, respectively. The dependent variable in each regression is denoted by the corresponding panel title. Controls include county-level demographic characteristics (i.e. population density, percentage of males, average age, poverty, education, urban area, the percentage of immigrants) and countylevel health characteristics (i.e. the percentage of adults with obesity, in "poor health", with diabetes, and who smoke). Standard errors are clustered at the state level. ${ }^{* * *} \mathrm{p}<.001,{ }^{* *} \mathrm{p}<.01,{ }^{*} \mathrm{p}<.05$. 
Table 12: Mask wearing, ethnic fragmentation, and racial segregation

\begin{tabular}{|c|c|c|c|c|c|}
\hline & $(1)$ & $(2)$ & $(3)$ & $(4)$ & $(5)$ \\
\hline \multicolumn{6}{|c|}{ Panel A: Share of people who say that they frequently wear a mask } \\
\hline \multicolumn{6}{|c|}{ 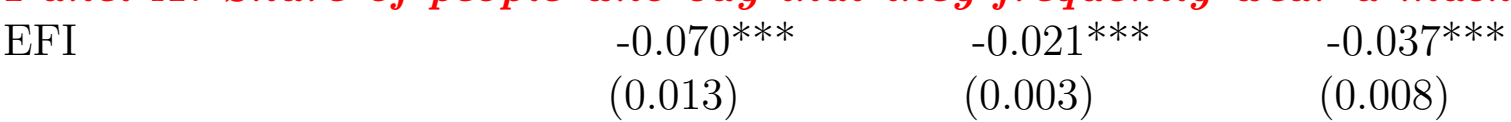 } \\
\hline Black/White Segr. index & & $\begin{array}{l}-0.009 * * \\
(0.004)\end{array}$ & $\begin{array}{l}-0.012^{* *} \\
(0.004)\end{array}$ & & \\
\hline White/non-white Segr. index & & & & $\begin{array}{l}-0.037^{*>} \\
(0.009)\end{array}$ & $\begin{array}{l}*-0.029^{* * *} \\
(0.008)\end{array}$ \\
\hline Observations & 2,983 & 2,063 & 2,063 & 2,745 & 2,745 \\
\hline \multicolumn{6}{|c|}{ Panel B: Share of people who say that they always wear a mask } \\
\hline EFI & $\begin{array}{l}-0.151^{* * *} \\
(0.022)\end{array}$ & & $\begin{array}{l}-0.045^{* *} * \\
(0.007)\end{array}$ & & $\begin{array}{l}-0.082^{* * *} \\
(0.015)\end{array}$ \\
\hline Black/White Segr. index & & $\begin{array}{l}-0.024^{* *} \\
(0.010)\end{array}$ & $\begin{array}{l}-0.031^{* *>} \\
(0.010)\end{array}$ & & \\
\hline White/non-white Segr. index & & & & $\begin{array}{l}-0.088^{*>} \\
(0.021)\end{array}$ & $\begin{array}{c}*_{-} 0.070 * * * \\
(0.020)\end{array}$ \\
\hline Observations & 2,983 & 2,063 & 2,063 & 2,745 & 2,745 \\
\hline State FE & $\checkmark$ & $\checkmark$ & $\checkmark$ & $\checkmark$ & $\checkmark$ \\
\hline
\end{tabular}

Note: In all specifications, the measure of mask wearing is adjusted for the cumulative number of COVID-19 cases reported in June 7, 2020 (the date on which the self-reported mask wearing data was collected). Each column of each panel reports coefficients from a separate regression. The dependent variable in each regression is denoted by the corresponding panel title. Controls include county-level demographic characteristics (i.e. population density, percentage of males, average age, poverty, education, urban area, the percentage of immigrants) and county-level health characteristics (i.e. the percentage of adults with obesity, in "poor health", with diabetes, and who smoke). Standard errors are clustered at the state level. ${ }^{* * *} \mathrm{p}<.001,{ }^{* *} \mathrm{p}<.01,{ }^{*} \mathrm{p}<.05$. 


\section{Appendix}

Table A1: Emergency declarations, racial segregation (white vs non-white), and COVID-19 outcomes

$\begin{array}{llll}(1) & (2) & (3) & (4)\end{array}$

\section{Government policy: National Emergency Declaration}

Panel A: Covid-19 cases

Post national emergency

White/non-white Segr. index

Post national emergency $\times$ White/non-white Segr. index

Observations

Post national emergency

White/non-white Segr. index

Post national emergency $\times$ White/non-white Segr. index

Observations

\section{Panel B: Covid-19 deaths}

(92.21) (160.70)

$\begin{array}{lllll}14.00^{* * *} & 0.00^{* *} & -3.39 & -9.86^{* *} & \\ (4.97) & (0.00) & (2.06) & (3.80) & \\ & 22.21^{* * *} & 22.21^{* * *} & 22.37^{* * *} & 22.21^{* * *} \\ & (7.89) & (7.89) & (7.93) & (7.89) \\ 385,158 & 385,158 & 385,158 & 382,674 & 385,158\end{array}$

\section{Government policy: County Emergency Declaration}

Panel C: Covid-19 cases

Post county emergency

White/non-white Segr. index

Post county emergency $\times$ White/non-white Segr. index

Observations

White/non-white Segr. index

Post county emergency $\times$ White/non-white Segr. index

Observations

State FE

County FE

Day FE

Controls

$\begin{array}{ccccc}570.58^{* * *}-516.15^{*} & -1327.73^{* *}-1514.63^{* * *} 1612.33^{* * *} \\ (146.72) & (291.95) & (493.17) & (521.83) & (513.43) \\ 20.17^{* *} & 0.01^{*} & -3.81 & -10.91^{*} & \\ (7.73) & (0.00) & (4.53) & (5.77) & \\ & 34.12^{* *} & 33.77^{* *} & 32.74^{* *} & 31.79^{* *} \\ & (13.00) & (12.78) & (12.56) & (12.25) \\ 112,056 & 112,056 & 112,056 & 111,642 & 112,056\end{array}$

\section{Panel D: Covid-19 deaths}

Note: Each column is from a separate regression. Ethnic divisions is measured by the level of residential segregation between Whites and non-Whites. Controls include county-level characteristics (i.e. population density, percentage of males, average age, poverty, education, urban area, the percentage of immigrants) and county-level health characteristics (i.e. the percentage of adults with obesity, "poor health", diabetes, and who smoke). 
Table A2: Other mobility restriction policies, racial segregation (white vs non-white), and COVID-19 outcomes

$\begin{array}{lllll}(1) & (2) & (3) & (4) & (5)\end{array}$

Government policy: National Stringency Index

Stringency index

Panel A: Covid-19 cases

White/non-white Segr. index

$\begin{array}{lllll}5.00^{* * *} & -5.73^{* *} & & & \\ (1.46) & (2.55) & & & \\ 13.34^{* * *} & -2.92^{* * *} & -6.19^{* *} & -12.38^{* *} & \\ (4.79) & (1.05) & (2.94) & (4.70) & \\ & 0.35^{* * *} & 0.35^{* * *} & 0.35^{* * *} & 0.35^{* * *} \\ & (0.13) & (0.13) & (0.13) & (0.13) \\ 376,785 & 376,785 & 376,785 & 374,355 & 376,785\end{array}$

Stringency index $\times$ White/non-white Segr. index

376,785

Panel B: Covid-19 deaths

Stringency index

$\begin{array}{cllll}0.28^{* * *} & -0.40^{* *} & & & \\ (0.10) & (0.19) & & & \\ 0.84^{* *} & -0.18^{* *} & -0.43^{* *} & -0.89^{* *} & \\ (0.35) & (0.08) & (0.20) & (0.38) & \\ & 0.02^{* *} & 0.02^{* *} & 0.02^{* *} & 0.02^{* *} \\ & (0.01) & (0.01) & (0.01) & (0.01) \\ 376,785 & 376,785 & 376,785 & 374,355 & 376,785\end{array}$

Government policy: County Safer-at-Home

White/non-white Segr. index

Stringency index $\times$ White/non-white Segr. index

Observations

\section{Panel C: Covid-19 cases}

Post county safer-at-home order

\begin{tabular}{ccccc}
$903.44^{* * *}-1612.70^{* * *}$ & \multicolumn{4}{l}{$-2742.16^{* * *}-2814.77^{* * *}-2851.03^{* * *}$} \\
$(185.20)$ & $(598.39)$ & $(745.58)$ & $(745.56)$ & $(723.47)$ \\
$43.74^{* * *}$ & $0.25^{* *}$ & 3.06 & $-27.59^{* *}$ & \\
$(12.49)$ & $(0.11)$ & $(5.49)$ & $(10.75)$ & \\
& $80.47^{* * *}$ & $80.51^{* * *}$ & $79.31^{* * *}$ & $79.24^{* * *}$ \\
& $(22.64)$ & $(22.61)$ & $(22.91)$ & $(23.12)$ \\
20,286 & 20,286 & 20,286 & 20,286 & 20,286
\end{tabular}

White/non-white Segr. index

Post county safer-at-home order $\times$ White/non-white Segr. index

Observations

Panel D: Covid-19 deaths

Post county safer-at-home order

$\begin{array}{lllll}32.32^{* * *} & -56.46^{* *} & -101.72^{* * *} & -104.08^{* * *} & -104.64^{* * *} \\ (8.31) & (21.63) & (28.32) & (28.53) & (28.09) \\ 1.54^{* * *} & 0.00^{*} & 0.16 & -0.94^{* *} & \\ (0.46) & (0.00) & (0.28) & (0.42) & \\ & 2.84^{* * *} & 2.84^{* * *} & 2.79^{* * *} & 2.77^{* * *} \\ & (0.84) & (0.84) & (0.85) & (0.85) \\ & & & 20.286 & 20.286\end{array}$

White/non-white Segr. index

Post county safer-at-home order $\times$ White/non-white Segr. index

$20,286 \quad 20,286$

20,286

20,286

20,286

Observations

Government policy: County Business Closure

Post county business closure

Panel E: Covid-19 cases

White/non-white Segr. index

$1886.69^{*}-1492.62$

$\begin{array}{lllll}1855.18) & (1675.41) & (2161.08) & (2303.53) & (2300.31)\end{array}$

$\begin{array}{lcccc}52.00 & (1675.41) & (2161.08) & (2303.53) & (2300.31)\end{array}$

$\begin{array}{llll}52.00 & 0.11 & -34.25 & -58.80\end{array}$

Post county business closure $\times$ White/non-white Segr. index
$\begin{array}{llll}(33.81) & (0.07) \quad(19.62) & (33.16)\end{array}$
$\begin{array}{llll}96.80 & 95.25 & 92.83 & 92.80\end{array}$

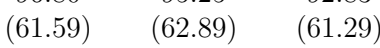

$(61.18)$

Observations

3,450

3,450

3,450

3,450

3,450

Panel F: Covid-19 deaths

Post county business closure

$\begin{array}{lllll}83.51^{*} & -68.62 & -181.93^{*} & -179.27 & -177.97\end{array}$

White/non-white Segr. index

(41.49)

$(76.48)$

(98.77)

(98.26)

(98.33)

Post county business closure $\times$ White/non-white Segr. index

$(1.54) \quad(0.00) \quad(1.04) \quad(1.52)$

$0.00 \quad-1.64 \quad-2.58$

$\begin{array}{lll}4.36 & 4.29 & 4.20\end{array}$

Observations

3,450

3,450

3,450

3,450

(2.81)

\begin{tabular}{|c|c|c|c|c|}
\hline Observations & 3,450 & 3,450 & 3,450 & 3,450 \\
\hline State FE & & $\checkmark$ & $\checkmark$ & \\
\hline County FE & & & & $\checkmark$ \\
\hline Day FE & & $\checkmark$ & $\checkmark$ & $\checkmark$ \\
\hline Controls & & & $\checkmark$ & \\
\hline
\end{tabular}

Note: Each column is from a separate regression. Ethnic divisions is measured by the level of racial residential segregation between white and non-white. High and low res. seg. refer to counties with above- and below-median values of the racial residential segregation index, respectively. Controls include county-level characteristics (i.e. population density, percentage of males, average age, poverty, education, urban area, the percentage of immigrants) and county-level health characteristics (i.e. the percentage of adults with obesity, "poor health", diabetes, and who smoke). 
Table A3: Emergency declarations, ethnic fragmentation, and COVID-19 by level of racial segregation (white vs non-white)

Low res. seg. High res. seg. Low res. seg. High res. seg.

(1)

(2)

(3)

(4)

\section{Government policy: National Emergency declaration}

Panel A: Covid-19 cases

Post national emergency

$73.72^{* * *}$

$574.70^{* * *}$

(10.07)

(177.44)

EFI

$208.63^{* * *}$

$2646.75^{* *}$

(50.81)

(991.55)

Post national emergency $\times$ EFI

$330.85^{* * *}$

(80.59)

4197.18**

Observations

195,408

189,750

195,408

(1573.13)

189,750

Panel B: Covid-19 deaths

Post national emergency

$2.77^{* * *}$

$33.16^{* *}$

$(0.39)$

$(12.43)$

EFI

$7.07^{* * *}$

$160.74 * *$

(1.76)

$(75.84)$

Post national emergency $\times$ EFI

$11.22^{* * *}$

$254.91^{* *}$

$(2.80)$

(120.33)

Observations

195,408

189,750

195,408

189,750

\section{Government policy: County Emergency declaration}

Panel C: Covid-19 cases

Post county emergency

$163.79^{* * *}$

936.31***

(24.66)

(261.40)

$-388.36^{* * *}$

$-3090.41^{* * *}$

EFI

$475.64^{* * *}$

$3365.93^{* * *}$

(93.14)

(880.56)

Post county emergency $\times$ EFI

(126.55)

(988.95)

Observations

54,510

57,546

$778.09^{* * *}$

(213.16)

$5335.91^{* * *}$

(1615.59)

$54,510 \quad 57,546$

\section{Panel D: Covid-19 deaths}

Post county emergency

$\begin{array}{ll}6.20^{* * *} & 44.93^{* * *} \\ (0.89) & (13.28) \\ 16.86^{* * *} & 155.99^{* * *} \\ (4.20) & (52.66)\end{array}$

$-13.85^{* * *}$

(3.08)

$-146.41^{* * *}$

(44.88)

EFI

$(4.20)$

(52.66)

Post county emergency $\times$ EFI

$27.67^{* * *}$

(7.06)

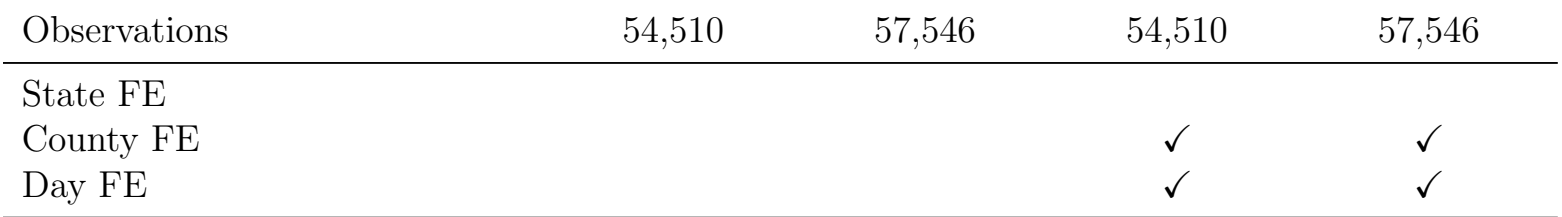

Note: Each column is from a separate regression. High and low res. seg. refer to counties with above- and below-median values of the racial residential segregation index, respectively. Controls include county-level characteristics (i.e. population density, percentage of males, average age, poverty, education, urban area, the percentage of immigrants) and county-level health characteristics (i.e. the percentage of adults with obesity, "poor health", diabetes, and who smoke). 
Table A4: Other mobility restriction policies, ethnic fragmentation, and COVID-19 by level of racial segregation (White vs. non-white)

Low res. seg. High res. seg. Low res. seg. High res. seg. (1)

(2)

(3)

(4)

\section{Government policy: National Stringency index}

Panel A: Covid-19 cases

Stringency index

$\begin{array}{ll}1.13^{* * *} & 8.98^{* * *} \\ (0.15) & (2.81) \\ 193.63^{* * *} & 2518.99^{* *} \\ (47.06) & (955.71)\end{array}$

EFI

Stringency index $\times$ EFI

Observations

191,160

185,625

$5.06^{* * *}$

$(1.23)$

191,160

(24.96)

185,625
Stringency index

EFI

Stringency index $\times$ EFI

Observations

\section{Panel B: Covid-19 deaths}

$\begin{array}{ll}0.04^{* * *} & 0.52^{* *} \\ (0.01) & (0.20) \\ 6.62^{* * *} & 152.51^{* *} \\ (1.65) & (72.61)\end{array}$

$0.17^{* * *}$

(0.04)

$3.98^{* *}$

$191,160 \quad 185,625 \quad 191,160$

(1.90)

\section{Government policy: County Safer-at-Home}

Post county safer-at-home order

EFI

Post county safer-at-home order $\times$ EFI

Observations

10,074

Panel C: Covid-19 cases

$\begin{array}{llcc}282.71^{* * *} & 1489.51^{* * *} & -189.94 & -3337.49^{* * *} \\ (54.40) & (372.79) & (121.87) & (919.80) \\ 201.07 & 2765.83^{* * *} & & \\ (120.21) & (526.83) & & \\ & & 399.66 & 5128.87^{* * *} \\ & & (224.58) & (1034.22) \\ 10,074 & 10,212 & 10,074 & 10,212\end{array}$

Panel D: Covid-19 deaths

Post county safer-at-home order

$\begin{array}{cc}10.32^{* * *} & 53.09^{* * *} \\ (2.96) & (16.65) \\ 2.94 & 99.83^{* * *} \\ (4.64) & (29.08)\end{array}$

$-2.90$

$-129.77^{* *}$

(44.12)

EFI

$(4.64)$

6.41

(9.09)

$184.63^{* * *}$

Post county safer-at-home order $\times$ EFI

10,074

10,212

10,074

(55.91)

Observations

Government policy: County Business closure

Panel E: Covid-19 cases

Post county business closure

EFI

Post county business closure $\times$ EFI

Observations

Post county business closure

EFI

Post county business closure $\times$ EFI

$\begin{array}{lc}111.75 & 3042.94^{* *} \\ (83.49) & (1143.31) \\ 231.99^{* *} & 6415.42^{* *} \\ (69.06) & (1980.32)\end{array}$

$1,380-2,070$

Panel F: Covid-19 deaths

$\begin{array}{ll}5.73 & 134.01^{* *} \\ (4.77) & (51.51) \\ 14.56^{* * *} & 311.03^{* *} \\ (2.41) & (110.99)\end{array}$

$-113.10$

(67.69)

$-7461.37^{* * *}$

(1984.46)

$416.08^{*}$

(144.91)

$12165.55^{* *}$

1,380

(3757.46)

2,070

$(2.41)$

$-8.55$

(4.23)

$-347.51^{* *}$

(118.25)

comty business closire $\times \mathrm{EFI}$

$\begin{array}{lc}26.17^{* *} & 592.77^{* *} \\ (5.65) & (212.71)\end{array}$

Observations

1,380

2,070

1,380

2,070

State FE

County FE

Day FE

Note: Each column is from a separate regression. High and low res. seg. refer to counties with above- and below-median values of the racial residential segregation index, respectively. Controls include county-level characteristics (i.e. population density, percentage of males, average age, residential segregation index, respectively. Controls include county-level characteristics (i.e. population density, percentage of males, average age,
poverty, education, urban area, the percentage of immigrants) and county-level health characteristics (i.e. the percentage of adults with obesity, "poor health", diabetes, and who smoke). 
Table A5: Federal state of emergency, ethnic fragmentation, and Google mobility measures by level of racial segregation (white vs non-white)

\begin{tabular}{|c|c|c|c|c|}
\hline & $\begin{array}{l}\text { Low res. seg. } \\
\text { (1) }\end{array}$ & $\begin{array}{l}\text { High res. seg. } \\
\text { (2) }\end{array}$ & $\begin{array}{l}\text { Low res. seg. } \\
\text { (3) }\end{array}$ & $\begin{array}{l}\text { High res. seg. } \\
\text { (4) }\end{array}$ \\
\hline \multicolumn{5}{|c|}{ Panel A: Retail } \\
\hline Post national emergency & $\begin{array}{l}-17.21^{* * *} \\
(0.60)\end{array}$ & $\begin{array}{l}-14.56^{* * *} \\
(0.64)\end{array}$ & & \\
\hline EFI & $\begin{array}{l}8.92^{* * *} \\
(1.63)\end{array}$ & $\begin{array}{l}9.60^{* * *} \\
(1.40)\end{array}$ & & \\
\hline Post national emergency $\times$ EFI & & & $\begin{array}{l}15.70^{* * *} \\
(2.51)\end{array}$ & $\begin{array}{l}19.21^{* * *} \\
(2.05)\end{array}$ \\
\hline Observations & 86,968 & 106,931 & 86,956 & 106,929 \\
\hline \multicolumn{5}{|c|}{ Panel B: Grocery } \\
\hline Post national emergency & $\begin{array}{l}-3.50^{* * *} \\
(0.48)\end{array}$ & $\begin{array}{l}-3.78^{* * *} \\
(0.26)\end{array}$ & & \\
\hline EFI & $\begin{array}{l}-2.57^{*} \\
(1.32)\end{array}$ & $\begin{array}{l}-1.27 \\
(1.06)\end{array}$ & & \\
\hline Post national emergency $\times$ EFI & & & $\begin{array}{l}1.81 \\
(2.34)\end{array}$ & $\begin{array}{c}1.91^{*} \\
(1.13)\end{array}$ \\
\hline Observations & 82,422 & 101,306 & 82,410 & 101,302 \\
\hline \multicolumn{5}{|c|}{ Panel C: Parks } \\
\hline Post national emergency & $\begin{array}{l}-19.35^{* * *} \\
(2.12)\end{array}$ & $\begin{array}{l}-19.79^{* * *} \\
(1.40)\end{array}$ & & \\
\hline EFI & $\begin{array}{l}-5.14 \\
(4.22)\end{array}$ & $\begin{array}{l}-0.60 \\
(1.80)\end{array}$ & & \\
\hline Post national emergency $\times$ EFI & & & $\begin{array}{c}0.90 \\
(6.36)\end{array}$ & $\begin{array}{l}1.13 \\
(4.61)\end{array}$ \\
\hline Observations & 23,686 & 41,252 & 23,657 & 41,218 \\
\hline \multicolumn{5}{|c|}{ Panel D: Transit } \\
\hline Post national emergency & $\begin{array}{l}-9.05^{* * *} \\
(0.90)\end{array}$ & $\begin{array}{l}-6.86^{* * *} \\
(0.35)\end{array}$ & & \\
\hline EFI & $\begin{array}{l}2.87 \\
(2.48)\end{array}$ & $\begin{array}{l}1.28 \\
(0.87)\end{array}$ & & \\
\hline Post national emergency $\times$ EFI & & & $\begin{array}{l}-1.08 \\
(2.31)\end{array}$ & $\begin{array}{l}7.47^{* * *} \\
(2.23)\end{array}$ \\
\hline Observations & 39,987 & 60,776 & 39,983 & 60,765 \\
\hline \multicolumn{5}{|c|}{ Panel E: Workplace } \\
\hline Post national emergency & $\begin{array}{l}-9.57^{* * *} \\
(0.61)\end{array}$ & $\begin{array}{l}-7.15^{* * *} \\
(0.62)\end{array}$ & & \\
\hline EFI & $\begin{array}{l}8.00^{* * *} \\
(1.23)\end{array}$ & $\begin{array}{l}9.99^{* * *} \\
(1.34)\end{array}$ & & \\
\hline Post national emergency $\times$ EFI & & & $\begin{array}{l}14.66^{* * *} \\
(2.18)\end{array}$ & $\begin{array}{l}17.17^{\text {*** }} \\
(1.87)\end{array}$ \\
\hline Observations & 125,645 & 131,133 & 125,640 & 131,131 \\
\hline \multicolumn{5}{|c|}{ Panel F: Residential } \\
\hline Post national emergency & $\begin{array}{l}2.21^{* * *} \\
(0.15)\end{array}$ & $\begin{array}{l}1.67^{* * *} \\
(0.14)\end{array}$ & & \\
\hline EFI & $\begin{array}{l}-2.22^{* * *} \\
(0.40)\end{array}$ & $\begin{array}{l}-3.10^{* * *} \\
(0.31)\end{array}$ & & \\
\hline Post national emergency $\times$ EFI & & & $\begin{array}{l}-2.62^{* * *} \\
(0.74)\end{array}$ & $\begin{array}{l}-3.90^{* * *} \\
(0.45)\end{array}$ \\
\hline Observations & 45,742 & 74,964 & 45,737 & 74,962 \\
\hline State FE & & & & \\
\hline County FE & & & $\checkmark$ & $\checkmark$ \\
\hline Day FE & & & $\checkmark$ & $\checkmark$ \\
\hline
\end{tabular}

Note: In this table, mobility measures are adjusted for the cumulative number of COVID-19 cases. High and low res. seg. refer to counties with above- and below-median values of the racial residential segregation index, respectively. Controls include county-level characteristics (i.e. population density, percentage of males, average age, poverty, education, urban area, the percentage of immigrants) and county-level health characteristics (i.e. the percentage of adults with obesity, "poor health", diabetes, and who smoke). 
Table A6: County state of emergency, ethnic fragmentation, and Google mobility measures by level of racial segregation (white vs non-white)

Low res. seg. High res. seg. Low res. seg. High res. seg. (1)

(2)

(3)

Panel A: Retail

Post county emergency

$\begin{array}{ll}-12.35^{* * *} & -10.93^{* * *} \\ (0.72) & (0.86) \\ 7.62^{* * *} & 8.67^{* * *} \\ (1.77) & (0.97)\end{array}$

$-9.45^{* * *} \quad-10.96^{* * *}$

EFI

(1.77)

(0.97)

Post county emergency $\times$ EFI

30,358

36,742

(1.65)

$14.58^{* * *} \quad 19.90^{* * *}$

(2.79) (3.04)

Observations

Panel B: Grocery

Post county emergency

$-7.31^{* * *}$

$-6.89^{* * *}$

(0.48)

$(0.46)$

$-0.19$

$-0.07$

EFI

(1.06)

(1.23)

Post county emergency $\times$ EFI

29,536

35,327

30,355

36,741

Observations

\section{Panel C: Parks}

Post county emergency

EFI

$\begin{array}{ll}-19.83^{* * *} & -19.46^{* *} \\ (2.46) & (1.75) \\ -0.28 & -3.23 \\ (6.45) & (2.37)\end{array}$

$-5.58^{* * *}$

(1.17)

$-7.89^{* * *}$

Post county emergency $\times$ EFI

\section{4,083}

20,195

2.71

$4.91^{* *}$

(2.45)

(1.90)

29,535

35,325

Observations

Panel D: Transit

Post county emergency

EFI

$\begin{array}{cc}-7.24^{* * *} & -6.00^{* * *} \\ (0.85) & (0.40) \\ 3.97 & 1.44 \\ (4.55) & (1.22)\end{array}$

$\begin{array}{ll}-12.51^{* *} & -11.15^{* *} \\ (5.29) & (4.21)\end{array}$

$\begin{array}{ll}10.81 & 6.67\end{array}$

(9.02) (6.82)

$14,077 \quad 20,186$

Post county emergency $\times$ EFI

(1.22)

$-8.25^{* * *}$

(3.89) (1.66)

$(4.55)$

$-2.30$

$9.38^{* * *}$

(7.23)

(3.19)

Observations

17,483

25,169

17,480

25,164

Panel E: Workplace

Post county emergency

$\begin{array}{ll}-5.32^{* * *} & -4.56^{* * *} \\ (0.84) & (0.79) \\ 8.04^{* * *} & 10.48^{* * *} \\ (2.04) & (1.47)\end{array}$

$-6.32^{* * *}$

$-6.63^{* * *}$

(1.31)

(1.05)

EFI

Post county emergency $\times$ EFI

37,725

41,603

$14.46^{* * *}$

$16.54^{* * *}$

(2.56)

(2.01)

Observations

\section{Panel F: Residential}

Post county emergency

$1.05^{* * *}$
$(0.18)$
$-2.01^{* * *}$
$(0.39)$

$0.78^{* * *}$

$(0.13)$

EFI

Post county emergency $\times$ EFI

$$
-3.07^{* * *}
$$

$0.71^{*}$

$1.21^{* * *}$

(0.41)

(0.38)

$-2.03^{* * *}$

$-3.50 * * *$

$(0.49)$

$(0.51)$

Observations

20,381

29,043

20,380

29,043

State FE

County FE

Day FE

Note: In this table, mobility measures are adjusted for the cumulative number of COVID-19 cases. High and low res. seg. refer to counties with above- and below-median values of the racial residential segregation index, respectively. Controls include county-level characteristics (i.e. population density, percentage of males, average age, poverty, education, urban area, the percentage of immi-

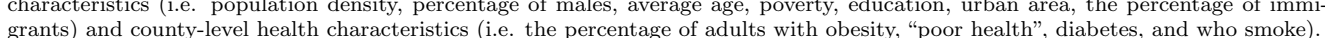


Table A7: Effect of the interaction between emergency declarations and EFI on COVID-19 outcomes by level of racial segregation

\begin{tabular}{|c|c|c|c|c|}
\hline & \multicolumn{2}{|c|}{ Federal state of emergency } & \multicolumn{2}{|c|}{ County state of emergency } \\
\hline & $\begin{array}{c}\text { Cases } \\
(1)\end{array}$ & $\begin{array}{c}\text { Deaths } \\
(2)\end{array}$ & $\begin{array}{c}\text { Cases } \\
(3)\end{array}$ & $\begin{array}{c}\text { Deaths } \\
(4)\end{array}$ \\
\hline Decile 1: Policy $\times$ EFI & $\begin{array}{l}113.97^{* * *} \\
(39.76)\end{array}$ & $\begin{array}{c}2.32^{*} \\
(1.21)\end{array}$ & $\begin{array}{l}106.43 \\
(88.42)\end{array}$ & $\begin{array}{l}4.33^{* * * *} \\
(1.34)\end{array}$ \\
\hline Observations & 29,808 & 29,808 & 6,486 & 6,486 \\
\hline Decile 2: Policy $\times$ EFI & $\begin{array}{l}367.64^{* * *} \\
(103.17)\end{array}$ & $\begin{array}{l}12.73^{* * *} \\
(4.18)\end{array}$ & $\begin{array}{l}772.14^{* * *} \\
(183.18)\end{array}$ & $\begin{array}{l}27.82^{* * *} \\
(9.04)\end{array}$ \\
\hline Observations & 28,980 & 28,980 & 7,866 & 7,866 \\
\hline Decile 3: Policy $\times$ EFI & $\begin{array}{l}598.26^{* *} \\
(238.41)\end{array}$ & $\begin{array}{l}21.81^{* *} \\
(10.32)\end{array}$ & $\begin{array}{l}1557.58^{* *} \\
(714.50)\end{array}$ & $\begin{array}{c}59.03^{*} \\
(32.97)\end{array}$ \\
\hline Observations & 27,738 & 27,738 & 7,590 & 7,590 \\
\hline Decile 4: Policy $\times$ EFI & $\begin{array}{l}1264.99^{* *} \\
(570.54)\end{array}$ & $\begin{array}{c}52.64^{*} \\
(29.35)\end{array}$ & $\begin{array}{l}1565.82^{* *} \\
(579.88)\end{array}$ & $\begin{array}{l}54.93^{* *} \\
(23.77)\end{array}$ \\
\hline Observations & 27,876 & 27,876 & 10,212 & 10,212 \\
\hline Decile 5: Policy $\times$ EFI & $\begin{array}{l}1455.85^{* * *} \\
(408.06)\end{array}$ & $\begin{array}{l}55.07^{* * *} \\
(17.98)\end{array}$ & $\begin{array}{l}1923.35^{* * *} \\
(557.43)\end{array}$ & $\begin{array}{l}80.66^{* * *} \\
(27.67)\end{array}$ \\
\hline Observations & 31,878 & 31,878 & 12,144 & 12,144 \\
\hline Decile 6: Policy $\times$ EFI & $\begin{array}{l}2692.73^{* *} \\
(1046.15)\end{array}$ & $\begin{array}{l}143.26 \\
(94.92)\end{array}$ & $\begin{array}{l}2838.35^{* *} \\
(1045.45)\end{array}$ & $\begin{array}{l}61.72^{* *} \\
(29.03)\end{array}$ \\
\hline Observations & 29,670 & 29,670 & 10,488 & 10,488 \\
\hline Decile 7: Policy $\times$ EFI & $\begin{array}{l}2362.26^{* * *} \\
(673.42)\end{array}$ & $\begin{array}{l}109.65^{* * *} \\
(35.53)\end{array}$ & $\begin{array}{l}2594.85^{* * *} \\
(907.13)\end{array}$ & $\begin{array}{l}114.93^{* *} \\
(44.96)\end{array}$ \\
\hline Observations & 26,634 & 26,634 & 9,384 & 9,384 \\
\hline Decile 8: Policy $\times$ EFI & $\begin{array}{l}5541.75^{* * *} \\
(1681.53)\end{array}$ & $\begin{array}{l}280.45^{* * *} \\
(87.17)\end{array}$ & $\begin{array}{l}\text { 8343.28*** } \\
(2211.63)\end{array}$ & $\begin{array}{l}406.51^{* * *} \\
(109.61)\end{array}$ \\
\hline Observations & 28,428 & 28,428 & 9,798 & 9,798 \\
\hline Decile 9: Policy $\times$ EFI & $\begin{array}{l}5140.14^{* *} \\
(2031.53)\end{array}$ & $\begin{array}{l}277.55^{* *} \\
(105.88)\end{array}$ & $\begin{array}{c}6108.24 \\
(4170.09)\end{array}$ & $\begin{array}{c}238.10 \\
(150.82)\end{array}$ \\
\hline Observations & 26,496 & 26,496 & 9,384 & 9,384 \\
\hline Decile 10: Policy $\times$ EFI & $\begin{array}{l}15062.30^{* *} \\
(6439.11)\end{array}$ & $\begin{array}{l}1114.38^{*} \\
(586.54)\end{array}$ & $\begin{array}{l}14342.64^{* *} \\
(6037.95)\end{array}$ & $\begin{array}{l}771.34^{* *} \\
(358.58)\end{array}$ \\
\hline Observations & 28,014 & 28,014 & 8,832 & 8,832 \\
\hline County FE & $\checkmark$ & $\checkmark$ & $\checkmark$ & $\checkmark$ \\
\hline Day FE & $\checkmark$ & $\checkmark$ & $\checkmark$ & $\checkmark$ \\
\hline Policy and EFI Controls & $\checkmark$ & $\checkmark$ & $\checkmark$ & $\checkmark$ \\
\hline
\end{tabular}

Note: Each row is from a separate regression. The table shows estimates of the effect of the interaction between emergency declarations and EFI on COVID-19 outcomes separately for different deciles of racial residential segregation. 
Table A8: Effect of EFI on social associations rate by level of racial segregation

Membership in association

(1)

Decile 1: EFI

0.80

Observations

210

Decile 2: EFI

Observations 204

Decile 3: EFI

Observations 191

Decile 4: EFI $-1.87$

Observations 190

Decile 5: EFI

Observations 224

Decile 6: EFI $-4.05$

Observations 208

Decile 7: EFI

Observations 183

Decile 8: EFI

Observations 201

Decile 9: EFI $-3.64^{*}$ (1.90)

Observations 181

Decile 10: EFI $-7.16^{* * *}$

Observations 195

State FE $\checkmark$

Note: Each row is from a separate regression. Social associations rate is measured as the number of membership associations per 10,000 individuals in a county. The table shows estimates of the effect of EFI on social associations rate for different deciles of racial residential segregation. 